\title{
Three-dimensional Numerical Modeling Encompassing the Stability of a Vertical Gas Well Subjected to Longwall Mining Operation - A Case Study
}

Bonaventura Alves Mangu Bali

Follow this and additional works at: https://researchrepository.wvu.edu/etd

\section{Recommended Citation}

Bali, Bonaventura Alves Mangu, "Three-dimensional Numerical Modeling Encompassing the Stability of a Vertical Gas Well Subjected to Longwall Mining Operation - A Case Study" (2018). Graduate Theses, Dissertations, and Problem Reports. 7061.

https://researchrepository.wvu.edu/etd/7061

This Thesis is protected by copyright and/or related rights. It has been brought to you by the The Research Repository @ WVU with permission from the rights-holder(s). You are free to use this Thesis in any way that is permitted by the copyright and related rights legislation that applies to your use. For other uses you must obtain permission from the rights-holder(s) directly, unless additional rights are indicated by a Creative Commons license in the record and/ or on the work itself. This Thesis has been accepted for inclusion in WVU Graduate Theses, Dissertations, and Problem Reports collection by an authorized administrator of The Research Repository @ WVU. For more information, please contact researchrepository@mail.wvu.edu. 


\title{
THREE-DIMENSIONAL NUMERICAL MODELING ENCOMPASSING \\ THE STABILITY OF A VERTICAL GAS WELL SUBJECTED TO \\ LONGWALL MINING OPERATION - A CASE STUDY
}

\author{
Bonaventura Alves Mangu Bali
}

Thesis submitted to the

Benjamin M. Statler College of Engineering and Mineral Resources

at West Virginia University

in partial fulfillment of the requirement for the degree of

\section{Master of Science \\ in \\ Mining Engineering}

\author{
Brijes Mishra, Ph.D., Chair \\ John Quaranta, Ph.D., PE. \\ Ihsan Berk Tulu, Ph.D.
}
Department of Mining Engineering
Morgantown, West Virginia

May 2018
Keywords: Numerical Modeling, Gas Well Stability, Longwall Mining, Ground Control, Rock Mechanics, FLAC3D

\section{Copyright 2018 C Bonaventura Alves Mangu Bali}




\section{ABSTRACT \\ Three-dimensional numerical modeling encompassing the stability of a vertical gas well subjected to longwall mining operation - a case study}

\section{Bonaventura Alves Mangu Bali}

Longwall mining has been one of the prominent underground mining methods for extracting coal in the United States for many years due to its production efficiency. However, the method itself can possibly cause problems to surface structures, i.e. gas wells, buildings, roads, etc., that are built or located nearby mining operations. In recent years, significant gas resources have been identified to be located underlying coal deposits, particularly in Southwestern Pennsylvania, West Virginia, and Ohio. As a result, within the time frame of the last 10 years, more than 800 gas well have been drilled through active and future underground longwall mining. Practically, strata deformation caused by longwall mining could induce high stresses and deformation, which may lead to the instability of a gas well. Therefore, it is imperative that gas well stability penetrating longwall mining operation should be investigated and studied in order to maintain the stability of the gas well, as well as to enhance the safety of underground longwall mining working face and it's operation.

In this study, various three-dimensional numerical models were developed using Finite Difference Method in FLAC ${ }^{3 \mathrm{D}}$ program and calibrated against an actual gas failure case cited in Peng et al. (2003). Field observation of the case study indicated that the gas well failed after second panel mining. In the previous study, Peng et al. (2003) used the Finite Element Method in ABAQUS program to simulate the gas well failure in order to find out the reason behind the gas well failure. They found out that that the presence of clay layer between two strong strata induced high stresses on the gas well casing and causing the high compressive strain at the gas well failure horizon. For this study, the main objective is to assess the influence of overburden depth and the presence of soft strata on the stability of the vertical gas well subjected to longwall mining operation. In addition, the determination of suitable pillar size for protecting the vertical gas well from failure, as a result of longwall mining, will also be investigated.

The results of this study indicate that the overburden depth, soft strata presence, and the pillar size of a longwall mine plays an important role on the gas well stability penetrating longwall 
mining abutment pillar. It was found that the deeper the overburden depth of a mine, the higher possibility for gas well to fail under axial compression. The critical overburden depth for the gas well to survive is $600 \mathrm{ft}$. $(183 \mathrm{~m})$. However, it should be noted that the obtained critical overburden depth is specific to the given case study. This study revealed that the geological condition of a mine, such as the presence of soft strata, could induce stresses and deformation on the gas well, which will lead to the instability issue of the gas well. The gas well would typically face more instability issue when it is drilled through a horizon, where the presence of soft strata takes place in between two layers of strong strata. In addressing the need of suitable pillar size for protecting the gas well from failure as a result of longwall mining, it is determined in this study that in order to maintain the stability of the gas well for the case study, considering three entry system, the pillar size should be $80 \mathrm{ft}(24.4 \mathrm{~m})$ wide rib to rib. Whereas if the four-entry system is used, the size of the pillar should be kept at $48 \mathrm{ft}$ (14.6 m) wide rib to rib.

The main significance of this study is that it not only proposes a numerical modelling procedure for assessing the stability of gas well subjected to longwall mining operation of the particular case study, but it can also be used for other similar projects. This study concludes that with the accurate data input of rock and casing properties, as well as the gob model simulation, the numerical modelling analysis approach presented in this thesis will be able to accurately predict the stability of the vertical gas well penetrating longwall mining abutment pillar. 


\section{DEDICATION}

I would like to dedicate the successful achievement of this thesis as well as my master's degree to my wife, Zelia Martinha da Cruz, and my son, Michael Vial

da Cruz Mangu Bali, who have been patiently keeping the love and faith between us and continuously support and encourage me when I struggled for my academic life away from home.

Their prayers, understanding, support and most of all their love have been the key success of my academic life.

\section{Also}

To

My daddy, Donatus Mangu Bali, and Mom, Serena Alves whom I owe my life \& my six siblings, Egi, Ety, Emen, Nona, Afon and Bale, You all gave me strong roots, unconditional love and the courage of my convictions. You all were always there for me to support no matter what and none of this achievement would have been possible without you all.

Ba maromak no hau rain moris fatin, Same - Manufahi-Timor Leste To god and the place where my story begins, Same - Manufahi-Timor leste 


\section{ACKNOWLEDGEMENTS}

\section{Take Me Home, Country Roads! I'm a Proud Mountaineer Alumni.}

By far, this research work has been the most enjoyable one and a half years of work in my life, and this thesis has been the longest manuscript in English I have ever written. However, I am glad that finally I knocked it out of the park. The journey I have been through in the last one and a half years in Morgantown-WV was, is, and will be remembered all of my life.

As this research has reached its end, I would like to acknowledge all the people that have helped me making the successful of this research became possible. First of all, I would like to express my gratitude to my research adviser, Dr. Brijes Mishra, Ph.D. who got me hooked into one of the challenging topic in ground control research, which is the stability prediction of a vertical gas well subjected to longwall mining operation using numerical modeling approach. I appreciate his guidance, critical thoughts and encouragement during the ongoing process of this research work. Without any doubt, it has been my great honor to have worked under his supervision.

I thank to Dr. John Quaranta, Ph.D. P.E. from whom I learnt and dig more an interesting Civil Engineering field of study, Geotechnical engineering. I also appreciate the time he has spared to review and revise my research work. I also would like to thank Dr. Ihsan Berk Tulu, Ph.D. for his valuable support and suggestions for improving the output of this thesis. I also would like to express my sincere appreciation to Dr. Yi Luo, Ph.D. P.E. for his valuable discussion and inputs regarding the instability issue of the gas well occurred in the field. I wish I could have been more proactive to discuss the results of this thesis with them so that I could apply their expert knowledge and thought in this thesis to the greatest extent possible.

I would like to recognize and acknowledge the support from the Fulbright Scholarship program for providing a fully funded scholarship for my master's degree program. Without Fulbright, I would not have made it here in Morgantown and finished up this research work.

Last but not least, I would also like to thank all my friends and colleagues that have shared and made my academic life in the U.S. become much more wonderful and meaningful: Cate Johnson and Family, Howard Chueh, Rei Adachi, Debashis Das, Sameer Mittel, Bhardwaj Pandit, Prasoon Garg, Priyash Mishra, Neel Gupta, Annand Nandula, Yuting Xue, Danqing Gao, Sitraka, and two of my Timorese fellow, Natalino and Aida. 


\section{TABLE OF CONTENTS}

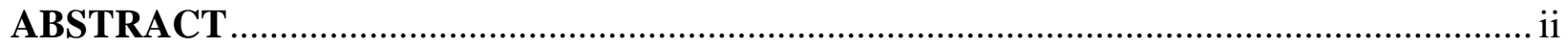

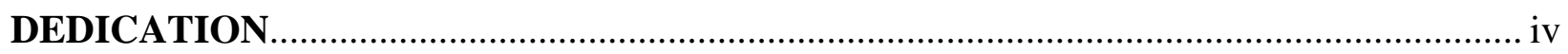

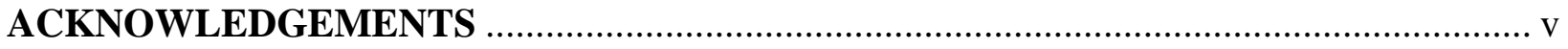

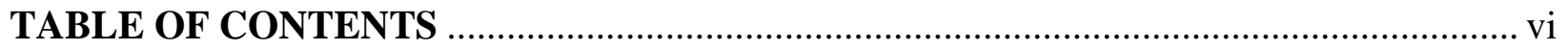

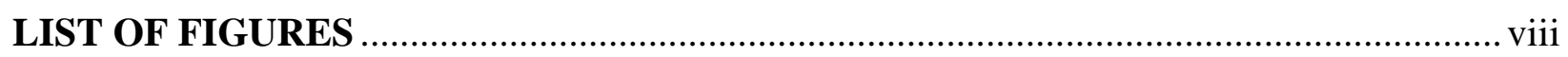

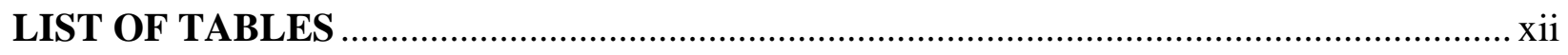

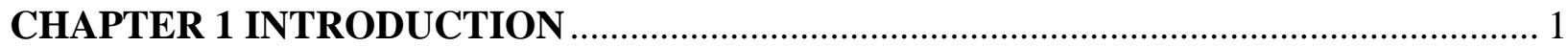

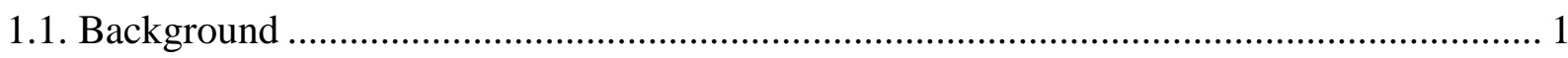

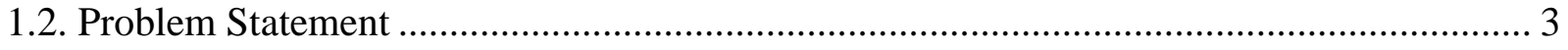

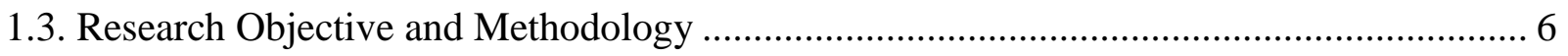

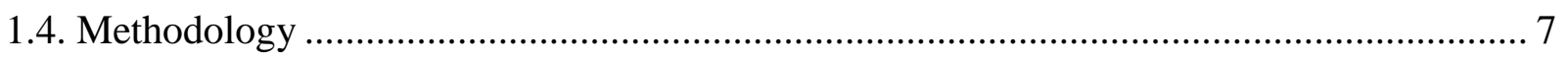

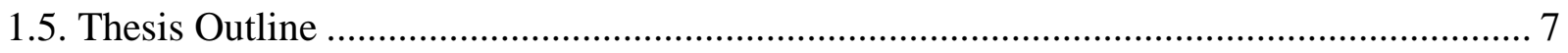

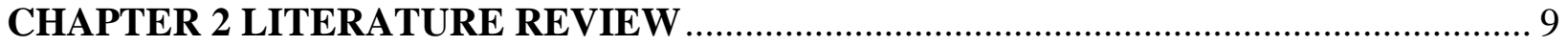

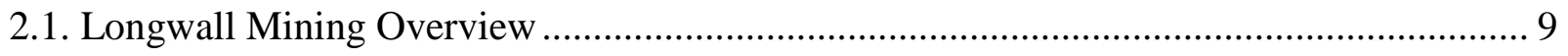

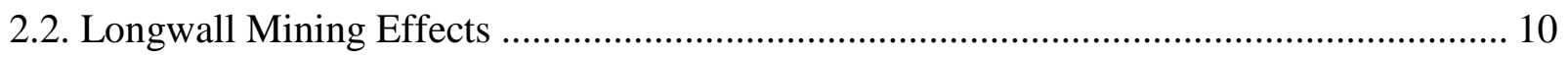

2.3. Pillar Design for Longwall Mining ..................................................................... 12

2.4. Gas Well Deformation Subjected to Longwall Mining Operation ................................ 16

2.5. Federal Regulations for Mining in Oil and Gas Well Protective Area ........................... 20

2.6. Numerical Modelling Analysis using FLAC $^{3 \mathrm{D}}$ Program .............................................. 21

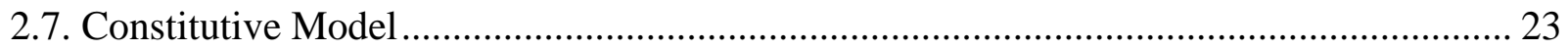

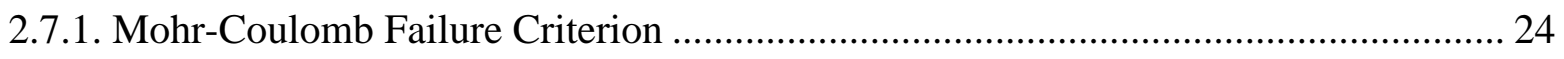

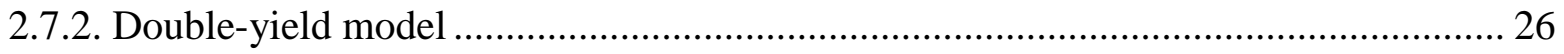

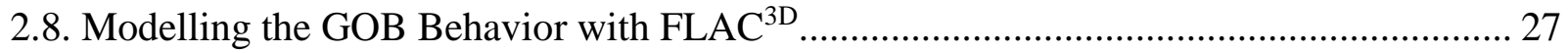

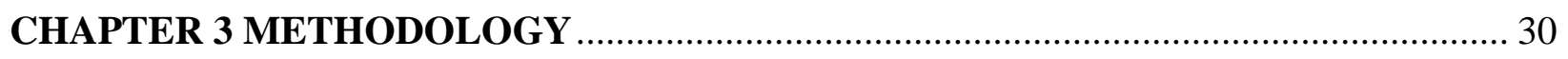

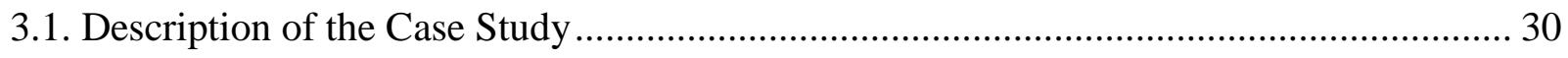

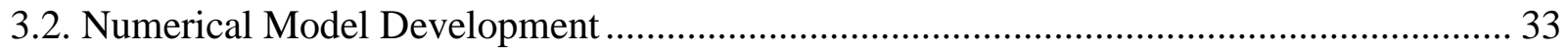

3.2.1. Model Geometry and Boundary Condition ......................................................... 34

3.2.2. Selected Constitutive Model ................................................................................... 38

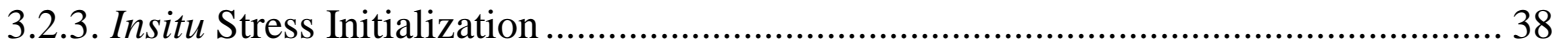


3.2.4. Physical and Mechanical Properties of the Rock Strata ........................................ 39

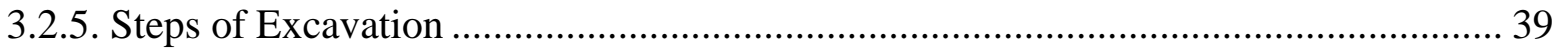

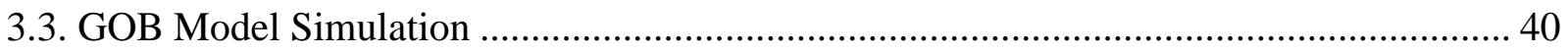

3.4. Gas Well Stability Analysis Approach.................................................................... 42

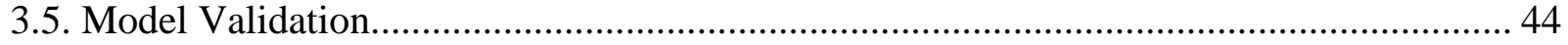

3.5.1. Validation of the Simulated Model with the Previous Study .................................. 44

3.5.2. Validation of the Stress Distribution on the GOB area and Pillar System ................ 45

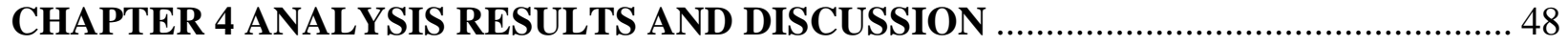

4.1. Assessing the Effect of Overburden Depth ............................................................. 48

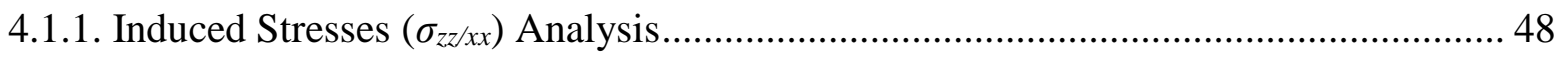

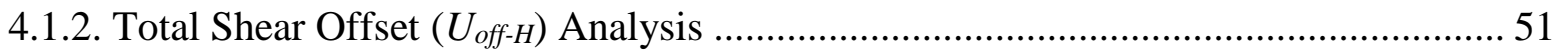

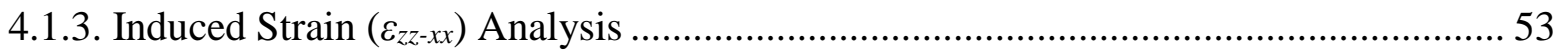

4.2. Assessing the Effect of the Presence of Soft Strata ................................................. 59

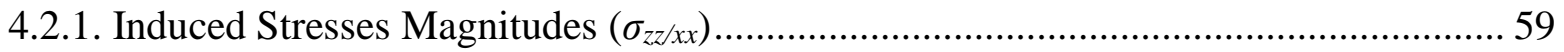

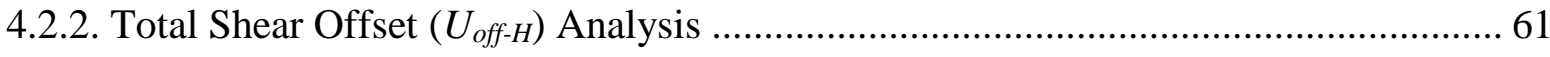

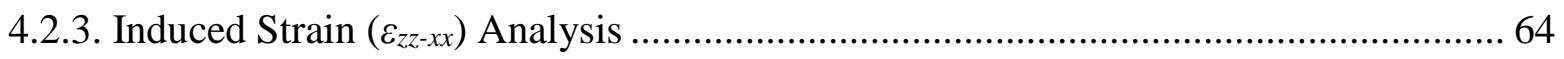

CHAPTER 5 - DETERMINATION OF SUITABLE PILLAR SIZE FOR PROTECTING

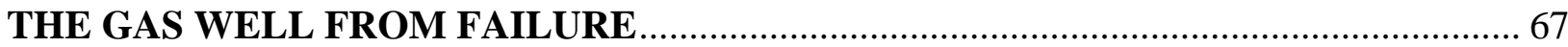

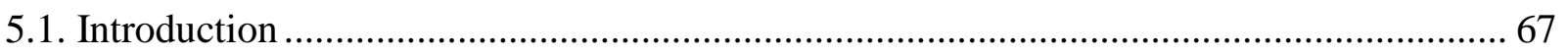

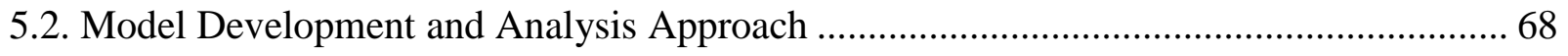

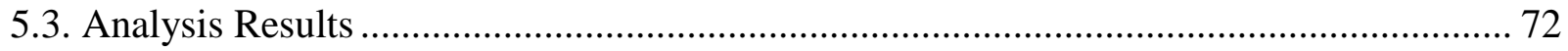

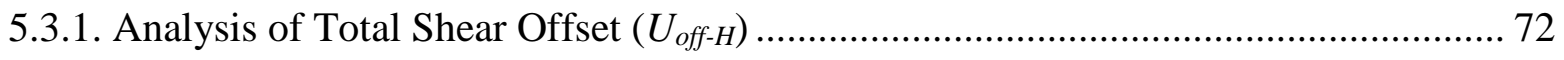

5.3.2. Analysis of Lateral and Axial Strain $\left(\varepsilon_{x x / z z}\right)$ Distribution...................................... 74

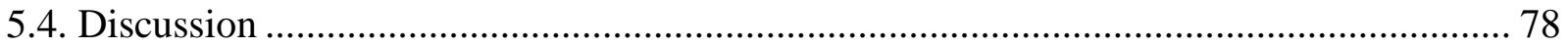

CHAPTER 6 CONCLUSION AND RECOMMENDATION ....................................... 81

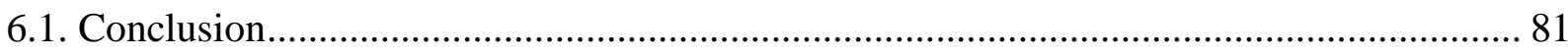

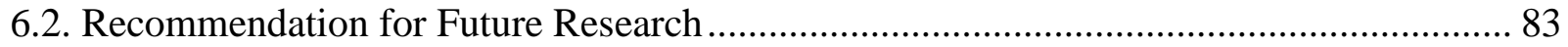

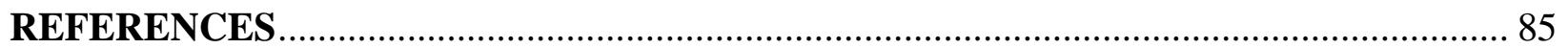




\section{LIST OF FIGURES}

Figure 1.1 Primary source of energy in the U.S. from 1949 to 2016. Y axis value from the left hand side is in Quadrilion BTU. (Source: U.S. Energy and Information

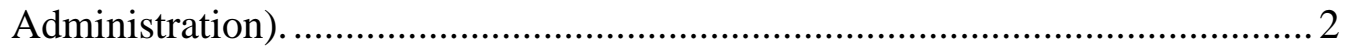

Figure 2.1 Typical longwall mining layout (Modified from Peng, 2006)........................ 9

Figure 2.2 a. Deformation in horizontal and vertical direction occurred in the face and immediate roof (Whittaker and Reddish, 1989), b. strata deformation due to longwall mining (Kolebaevna, 1968).

Figure 2.3 Abutment pressure around a typical Longwall panel (Whittaker and Reddish, 1989) 12

Figure 2.4 Gas well in Appalachia coal basin. (U.S. Energy Information Administration, 2017)

Figure 2.5 Typical vertical gas well failure mode: a. Tension failure mode, b. Compression failure mode, and c. Shear failure mode (Modified from Liu et al. 2014)........ 17

Figure 2.6 Simplified mechanical model of slippage presence on a rock stratum (Chen et al. 2012) 18

Figure 2.7 Gas well pillar supporting guideline (Commonwealth of Pennsylvania, 1957). Shaded area represents the required bearing area for various overburden depth. 20

Figure 2.8 Location of gas well failure (Peng et al. 2003) ........................................ 21

Figure 2.9 Calculation cycle of FLAC3D program (Itasca, 2017) .................................23

Figure 2.10 Mohr coulomb failure envelope........................................................25

Figure 2.11 The pressure and volumetric strain curve of the double yielding model (Itasca, 2017). 26

Figure 2.12 Comparison of the stress-strain relationship between Salamon's model and the FLAC $^{3 \mathrm{D}}$ model (Li et al. 2017). 29 
Figure 3.1 Longwall panel layout (Peng et al. 2003). Location of the gas well is marked with a circle in the middle of an abutment pillar. 1ft: 0.3048 m.................... 31

Figure 3.2 Column of lithology of the case study (Peng et al. 2003)............................. 32

Figure 3.3 Gas well failure recorded in the field (Modified from Luo et al. 1999) ........... 33

Figure 3.4 FLAC ${ }^{3 D}$ Model Geometry for the scenario I. The gas well showing on blue colour is penetrated through longwall mining abutment pillar from surface to the bottom of the simulated model. ................................................................. 35

Figure 3.5 FLAC ${ }^{3 D}$ Model Geometry for the scenario II: a. Model with the presence of soft strata, $b$. Model without soft strata presence. The gas well showing on blue colour is penetrated through longwall mining abutment pillar from surface to the bottom of the simulated model.

Figure 3.6 Comparison of strain-hardening curve for GOB material obtained by Salamon's equation and Double-yield model in FLAC ${ }^{3 \mathrm{D}}$ program.

Figure 3.9 Analysis results for model calibration. The model is calibrated against the previous study (Peng et al. 2003). 45

Figure 3.10 Vertical stress distribution recorded on the gob area and pillar system after first panel mining......

Figure 3.11 Predicted stress on the pillar system obtained by ALPS and FLAC ${ }^{3 D}$ analysis 47

Figure 4.1 Predicted induced stresses distribution in axial and lateral direction with varying overburden depth, after: a and c. first panel mining, b and d. second panel mining.

Figure 4.2 Analysis of predicted maximum induced stresses distribution with varying overburden depth, after: a and c. first panel mining, b and d. second panel mining. 50

Figure 4.3 Predicted total lateral shear offset $\left(U_{\text {off- } H}\right)$, after: a. first panel mining, b. second panel mining. Orange dashed line refers to the critical lateral shear offset......52

Figure 4.4 Analysis of predicted maximum total shear offset $\left(U_{\text {off- } H}\right)$ as a function of overburden depth, after: a. first panel mining, b. second panel mining............53 
Figure 4.5 Predicted axial strain $\left(\varepsilon_{z z}\right)$, after: a. first panel mining, b. second panel mining, with varying overburden depth. Orange dashed line refers to the critical axial strain (0.005).

Figure 4.6 Predicted lateral strain $\left(\varepsilon_{x x}\right)$ after: a. first panel mining, b. second panel mining, with varying overburden depth. Orange dashed line refers to the critical lateral strain (0.005). 56

Figure 4.7 Analysis of predicted maximum axial strain $\left(\varepsilon_{z z}\right)$, after: a. first panel mining, b. second panel mining. Green dashed line refers to the critical strain magnitude.57

Figure 4.8 Analysis of Predicted maximum lateral strain $\left(\varepsilon_{x x}\right)$ as a function of overburden depth, after: a. first panel mining, b. second panel mining...........................58

Figure 4.9 Predicted induced stresses distribution in axial and lateral direction, after: a and c. first panel mining, $b$ and $d$. second panel mining. 60

Figure 4.10 Predicted total lateral shear offset $\left(\mathrm{U}_{\text {off-H}}\right)$, after: a. first panel mining, b. second panel mining. Orange dashed line refers to the critical lateral shear offset...... 63

Figure 4.11 Predicted induced strain in axial and lateral direction, after: a and c. first panel mining, $b$ and $d$. second panel mining. Orange dashed line refers to the critical strain (0.005). 64

Figure 5.1 FLAC ${ }^{3 D}$ Model Geometry for the first scenario (Three-entry system). The gas well showing on blue colour is penetrated through longwall mining abutment pillar from surface to the bottom of the simulated model. 69

Figure 5.2 FLAC ${ }^{3 \mathrm{D}}$ Model Geometry for the second scenario (Four-entry system). The gas well showing on blue colour is penetrated through longwall mining abutment pillar from surface to the bottom of the simulated model............................ 70

Figure 5.3 Predicted total lateral shear offset $\left(U_{\text {off- } H}\right)$, after: first panel mining (a and c), b. second panel mining ( $b$ and $d$ ). Orange dashed line refers to the critical lateral shear offset. Figures 5.3. a and b corresponds to the simulated model scenario for the three-entry system, while Figures 5.3.c and d corresponds to the four-entry system. $1 \mathrm{ft}=0.3048 \mathrm{~m}$. 73 
Figure 5.4 Analysis results of maximum predicted total lateral shear offset $\left(U_{\text {off-H}}\right)$. Figure 10. $\mathrm{a}$ and $\mathrm{b}$ corresponds to the three-entry and four-entry system model scenario, respectively.

Figure 5.5 Predicted axial strain $\left(\varepsilon_{z z}\right)$ and lateral strain $\left(\varepsilon_{x x}\right)$, after: first panel mining (a and c), and second panel mining ( $\mathrm{b} \& \mathrm{~d}$ ), for the three-entry system model scenario. $1 \mathrm{ft}=0.3048 \mathrm{~m}$. 76

Figure 5.6 Predicted axial strain $\left(\varepsilon_{z z}\right)$ and lateral strain $\left(\varepsilon_{x x}\right)$, after: first panel mining (a and c), and second panel mining (b \& d), for the four-entry system model scenario. $1 \mathrm{ft}=0.3048 \mathrm{~m}$. 77

Figure 5.7 Analysis results of the maximum predicted axial strain $\left(\varepsilon_{z z}\right)$ and lateral strain $\left(\varepsilon_{x x}\right)$, after: first panel and second panel mining. Figures 5.7.a and b corresponds to the three-entry system, while Figures 5.7. $\mathrm{c}$ and d corresponds to the fourentry system of the simulated model scenario. $1 \mathrm{ft}=0.3048 \mathrm{~m}$. 78 


\section{LIST OF TABLES}

Table 2.1 The obtained mechanical properties of the gob material (Li et al. 2017)........29

Table 3.1 Physical and Mechanical properties of rock strata and casing used in

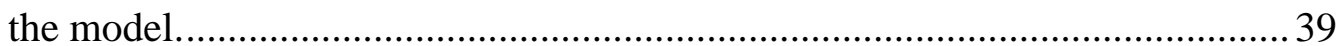

Table $3.2 \quad$ Predicted cap pressure for double-yield of gob model ............................... 40

Table $3.3 \quad$ Obtained mechanical properties for the gob material ................................. 41

Table $3.4 \quad$ Predicted total load acting on the pillar system ...........................................4 47

Table 4.1 Summary of predicted maximum induced stresses acting on the gas well for model with and without the presence of soft strata...................................... 62

Table 4.2 Summary of predicted maximum total shear offset along the gas well trajectory for model with and without the presence of soft strata.................................63

Table 4.3 Summary of maximum predicted induced strain magnitudes of the gas well for model with and without the presence of soft strata........................................66 


\title{
CHAPTER 1
}

\section{INTRODUCTION}

\author{
"If we don't stand for something, \\ we'll fall for anything" \\ -Dunne Capably
}

\subsection{Background}

Coal plays an important role in generating electricity in the United States (U.S.). Recent data obtained from the U.S. Energy and Information Administration presents that four trillion kilowatt hours $(\mathrm{kWh})$ of electricity were generated in the U.S. in 2016, with $34 \%$ of this source of energy coming from coal. Even though the coal production decreased in the last ten years, coal is still one of the major sources of energy in the U.S., along with the natural gas and crude oil (Figure 1.1).

Two primary methods for mining the coal deposit are surface and underground mining methods. Those two methods will be selected based on an extensive techno-economic feasibility study. Underground mining will typically be selected when surface mining is not technically feasible. Among various underground mining methods, Longwall mining has been one of the prominent underground mining methods for extracting coal under deep overburden depth. In longwall mining method, the extraction face of a mine panel is equipped with a row of hydraulic roof supports (shield), a machine to extract the coal from the coal panel face, known as shearer, and an armored face conveyor (AFC) to transport the mined coal to the surface (Peng et al. 2008).

Longwall mining has been one of the prominent underground method for extracting coal in the U.S. for many years due to its efficiency in production. However, the method itself can possibly cause problems to any structures, i.e. gas wells, buildings, roads, etc., that are built or 
located nearby the mining operation. In recent years, significant gas resources have been identified to be located underlying coal deposits, particularly in Southwestern Pennsylvania, West Virginia, and Ohio. As a result, the natural gas extraction is increasingly intersecting throughout many longwall mining operations. Su (2017) presents that within the time frame of last 10 years, more than 800 vertical gas well have been drilled through active and future underground longwall mining.

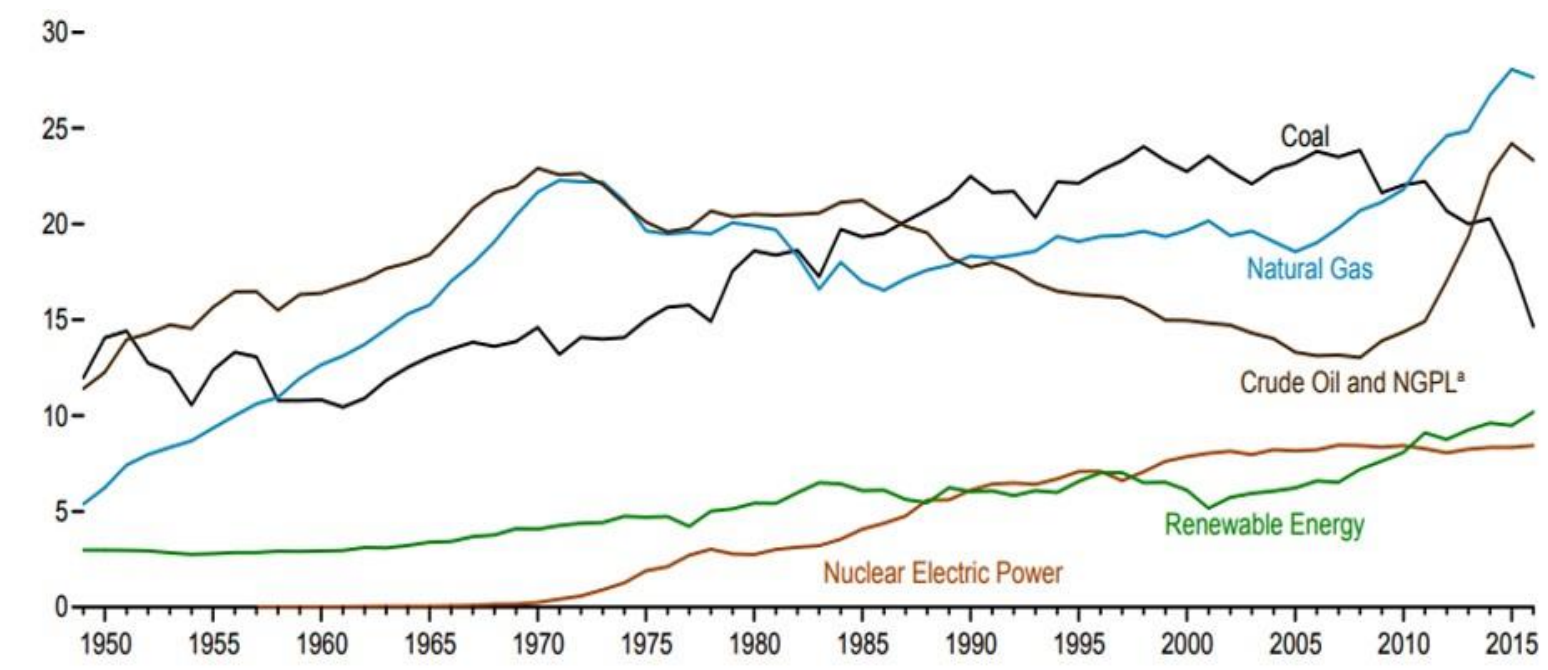

Figure 1.1 Primary source of energy in the U.S. from 1949 to 2016. Y axis value from the left hand side is in Quadrilion BTU. (Source: U.S. Energy and Information Administration).

The stress distribution in rock mass remains a great concern for rock mechanics and mining engineer in designing a mining operation. The complexity of understanding rock mass behavior may lead to the instability of vertical gas well that is drilled through a longwall mining abutment pillar. This condition has been one of the major challenges to ground control engineering research.

In a longwall mining operation, where a gas well is drilled through the coal seam, a protective pillar, known as abutment pillar, has to be placed to protect the gas well. However, 
maintaining the stability of the gas well has always been a challenging issue due to various factors that can affect the gas well stability, including induced stress magnitudes and its distribution, formation structure, and strata movement (Wang et al. 2011; Liu et al. 2014). Theoretically, a vertical gas well penetrating longwall abutment pillar can pose various challenges due to the ground and strata deformation, caused by longwall mining (Wang et al. 2014). In other words, during the extraction of the coal deposit, the rock strata above and below the coal seam will deform and this condition can possibly affect the instability condition for the vertical gas well.

Strata deformation in longwall mining could induce high stresses and deformations around the gas well, which may affect the stability and integrity of gas well production. This in turn, can lead to failure of the vertical gas well, which will directly increase the project maintenance cost and reduce the targeted gas production. In addition, gas well failure could potentially affect the safety of an underground longwall mining operation. Previous extensive studies present that inappropriate methods in controlling gas extraction may trigger an accident at the longwall mining working face and is hazardous to both mines and miners (Whittles et al. 2007; Zhang et al. 2009; Zeynali, 2012). Due to the complexity of understanding of induced stress and displacement distribution and their magnitudes along the gas well trajectory affected by coal extraction in longwall mining operation, the stability of a vertical gas well that is drilled through a longwall abutment pillar has been one of the challenging topics to be investigated in ground control research area.

\subsection{Problem Statement}

One of the challenges mining engineers face in an underground longwall project in which a vertical gas well is drilled through the longwall abutment pillar is to maintain the stability of the gas well structure from failure. Vertical gas well failure will lead to the decreasing of the targeted 
gas production and cause the unsafe environment for the mining operation. The Pennsylvania oil and gas division (Commonwealth of Pennsylvania, 1957) developed a standard guideline which present the pillar size requirement for protecting a gas well from failure in longwall mining area. The guideline was referred to 77 field cases where mining was conducted near the oil and gas wells. However, underground coal mines in 1957 or before mostly used room and pillar mining method. In other words, longwall mining method was not used yet for extracting coal under deep overburden. Due to the fact the standard guideline was not formulated using the data from modern longwall mining method, it is imperative that gas well stability penetrating longwall mining operation should be investigated and studied. This will give us a better understanding of the effect of longwall mining operation on the stability of gas well subjected to longwall mining operation as well as to enhance the safety of underground longwall mining working face and its operation.

Kicker and Park (1986) suggested that the longwall mining method requires an accurate decision in determining the size of entry and pillar system. In addition, Peng et al. (2003) proposed that pillar size of a longwall mining operation, where a gas well is penetrated through, should be designed adequately in order to maintain the stability of the gas well. A considerable number of studies have been conducted to determine a pillar size in a longwall mining operation. Analysis of Longwall Pillar Stability (ALPS) empirical technique (Mark, 1987) is the most commonly used method in the U.S. The empirical approach mostly considered the coal pillar to behave elastically. The approach ignores the complexities of geological and geotechnical condition of a mine and therefore, may produce an uncertainties results. Such approach can only be applied in hard rocks, where the rocks can be assumed to be completely elastic (Shabanimashcool and $\mathrm{Li}, 2012$ ). However, when a complex case where a gas well is penetrated through the abutment pillar, such empirical approaches cannot be applied. The complexity of stress and strain distribution acting on 
the gas well as a result of a surface or underground excavation makes it difficult to quantify using empirical approaches.

Very few gas well stability analysis in longwall mining area were conducted and most them were based on the numerical modelling approach. Su (2017) and Peng et al. (2003) performed a numerical analysis to assess the stability of a vertical gas well subjected to longwall mining operation. They found out that the presence of soft strata, such as clay layer, was one of the main reasons for gas well to face instability issue. Wang et al. (2014) proposed a method to appropriately design a gas well casing based on a predicted stress calculated by the Finite Element Method. Liang et al. (2014) conducted a study to assess the overburden depth influence on the stability of gas well penetrating longwall mining areas. Liang et al. (2015) assessed the dynamic impacts of gas well drilled through a longwall mining panel. However, the studies conducted by Liang et al. (2014) and Liang et al. (2015) did not consider the presence of gas well casing and the compaction process of gob in their simulated model. The behavior of the gob is imperative for accurately predicting the load distribution transferred to the longwall face, pillars, and tailgate sections (Bai et al. 2014; Shabanimashcool and Li, 2012). Therefore, when a simulated numerical model does not consider the gob-compaction process, it may produces an uncertainty predicted results.

In this thesis, various factors that accord with field practice have been considered, including the geology and mining geometry of the case study, the casing properties, and the gobcompaction simulation. This thesis will focus on developing the three dimensional numerical modeling using Finite Difference Method with the assistance of FLAC ${ }^{3 D}$ program to assess the stability of a vertical gas well subjected to longwall mining operation. In addition, the determination of suitable pillar size for protecting gas well from failure under the given geological 
condition and mining geometry will also be investigated. The simulated numerical models have been calibrated with a case study, cited in Peng et al (2003).

\subsection{Research Objective and Methodology}

In this research, a case study cited in Peng et al. (2003) was used. The main objective of this study is to develop and improve a scientific understanding of how the longwall mining operation affect the stability of a vertical gas well using the numerical modelling approach. Towards the mentioned objective, the following tasks were performed on this study:

Developing various three dimensional numerical models and performing numerical analysis to assess the effect of overburden depth and the presence of soft strata on the stability of the vertical gas well subjected to longwall mining operation. From this part of the study, the critical overburden depth for gas well to survive under the given geological condition and mining geometry of the case study will be determined. In addition, the role of the presence of soft strata on the gas well stability in longwall mining area will also be investigated.

Developing various three dimensional numerical models and performing numerical analysis to determine the suitable pillar size for protecting gas well from failure, under the given geological and mining condition. Out of this part of the study, the optimal pillar size under the three-entry and four-entry system of longwall mining will be selected, in order to maintain the stability of the gas well subjected to longwall mining operation. 


\subsection{Methodology}

This thesis focusses on assessing the stability of the vertical gas well subjected to longwall mining operation using numerical modelling approach. In order to obtain the targeted research objectives, various three dimensional numerical model were built using Finite Difference Method in FLAC ${ }^{3 \mathrm{D}}$ program. FLAC ${ }^{3 \mathrm{D}}$ was selected for this study since it is well accepted by the mining and geotechnical engineering community in various purposes, especially for rock and soil mechanic research area. The detailed methodology of using numerical modeling for assessing the stability of the gas well subjected to longwall mining operation will be discussed in Chapter 3 .

\subsection{Thesis Outline}

This thesis consists of six chapters and is organized as following:

\section{Chapter 1 - Introduction}

This chapter provides the background introduction, problem statement, research objective, briefly methodology, and thesis outline of this thesis.

\section{$>$ Chapter 2 - Literature Review}

In this chapter, the essential literature review of the longwall mining method and its effect on the gas well stability is discussed. In addition, previous studies of numerical modeling application for analyzing the stability of gas well subjected to longwall mining operation was also explored.

\section{Chapter 3 - Methodology}

The description of the case study and the detailed methodology and approach for assessing the stability of gas well is presented. 


\section{Chapter 4 - Analysis Results and Discussion}

The influence of overburden depth and the presence of soft strata on the stability of vertical gas well, as a result of longwall mining, is explored, analyzed, and discussed.

Chapter 5 - Determination of Suitable Pillar Size for Protecting the Gas Well from Failure

In this chapter, various numerical models were developed to determine the suitable pillar size for protecting gas well from failure. The analysis results of the simulated model will then be explored, analyzed and discussed.

Chapter 6 - Conclusion and Recommendation

This chapter summarizes the work completed in this research and recommends further studies needed to be conducted for future research. 


\section{CHAPTER 2}

\section{LITERATURE REVIEW}

\section{“Those who do not learn history}

are doomed to repeat it"

- George Santayana

\subsection{Longwall Mining Overview}

Longwall mining has been one of the prominent underground mining method for extracting coal in the U.S. for many years due to its production efficiency. Using this method, as shown on figure 2.1, the coal seam is continuously extracted in slices. The size of one cutting slice is about $3 \mathrm{ft}(0.9 \mathrm{~m})$ wide and 6 to $16 \mathrm{ft}$ ( 2 to $6 \mathrm{~m})$ thick, along a longwall face.

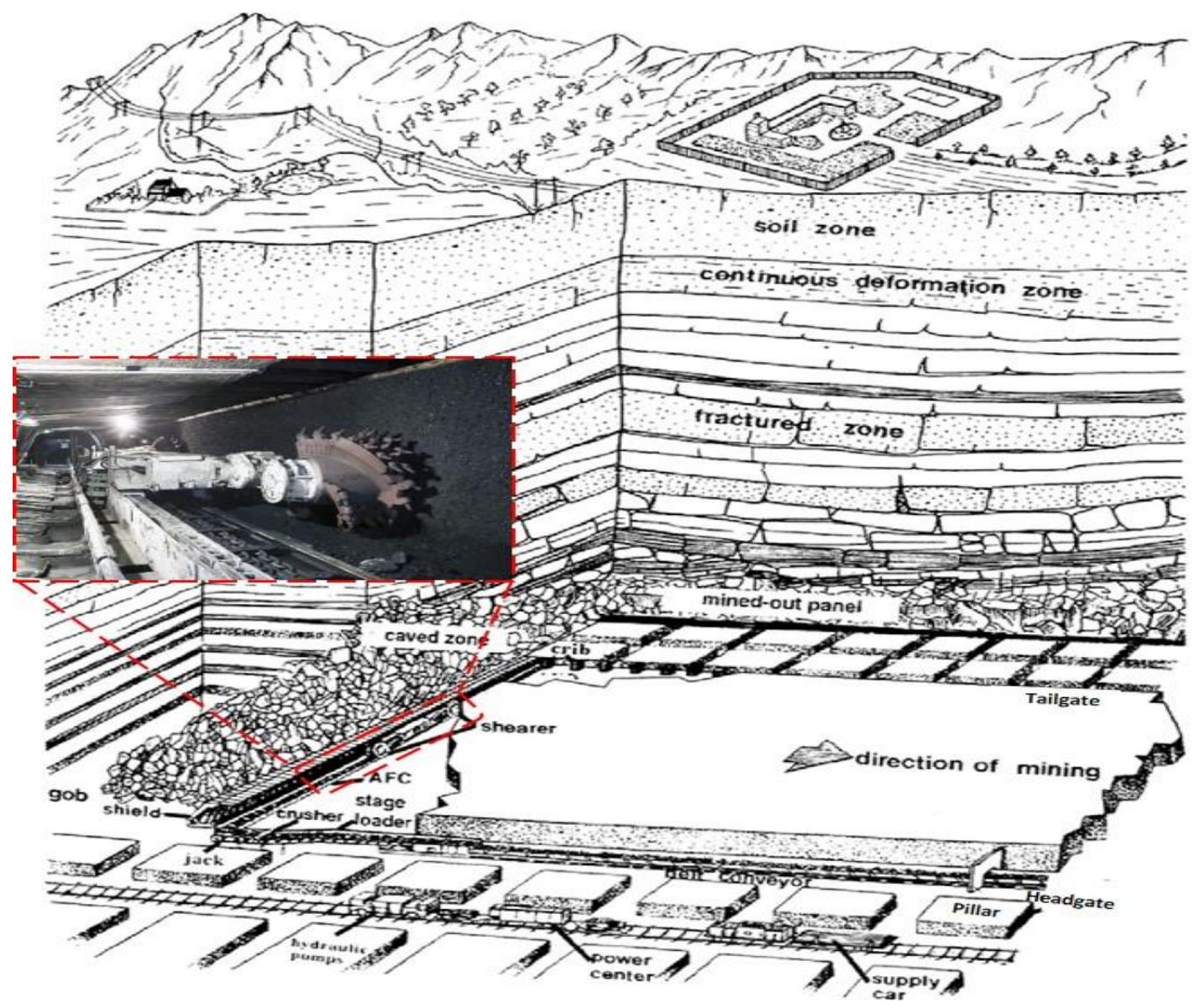

Figure 2.1 Typical longwall mining layout (Modified from Peng, 2006) 
The longwall face is developed by creating entries on both panel sides, known as headgate and tailgate entries. The longwall face is supported by series of hydraulic roof support, known as shield, along the entries longwall panel width. As a slice of coal is extracted, the shield is advanced forward in order to allow the rock strata above and behind the shield to cave in to the excavated coal area. In this case, the excavated coal area will be filled up by broken material, known as gob. In order to maintain the stability of the entry during its mining lifetime, several pillars with their specific geometry based on design requirement will be placed along the longwall panel.

\subsection{Longwall Mining Effects}

Due to longwall mining operation, the strata above and behind the longwall face is deformed massively in both the vertical and horizontal directions (Figure 2.2). As a result, the stress distribution changes and forms the abutment pressure (Figure 2.3). Figure 2.2 shows that as the longwall face moves forward, the rock strata bend as a cantilever beam and eventually gets fractured and caves into the excavated coal area. This in turn leads to the stress changing dynamically until an updated equilibrium is achieved. Abutment pressure is then developed along the longwall panel side and at the front of the longwall panel side, as shown on Figure 2.3.

It can be seen from Figure 2.3 that after a longwall panel is completely mined, the abutment pressure reaches its peak magnitude at the front side of a longwall face and it reduces as the length is away from the panel face. The abutment loads follow the role of cantilever beam theory, and

thus the magnitudes depend on the opening size (geometry of longwall panel) and properties of the immediate roof (Abbasi, 2016). As the caved materials become compacted and the extracted area is filled, the abutment load reduces and an updated equilibrium is reached. 

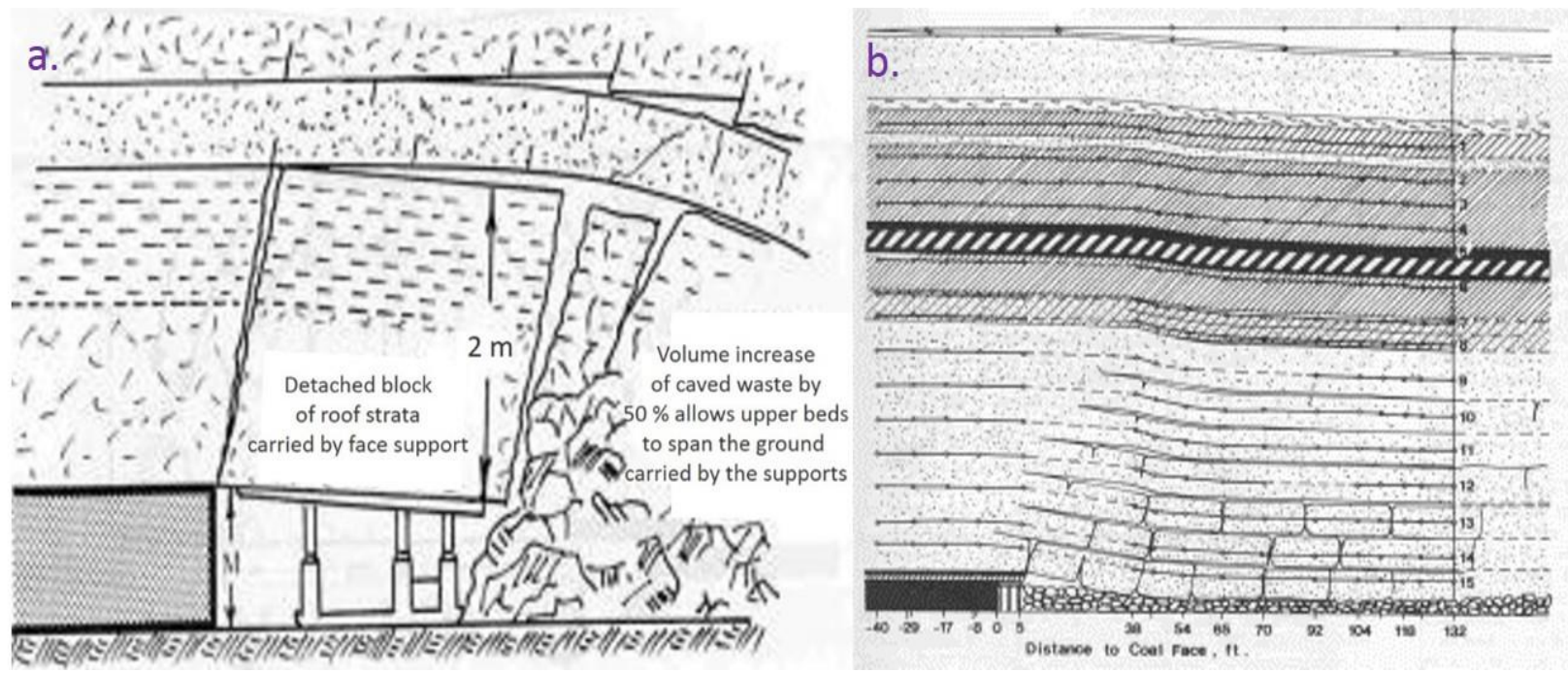

Figure 2.2 a. Deformation in horizontal and vertical direction occurred in the face and immediate roof (Whittaker and Reddish, 1989), b. strata deformation due to longwall mining (Kolebaevna, 1968).

In such large scale excavation, damage can possibly be related to the dissipated plastic energy (DPE). DPE that is stored in a rock mass can be quickly released, and this in turn, can lead to a massive deformation, which has always been a significant issue in field of ground control research. Various problems that can be affected by longwall mining are included, but not limited to: groundwater problems, which is related to reduction of the ground water level (Li et al. 2015; Newman et al. 2017), surface subsidence that can possibly lead to the damage of surface structures, such as roads, buildings, railroads, bridges etc., (Salmi et al. 2017; Iwanec et al. 2016; Peng et al. Luo et al. 2010; 1995; Luo, 1989) and the failure of a vertical gas well when it is drilled through a longwall mining operation area (Su, 2017; Liang et al. 2017; 2015; 2014; Want et al. 2014; Wang et al. 2013). 


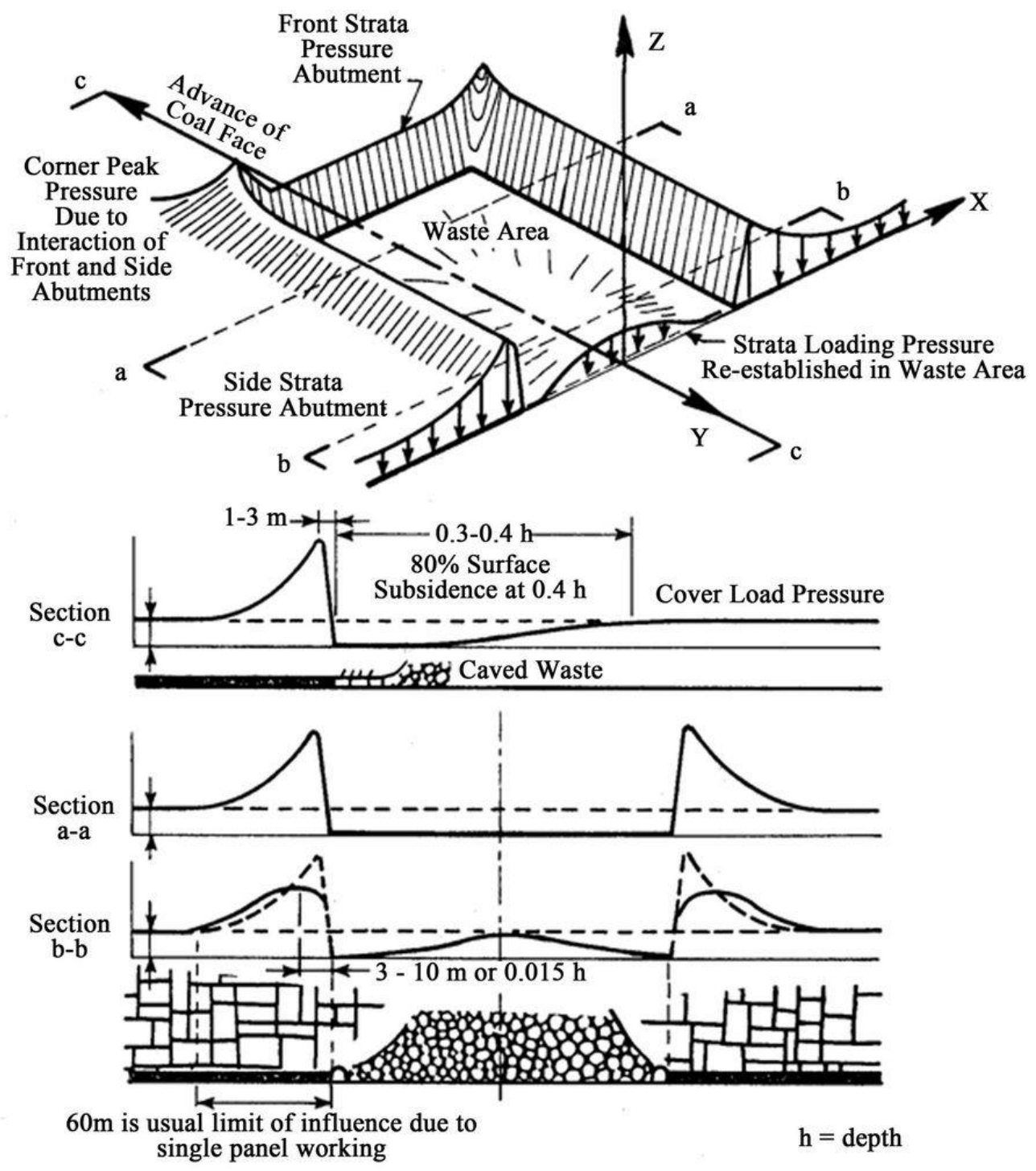

Figure 2.3 Abutment pressure around a typical Longwall panel (Whittaker and Reddish, 1989)

\subsection{Pillar Design for Longwall Mining}

When longwall mining method is used, it is imperative to design a pillar in such a way that can withstand for the lifetime of a longwall mining operation. Appropriate pillar design is critical for maintaining the stability of an underground openings and for providing a safe work environment for underground mine workers. There are many empirical formulas used to design a pillar. In the U.S., Analysis of Longwall Pillar Stability (ALPS) empirical technique (Mark, 1987) is the most commonly used method. A general agreement among researchers is that the strength 
of coal pillar increases with pillar width - to - height ratio. Two fundamental criteria needed to design a pillar using ALPS are first to quantify the strength of the pillar and second to analyze the stress acting on the pillar.

Using ALPS empirical technique, the pillar strength can be obtained using equations 2.2 to 2.10. (Mark, 1987):

$$
\mathrm{S}_{\mathrm{p}}=\mathrm{S}_{1}(0.64+0.36 \mathrm{w} / \mathrm{h}) \quad \text { Equation } 2.1
$$

Where,

$$
\begin{aligned}
& \mathrm{S}_{\mathrm{p}}=\text { Pillar strength }(\mathrm{Psi}) \\
& \mathrm{S}_{1}=\text { In situ coal strength (Psi) } \\
& \mathrm{w}=\text { Pillar width }(\mathrm{ft}) \\
& \mathrm{h}=\text { Pillar height }(\mathrm{ft})
\end{aligned}
$$

Then, the bearing capacity of a pillar can be quantified by the following expression,

$$
\mathrm{B}=[\Sigma(\mathrm{Sp}) \times(\mathrm{w}) \times(\mathrm{L})] \times \frac{144}{\mathrm{~L}+\mathrm{We}} \quad \text { Equation } 2.2
$$

Where,

$$
\begin{aligned}
\mathrm{B} & =\text { Bearing capacity }(\mathrm{lb} / \mathrm{ft}) \\
\mathrm{W} & =\text { Width of pillar }(\mathrm{ft}) \\
\mathrm{L} & =\text { Pillar length }(\mathrm{ft}) \\
\mathrm{W}_{\mathrm{e}} & =\text { Entry width }(\mathrm{ft})
\end{aligned}
$$

In terms of loads acting on the pillar, there are two loadings needed to be considered, including development and abutment loading. Development loads are the loads occurring on a pillar due to the overburden distributed load over the pillar, while the abutment loads are due to 
the weight of adjacent overburden as a result of coal that has been mined out from the longwall panel. Development load can be assessed by the following equation,

$$
\mathrm{L}_{\mathrm{d}}=\mathrm{H} \times \mathrm{Wt} \times \gamma
$$

Equation 2.3

Where,

$$
\begin{aligned}
& \mathrm{L}_{\mathrm{d}}=\text { Development load (lb/ft) } \\
& \mathrm{H}=\text { Depth of cover }(\mathrm{ft}) \\
& \mathrm{W}_{\mathrm{t}}=\text { Panel width (ft) } \\
& \gamma \quad=\text { Density of overburden (pcf) }
\end{aligned}
$$

The magnitude of abutment loads, which is occurred due to panel extraction, vary in Headgate $\left(\mathrm{L}_{\mathrm{H}}\right)$, tailgate $\left(\mathrm{L}_{\mathrm{T}}\right)$ and barrier pillars $\left(\mathrm{L}_{\mathrm{B}}\right)$ side. Following expressions can be used to assess the loading magnitudes at the headgate pillar, barrier pillar, and tailgate pillar locations:

$$
\begin{aligned}
\mathrm{L}_{\mathrm{H}} & =\left[\mathrm{L}_{\mathrm{d}}+\left(\mathrm{L}_{\mathrm{s}}\right) \times\left(\mathrm{F}_{\mathrm{h}}\right) \times(\mathrm{R})\right] & & \text { Equation } 2.4 \\
\mathrm{~L}_{\mathrm{B}} & =\left[\mathrm{L}_{\mathrm{d}}+\left(\mathrm{L}_{\mathrm{s}}\right)(\mathrm{R})\right] & & \text { Equation } 2.5 \\
\mathrm{~L}_{\mathrm{T}} & =\left[\mathrm{L}_{\mathrm{d}}+\left(\mathrm{L}_{\mathrm{s}}\right) \times(1+\mathrm{Ft})\right] & & \text { Equation 2.6 }
\end{aligned}
$$

Where,

$$
\begin{aligned}
& \mathrm{L}_{\mathrm{H}}=\text { Headgate pillar loading (lbs./ft) } \\
& \mathrm{L}_{\mathrm{B}} \quad=\text { Barrier Pillar loading (lbs./ft) } \\
& \mathrm{L}_{\mathrm{T}} \quad=\text { Tailgate pillar loading (lbs./ft) } \\
& \mathrm{L}_{\mathrm{d}} \quad=\text { Development loading (lbs./ft) } \\
& \mathrm{L}_{\mathrm{s}} \quad=\text { Total side abutment loading }(\mathrm{lbs} . / \mathrm{ft}) \\
& \mathrm{R} \quad=\text { Constant, following equation } 2.8
\end{aligned}
$$

Fh and Ft are constants of 0.5 and 0.7 , respectively. 
The value of total side abutment loading can be specified by following expression:

$$
\mathrm{L}_{\mathrm{S}}=\mathrm{H}^{2} \mathrm{x} \tan \beta \times \frac{\gamma}{2}
$$

Equation 2.7

Where $\beta$ (abutment angle) is considered to be $21^{\circ}$.

$$
\mathrm{R}=1-\left[\frac{D-w t}{D}\right]^{3}
$$

Equation 2.8

$\mathrm{D}$ is value for extend of side abutment load length and can be assessed using the following expression.

$$
\mathrm{D}=9.3 \sqrt{H}
$$

Equation 2.9.

Having various values obtained from the equation 2.1 to Equation 2.9, the stability factor of the pillar can be obtained by the following equations,

$$
\mathrm{SF}=\mathrm{B} / \mathrm{L}
$$

Equation 2.10.

Where,

$$
\begin{aligned}
& \mathrm{SF}=\text { Stability factor of a pillar } \\
& \mathrm{B}=\text { Bearing capacity of pillars }(\mathrm{lb} / \mathrm{ft}) \\
& \mathrm{L}=\text { Pillar load }(\mathrm{lb} / \mathrm{ft})
\end{aligned}
$$

Using the empirical analysis approach, as shown on Equation 2.1 to 2.10, the critical safety factor for pillar design in longwall mining is 1.3. However, when a gas well is drilled thorough a longwall mining abutment pillar, the safety factor for the pillar should be kept at 2.5 and the overall pillar system safety factor should be 2.0 , as standardized by the Pennsylvania Department of Environmental and Protection (2002). 


\subsection{Gas Well Deformation Subjected to Longwall Mining Operation}

Wang et al. (2014) reports that a vertical gas well that is drilled through a longwall mining abutment pillar could possibly experience various challenges due to the ground and strata deformation, induced by longwall mining. This in turn can lead to a gas well failure and potentially affect the safety of an underground longwall mining operation. Su (2017) reports that in the last decade, around 800 vertical gas well have been drilled through coal mining reserves in the U.S., particularly in the states of Pennsylvania, West Virginia, Ohio, Virginia and Tennessee as a result of the increase in shale gas production in the Appalachian coal mining area. As can be seen from Figure 2.4, there are a lot of oil and gas operations intersecting with coal mining region in Appalachian coal basin. The distribution of gas wells extend from New York in the north to Kentucky and Tennessee in the south.

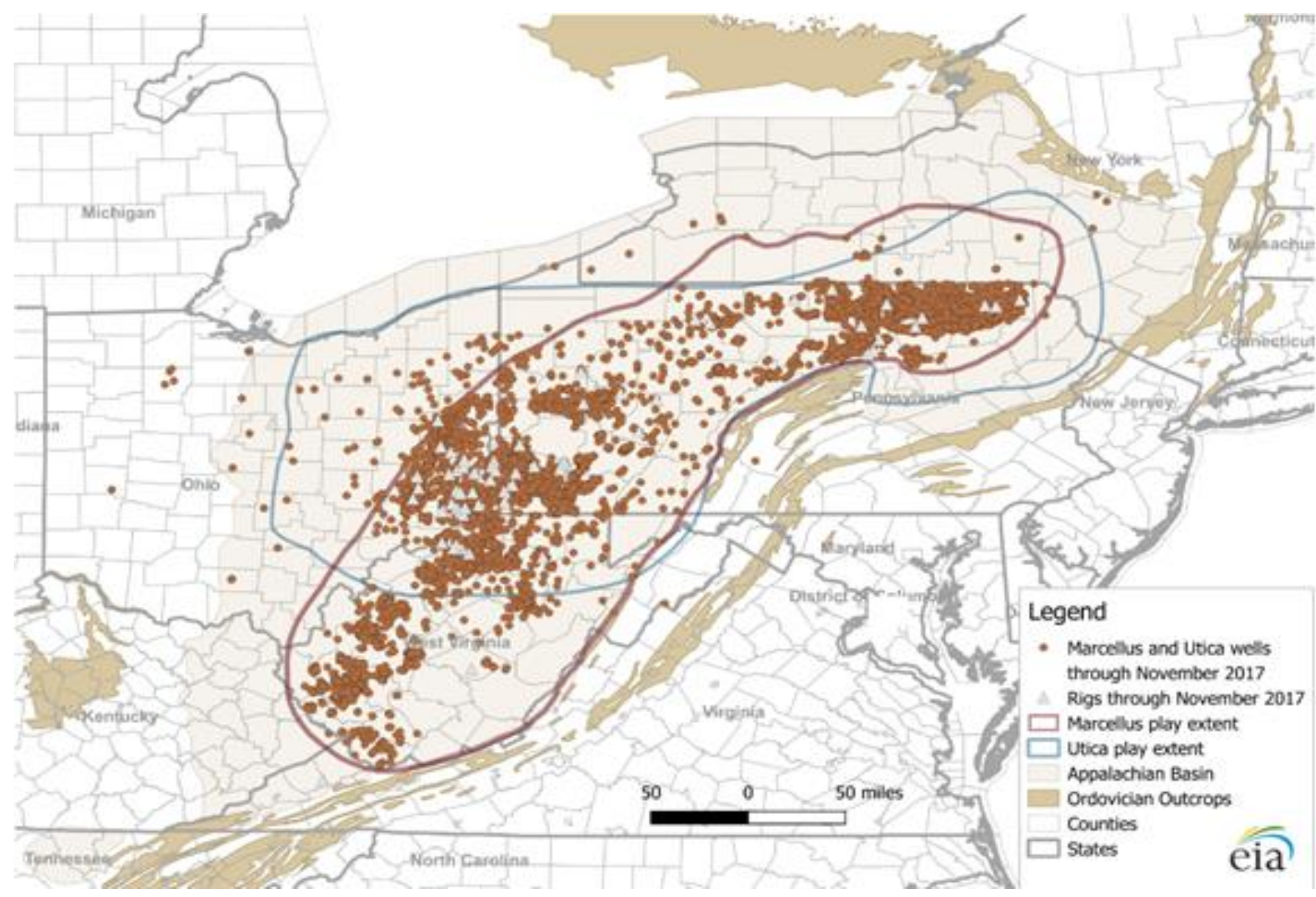

Figure 2.4 Gas well in Appalachia coal basin. (U.S. Energy Information Administration, 2017) 
It is critical to understand the gas well failure mechanism. Extensive studies had been conducted in the past to investigate the failure mechanism of gas well due to longwall coal extraction by analyzing the field monitoring data and the compare with the numerical modeling analysis. It was found that majority of the gas wells in longwall mining area could possibly fail in three failure modes and their combinations namely: (i) shear failure mode, (ii) compression failure mode and (iii) tension failure mode (Chen et al. 2012; Liang et al. 2014; Liang et al. 2015; Liang et al. 2017; Wang et al. 2014).
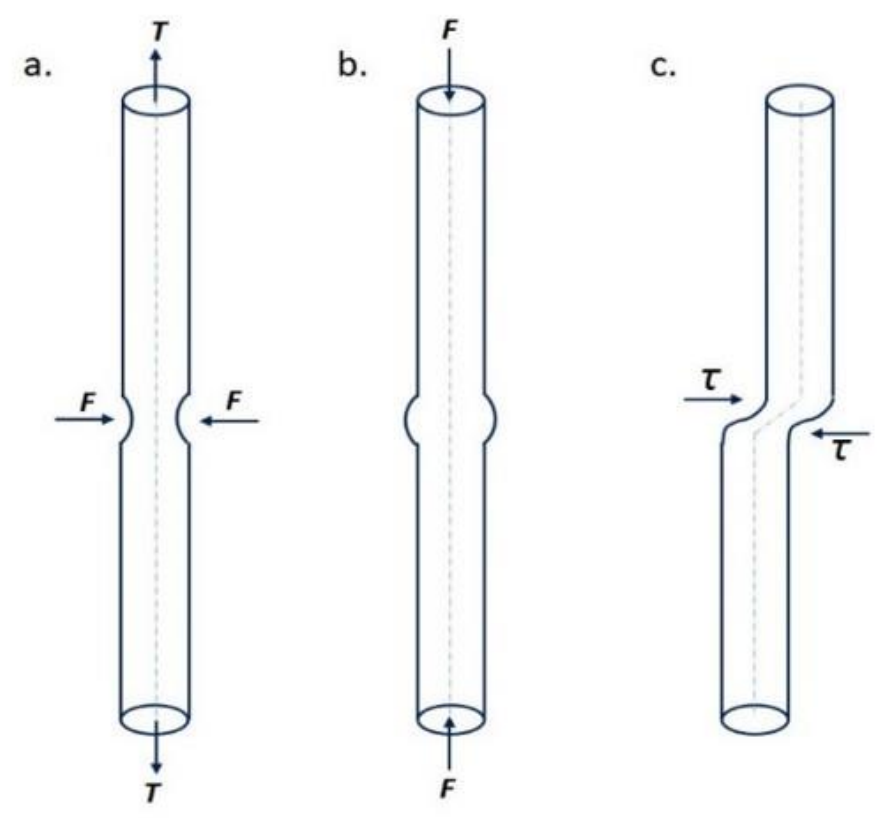

Figure 2.5 Typical vertical gas well failure mode: a. Tension failure mode, b. Compression failure mode, and c. Shear failure mode (Modified from Liu et al. 2014).

The typical gas well failure mode as a result of longwall mining is illustrated in Figure 2.5. The rock strata and gas well at a specific depth is subjected to vertical stress and locked into horizontal stress. As longwall panel excavation advances, the induced stresses distribution along the gas well trajectory may leads to compressive failure due to high compressive stress and deformation occurred in the axial direction, as shown on Figure 2.5 (b). Shear failure occurred due to the difference of rock strata properties that leads to the high magnitudes of horizontal shear 
offset in the horizon where the gas well is penetrated through. An example of slippage presence in a rock strata is shown on Figure 2.6. Slippage of rock strata can possibly induce high shear displacement, which in turn can lead to a shear failure of a gas well casing (Figure 2.5 (c)). Tensile failure mode occurred due to the incompatibility of axial displacement (rock layers separation) between adjacent layers as a result of longwall mining, as shown on Figure 2.5 (a).

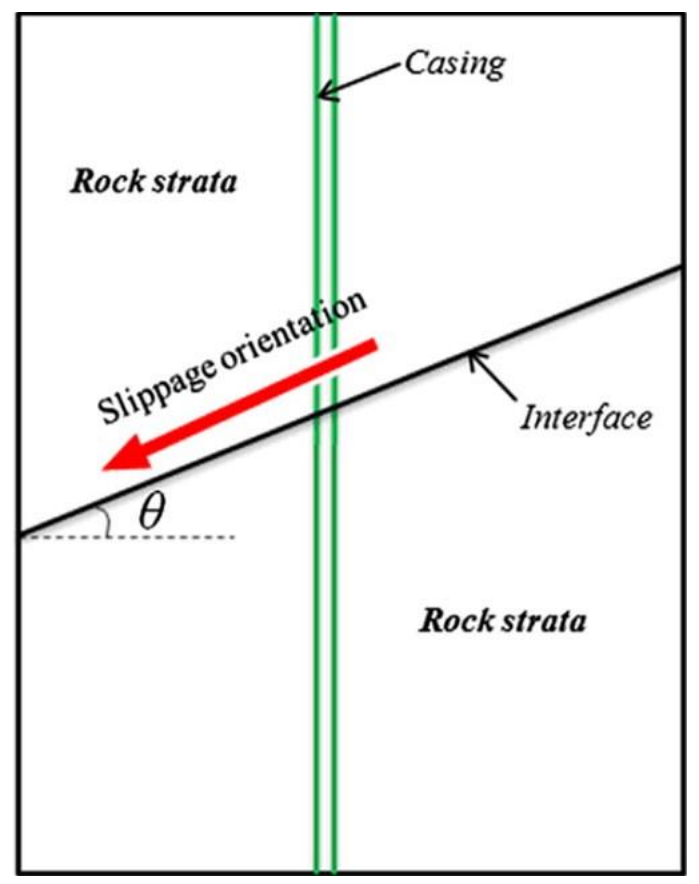

Figure 2.6 Simplified mechanical model of slippage presence on a rock stratum

(Chen et al. 2012)

Factors affecting the stability of a vertical gas well subjected to longwall mining operation are: geological condition of a mine, overburden depth, mining geometry, and casing material ( $\mathrm{Su}$, 2017; Liang et al. 2017, 2015, 2014; Cheng et al. 2012; Peng et al. 2003, and Luo et al. 1999). Liang et al. (2017) presented that as a result of longwall mining, the gas well could possibly fail in compression when it is penetrated through a soft stratum, and in tension when it is penetrated through a stiff strata. Similarly, Peng et al. (2003) and Luo et al. (1999) performed a gas well stability analysis based on a case study and found out that the failure of a gas well under axial 
compression will likely occurred in a horizon where the soft strata (i.e. clay layer) is present in between two strong strata (i.e. sandstone and or sandyshale layer). In other words, geological condition of a mine plays an important role on the stability of a vertical gas well penetrating a longwall mining operation.

Next, Liang et al. (2014) conducted a study on "Topographic influence on stability for gas wells penetrating longwall mining areas" based on assumption that the gas well is penetrated through a longwall mining pillar under various soft strata, containing soft and strong strata in an incised topography. He found that the well deformations are most prone to fail when mining is shallow (overburden depth less than 100 meter), then moderate when mining at an intermediate depth (overburden depth of around $200 \mathrm{~m}$ ), and then become large again in deep mining (overburden depth higher than $300 \mathrm{~m}$ ). However, this failure mechanism is not always the case for another case study, since induced displacement and strain magnitudes resulting from a longwall mining is site specific ( $\mathrm{Su}, 2017)$.

In terms of mine geometry influence, an earlier study by Kicker and Park (1986) suggested that the longwall mining method requires an accurate decision in determining the size of the entry and pillar system. In addition, Peng et al. (2003) proposed that the pillar size of a longwall mining operation, where a gas well is penetrated through, should be designed adequately in order to maintain the stability of the gas well. Therefore, it is critical to design a protective pillar that can support gas well to not fail as a result of longwall mining operation.

When considering gas well casing material properties, Chen et al. (2012) and Luo et al. (1999) found that the microspores and micro fractures on the gas well can also lead to the failure of a gas well casing when the casing is subjected to high induced stress resulting from longwall mining operation, due to it weakens the structure and strength of a casing. 


\subsection{Federal Regulations for Mining in Oil and Gas Well Protective Area}

The guideline presenting the required pillar size for protecting gas well in longwall mining area was enacted in 1957 by the Pennsylvania oil and Gas Division (Commonwealth of Pennsylvania, 1957) based on the analysis of 67 cases of gas well failures occurred in 77 case studies using room and pillar mining method, as shown on Figure 2.7.

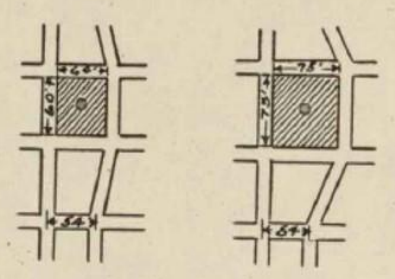

COVER O'TO $149^{\prime}$ COVER $150^{\prime}$ TO $249^{\prime}$

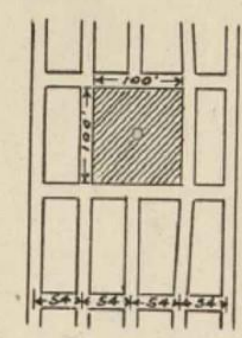

COVER 250'T0349'

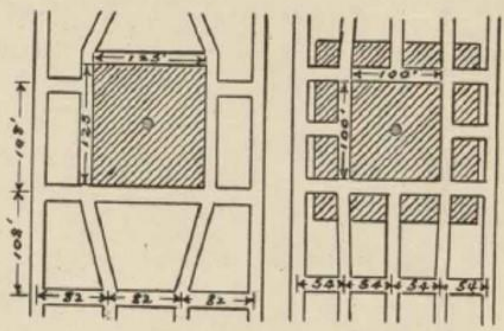

COVER 350'To 449'

(MIN. 10,000" BEARING AREA) (MIN. 15,600"BEARINGAREA)(MIN.ZZ,000"BEARINGaREA)

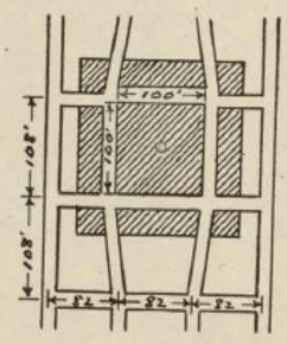

COVER 450'To 549

(MIN.23,000"BEARINGAREA)

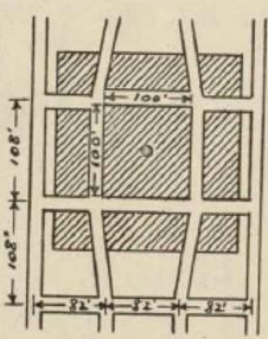

COVER 550' To $649^{\circ}$

(MIN. 32,000"'BEARING AREA)

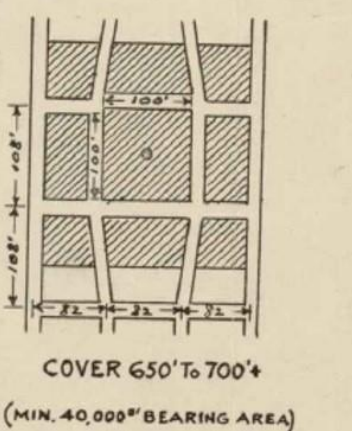

(MIN, 40,000" BEARING AREA)

Figure 2.7 Gas well pillar supporting guideline (Commonwealth of Pennsylvania, 1957). Shaded area represents the required bearing area for various overburden depth.

The guideline requires a protective pillar size from $60 \mathrm{ft}$ for overburden depth of lesser than

$149 \mathrm{ft}$ to a pillar size of $100 \mathrm{ft}$ for overburden depth higher than $250 \mathrm{ft}$. The additional pillar surrounding the core pillar will also increase as the overburden depth increases. The additional pillars surrounding the protective pillar where the gas well is penetrated through, are needed to increase the bearing capacity of a pillar area. The minimum bearing area of $10,000 \mathrm{ft}^{2}$ is needed 
for overburden depth ranging from 250-349 $\mathrm{ft}$, to a maximum of $40,000 \mathrm{ft}^{2}$ when the overburden depth is higher than $650 \mathrm{ft}$.

In terms of gas well failure location, the maximum distance away from extracted coal seam, where the gas well could possibly fail as a result of longwall mining, is $100 \mathrm{ft}(30.5 \mathrm{~m})$. In detail, $90 \%$ of the gas well failures occurred at the coal seam level and within a distance of $34 \mathrm{ft}$ away from the coal seam, and only $10 \%$ occurred at a distance greater than $34 \mathrm{ft}(10.4 \mathrm{~m})$ from the extracted coal seam floor (Figure 2.8).

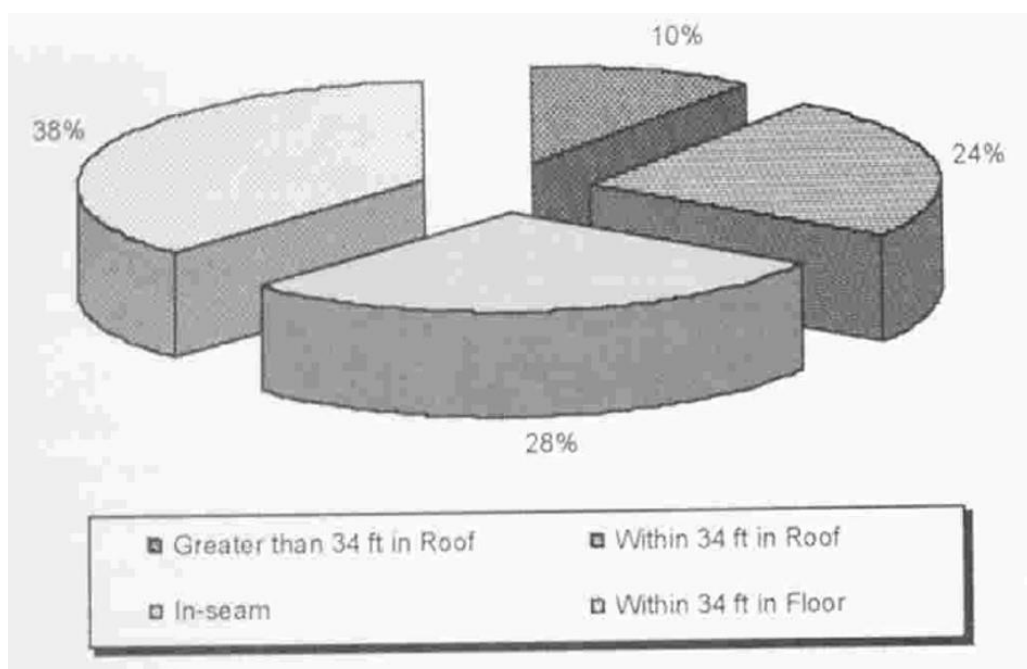

Figure 2.8 Location of gas well failure (Peng et al. 2003)

\subsection{Numerical Modelling Analysis using FLAC ${ }^{3 D}$ Program}

Due to an underground excavation, the initial state of stress is disturbed in both lateral and axial directions, known as induced stress, which will lead to a massive deformation. Understanding the magnitudes of stress and strain resulting from an excavation is one of the fundamental factors for any surface and or underground structure design. When longwall mining method is used, it is critical to design a pillar that can withstand for the entire longwall mining operation.

The empirical approach for pillar design is able to design an appropriate pillar size for a longwall mining operation. However, when a complex case where a gas well is penetrated through 
the abutment pillar, such empirical approaches cannot be applied. The complexity of stress and strain distribution acting on the gas well as a result of a surface or underground excavation makes it difficult to quantify using empirical approaches. Therefore, the numerical methods have been used widely used for stresses and strain analysis due to its simplicity and efficiency (Jing, 2001 and 2003; Starfield, 1998). Using the numerical method, the approximate results that satisfied the field condition can be obtained and therefore numerical model approach can be used to design any surface and underground structure under various complex conditions.

Finite difference method (FDM) is the oldest numerical method for solving differential equations. FLAC ${ }^{3 \mathrm{D}}$ (Fast Langrangian of Continua in 3 Dimensions) is a numerical modeling software using FDM for geotechnical analysis of soil, rock, ground support, and has been widely used in various engineering projects design (Itasca, 2017). Numerical modelling analysis using FDM, like FLAC ${ }^{3 \mathrm{D}}$, might be different with the analysis using Finite Element Method (FEM) as these two methods have differences in their analysis approach. FDM produces a direct approximation of the governing Partial Differential Equations (PDE) by replacing partial derivatives with finite difference spread over the area of interest (Jing and Hudson, 2002).

The capability to represent a three-dimensional mining geometries and design is one of the special features of FLAC ${ }^{3 \mathrm{D}}$ (Board, 2006). FLAC ${ }^{3 \mathrm{D}}$ was selected for this study since it is well accepted by the mining and geotechnical engineering community in various purposes, especially for rock and soil mechanic research area.

The basic solution scheme employed in FLAC ${ }^{3 \mathrm{D}}$ is shown on Figure 2.9. FLAC invokes the equation of motion and constitutive relations to describe the deformation of a given problem. The estimation of velocities and displacements from forces and stresses are estimated using the 
dynamic equation of motion. Velocities and displacements are then used to derive strain rates from which new stresses are generated.

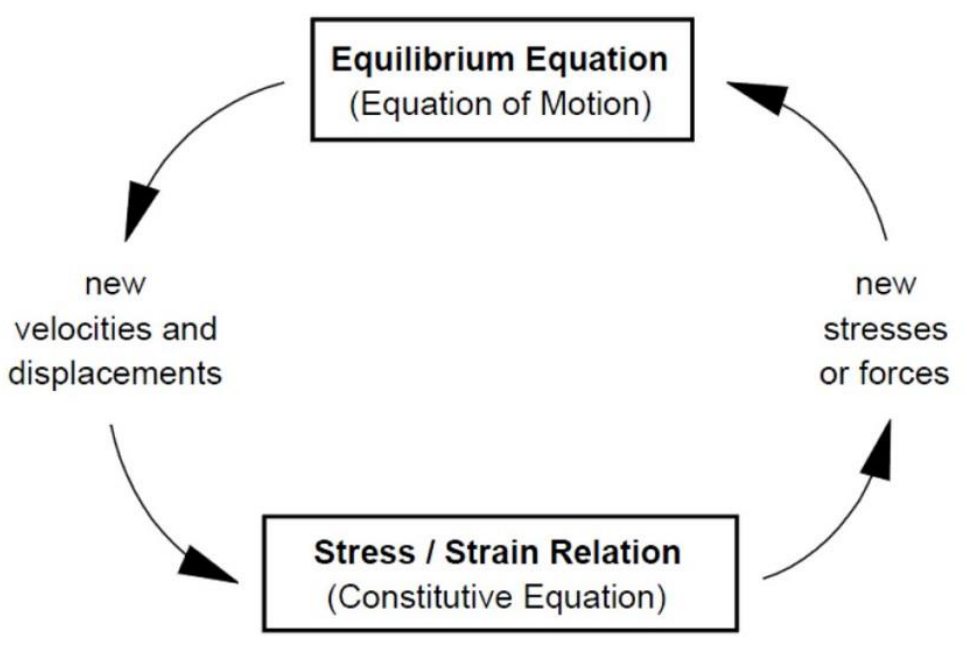

Figure 2.9 Calculation cycle of FLAC3D program (Itasca, 2017)

In order to build a FLAC ${ }^{3 \mathrm{D}}$ model and run a simulation, five fundamental steps must be specified: (i) selecting a finite difference grid, (ii) setting boundary condition, (iii) initializing the insitu stress condition, (iv) determining a constitutive model, and (v) selecting material properties of a model. After these conditions are defined in a model, the initial equilibrium state analysis of the simulated model will be performed. An alteration is then made (i.e. excavation or change boundary condition) for the model and then the resulting response is assessed. This procedure corresponds to the typical numerical modelling sequence of the FLAC ${ }^{3 \mathrm{D}}$ program (Itasca, 2017).

\subsection{Constitutive Model}

There are fourteen basic constitutive models introduced in FLAC ${ }^{3 \mathrm{D}}$ program. For this study, the elasto-plastic model under Mohr-Coulomb failure criterion and Double-Yield model under strain hardening failure criterion are used. These two constitutive models are used for different material properties. 


\subsubsection{Mohr-Coulomb Failure Criterion}

The Mohr-Coulomb failure criterion is one of the most widely used criteria in mining application due to its simplicity. However, the downside of this criteria is that it does not take into account of the effect of intermediate principal stress. This failure criterion also has been used in the earlier studies in analyzing the stability of gas well in longwall mining area (Liang et al. 2014; Liang et al. 2015; Liang et al. 2017; Wang et al. 2013).

The input parameters needed for analysis using Mohr-Coulomb criteria are: density $(\gamma)$, bulk modulus $(K)$, shear modulus $(G)$, friction angle $(\phi)$, cohesion $(c)$, dilation angle $(\psi)$, and tensile strength $(T)$ of the material. The input parameters of $K$ and $G$ can be determined by analyzing the value of Young's modulus $(E)$, and Poisson's ratio $(v)$, using the following equations,

$$
\begin{aligned}
& K=\frac{E}{3(1-2 v)} \\
& G=\frac{E}{2(1+v)}
\end{aligned}
$$

Equation 2.12

The Mohr-Coulomb failure criterion is shown in the plane as illustrated in Figure 7. This criterion predicts the shear strength of material $(\tau)$ as a function of the applied stress using the following equation,

$$
\tau=\sigma_{n} \tan \phi+c
$$

Where, $\tau$ is the shear strength of the material, $\mathrm{c}$ is the cohesion, $\sigma_{n}$ is the applied normal stress and $\phi$ is the friction angle. 
Cohesion is the inherent shear strength of the rock, which can prevent failure in cases of pure shearing, while friction angle is a friction coefficient, in that the product of the normal stress create opposition to sliding (Fahrman, 2016).

In order for a stress state to be plotted as one independent orientation point, the failure envelope can be expressed in the form of three principal stress states $\left(\sigma_{1}, \sigma_{2}, \sigma_{3}\right)$. Thus, the Mohr-Coulomb failure criterion formula on Equation 2.11, can be rewritten in terms of $\phi$, shown on Equation 2.13.

$$
\sigma_{1}=\frac{1+\sin \emptyset}{1-\sin \emptyset} \sigma_{3}+\frac{2 c \cos \emptyset}{1-\sin \emptyset}
$$

Where, $\sigma_{1}$ and $\sigma_{3}$ are respectively the maximum and minimum principal stresses.

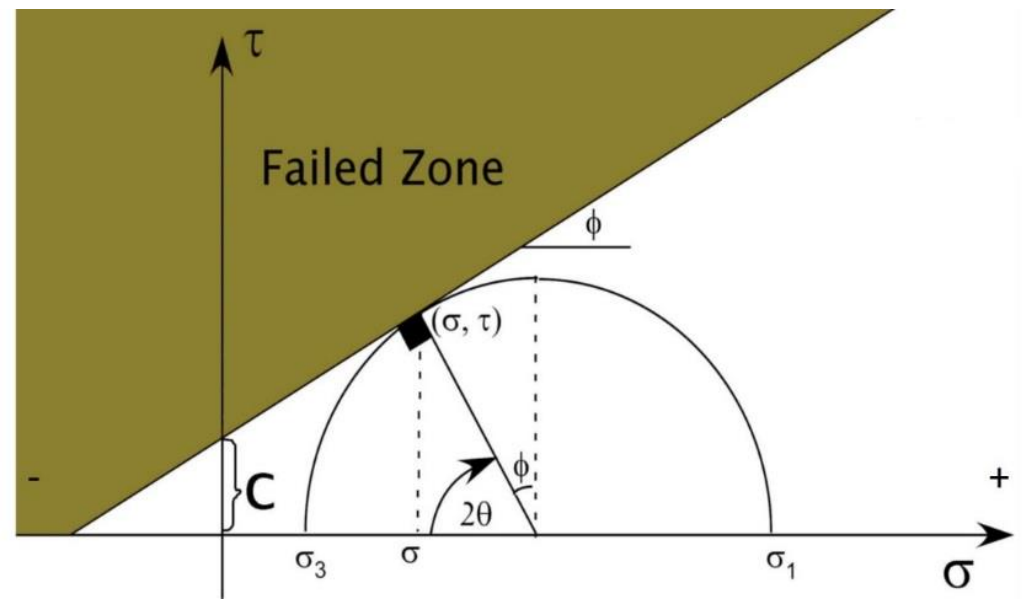

Figure 2.10 Mohr coulomb failure envelope

The Mohr's circle showing on Figure 2.10 represents a critical state of the failure zone. Any stress state under the failure envelope and not intersecting it is expected to be technically stable. In contrast, failure occurred if the stress acting on the material is above the failure envelope. Negative and positive sign convention on Figure 2.10 corresponds to the compressive and tension strength of the material, respectively. 


\subsubsection{Double-yield model}

The double-yield model represents material with the ability to be in high irreversible compacted state subjected to deformation. This material contains the backfill material or cemented material. The gob material in longwall mining can be assessed as strain hardening material, which means the modulus of the deformation increases with increasing compaction (Figure 2.11). This strain-hardening property can be simulated by the double yielding model in FLAC program (Yavuz, 2004; Li et al. 2015; Zhang et al. 2015; Jiang et al. 2017).

The double yielding model takes the permanent volume changes due to isotropic pressure into consideration by "cap pressure," in addition to the shear and tensile failure envelopes in the strain-softening model. The hardening behavior of the double yielding model is activated by volumetric plastic strain following a piecewise-linear defined table. Any laboratory-determined hardening behavior may be modeled by the double yielding model.

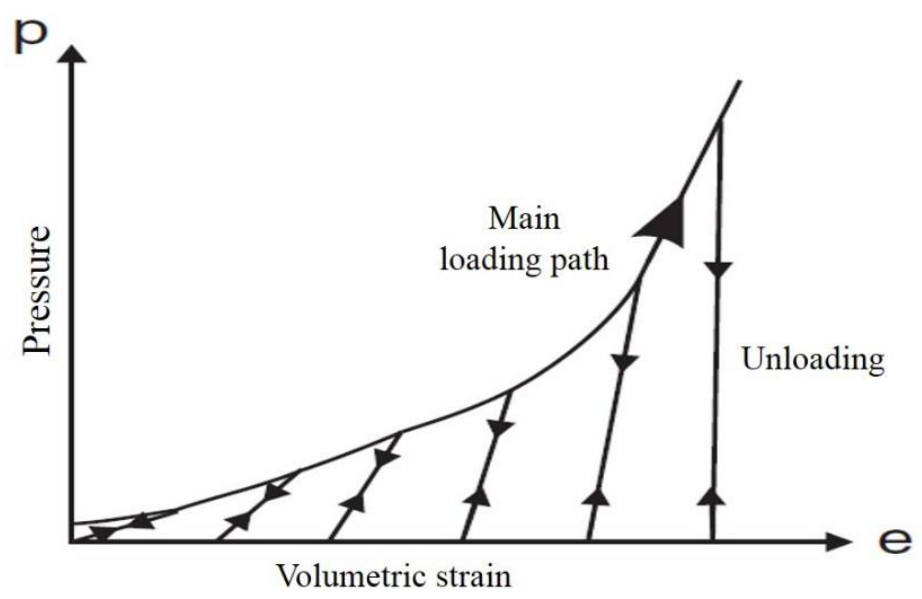

Figure 2.11 The pressure and volumetric strain curve of the double yielding model (Itasca, 2017). 


\subsection{Modelling the GOB Behavior with FLAC ${ }^{3 D}$}

After longwall panel extraction, the immediate roof strata above the extracted coal seam bend and cave into the free face of the coal seam being excavated, known as gob. The development of gob and overburden movement determine the loading on the adjacent coal pillar around the gob area during a longwall mining retreat process. The behavior of the gob is imperative for accurately predicting the distribution of the load transferred to the longwall face, pillars, and tailgate sections as well as the loads that are transferred to the vertical gas well in a longwall mining operation. Therefore, when a numerical model analysis is used, an appropriate gob model and its constitutive model is required to accurately assess the induced stress, strain and displacement distribution along a vertical gas well in response to the longwall mining operation.

Esterhuizen et al. (2010) presents two approaches for modeling the gob behavior, first is to explicitly model the gob formation process that includes variations in geology and loading condition, and the second approach is to implicitly model the gob compaction and load distribution in order to accurately model the load distribution affected by longwall mining. For this study, the second approach was used.

A stress-strain relationship of the gob material proposed by Salamon (1990) is widely used and therefore was selected for this study. Salamon's model follows the following strain-hardening equation.

$$
\sigma=\frac{E_{0} \varepsilon}{1-\varepsilon / \varepsilon_{m}}
$$

Where, $\sigma$ is the uniaxial stress applied on the gob, $E_{0}$ is the initial tangential modulus, $\varepsilon$ is the strain under the applied stress, $\varepsilon_{m}$ is the maximum possible volumetric strain. 
The initial tangential modulus heavily depends on the bulking factor $(b)$ and strength of rock layer $\left(\sigma_{c}\right)$. Yavus (2004) proposed the following equations to find the relationship between these parameters, which are as follows:

$$
\begin{aligned}
& E_{0}=\frac{10.39 \sigma_{c}{ }^{1.042}}{b^{7.7}} \\
& \varepsilon_{m}=\frac{b-1}{b}
\end{aligned}
$$

The value of bulking factor $(b)$ can be determined by using the following equation.

$$
b=\frac{\mathrm{h}_{\mathrm{cav}}+H}{h_{\text {cav }}}
$$

Where, $b$ is bulking factor, $\sigma_{c}$ is the strength of rock pieces, $\mathrm{h}_{\text {cav }}$ and $\mathrm{H}$ are the height of caving and height of coal seam. Finally, the stress-strain relationship of the gob material can be determined by substituting equations (2.16), (2.17), into (2.15), as expressed on the following expression:

$$
\sigma=\frac{10.39 \sigma_{c}{ }^{1.042}}{b^{7.7}} \times \frac{\varepsilon}{1-\frac{b}{b-1} \varepsilon_{m}}
$$

In FLAC ${ }^{3 \mathrm{D}}$ program, the Double-Yield model (presented on section 2.7) is appropriate to model the strain-hardening of gob material (Yavuz 2004; Li et al. 2015; Zhang et al. 2015). Two input parameters needed in Double-Yielding model of FLAC ${ }^{3 \mathrm{D}}$ program are material properties and cap pressure. The stress-strain relationship of gob, which is the input for cap pressure of Double-Yield model in FLAC ${ }^{3 \mathrm{D}}$, is obtained using equation 2.19. However, the challenges for the Double-Yielded model in FLAC ${ }^{3 \mathrm{D}}$ program is to determine the large input material properties required, including the input parameter of friction angle, dilation angle, bulk modulus, and shear modulus of the gob model. Therefore, in $\mathrm{FLAC}^{3 \mathrm{D}}$ a trial and error scheme is used in order to match 
the stress-strain relation curve of the double-yield model that is produced by salamon's model. Figure 2.12 shows an example of typical comparison of stress-strain relation curve using Salamon's model and FLAC ${ }^{3 \mathrm{D}}$. An example of obtained mechanical properties of the gob material using FLAC ${ }^{3 \mathrm{D}}$ is listed in Table 2.1.

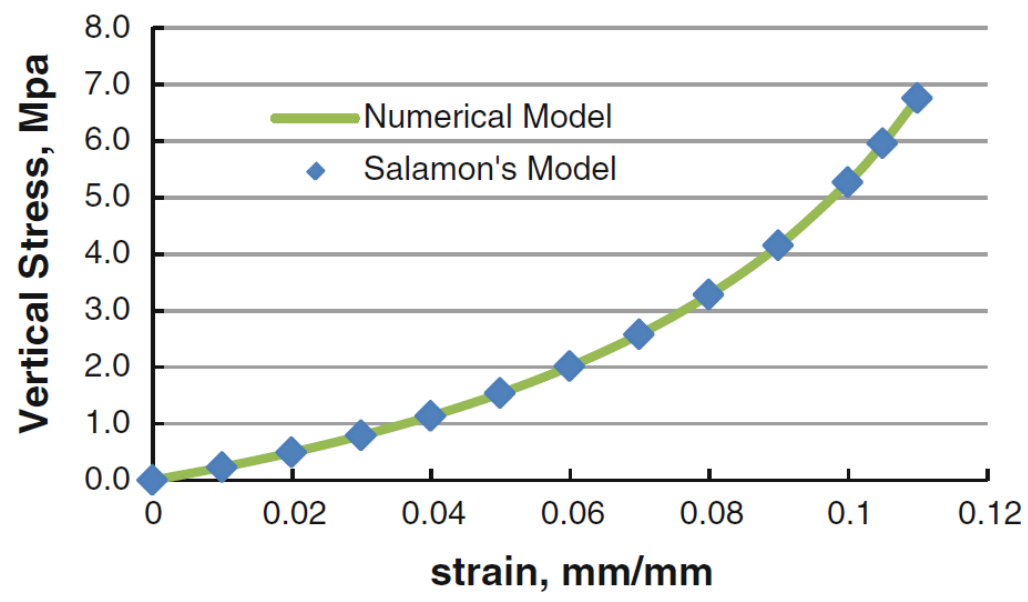

Figure 2.12 Comparison of the stress-strain relationship between Salamon's model and the FLAC ${ }^{3 \mathrm{D}}$ model (Li et al. 2017)

Table 2.1 The obtained mechanical properties of the gob material (Li et al. 2017)

\begin{tabular}{ccccc}
\hline $\begin{array}{c}\text { Density }(\gamma) \\
\mathrm{Kg} / \mathrm{m}^{3}\end{array}$ & $\begin{array}{c}\text { Bulk } \\
\text { modulus }(K)\end{array}$ & $\begin{array}{c}\text { Shear modulus } \\
\mathrm{MPa}\end{array}$ & $\begin{array}{c}\text { Friction } \\
\text { angle }(\phi)\end{array}$ & $\begin{array}{c}\text { Dilation } \\
\text { angle }(\varphi) \\
\text { degree }\end{array}$ \\
\hline 1000 & 8690 & 6350 & 20 & 5 \\
\hline
\end{tabular}




\section{CHAPTER 3}

\section{METHODOLOGY}

"We must revisit the idea that science is a methodology, not an ontology" -Linus Torvalds

This study is aimed to assess the stability of a vertical gas well subjected to longwall mining operation using the numerical modelling approach, based on a case study cited in Peng et al. (2003) and Luo et al. (1999). In the subsequent sections, the description of the case study and methodology using in this study are discussed in detail.

\subsection{Description of the Case Study}

The Pittsburgh coal seam has been extracted for many years using longwall mining method. Due to the recent increased production of shale gas in the U.S., many gas wells have been drilled through various longwall mining coal seams, especially in the Western region, including the Pittsburgh coal seam, Upper/Lower Freeport coal seam, and many other coal seams around the states.

The current case study is located over the Pittsburgh coal seam employing a $900 \mathrm{ft}$ (274 m) wide longwall panel. A three-entry longwall gateroad system was used and a two row of abutment and chain pillar, of dimensions $104 \mathrm{ft}(32 \mathrm{~m})$ by $68 \mathrm{ft}(21 \mathrm{~m})$ wide rib to rib was placed to protect the gas well that is penetrated through the coal seam. Figure 3.1 represents a spatial relationship between the vertical gas well, abutment pillar, chain pillar, and two longwall panels for the case study. The vertical gas well was constructed in three different structures, with a total depth of 5,971 $\mathrm{ft}(1820 \mathrm{~m})$. The gas well casing that penetrated the coal seam had an outer diameter and thickness 
of 8.625 and 0.875 inches, respectively, running from the depth of $29 \mathrm{ft}(9 \mathrm{~m})$ down to $2,210 \mathrm{ft}$ (674 $\mathrm{m})$ below the surface.

\section{Panel 2}

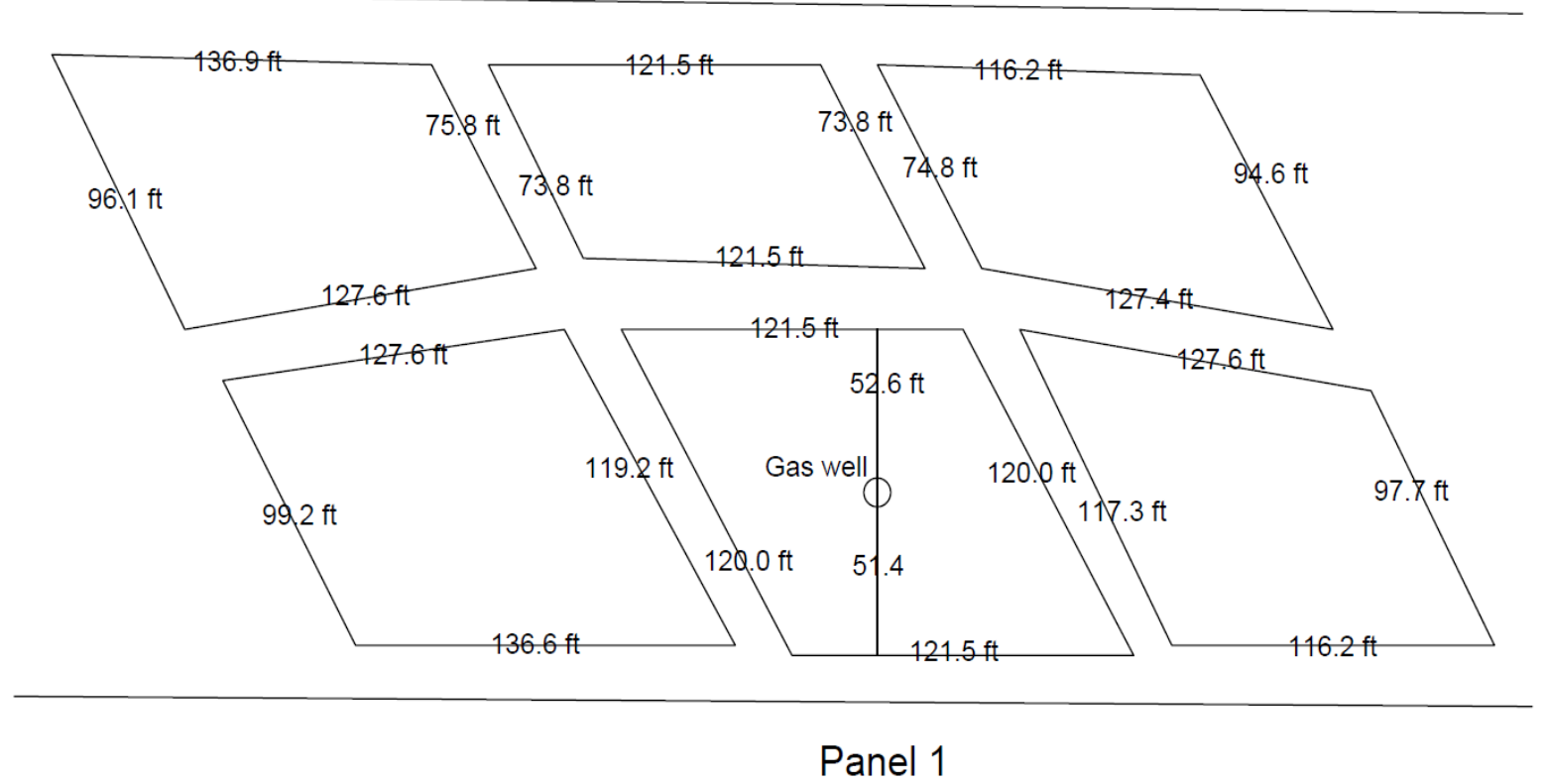

Figure 3.1 Longwall panel layout (Peng et al. 2003). Location of the gas well is marked with a circle in the middle of an abutment pillar. $1 \mathrm{ft}: 0.3048 \mathrm{~m}$.

The majority of the strata overlying the coal seam in the field was sandstone and sandyshale, with $30 \mathrm{ft}$ (9 m) of topsoil layer (Figure 2). The overburden depth, mining height, and the entry width was $943 \mathrm{ft}(287.4 \mathrm{~m}), 6 \mathrm{ft}(2 \mathrm{~m})$, and $16 \mathrm{ft}(5 \mathrm{~m})$, respectively. The stratigraphic column of the case study site indicates a clear demarcation of sandyshale which represents a strong stratum, while clay represents a soft stratum, and again a strong stratum represented by a sandstone below the coal seam. The sandyshale and sandstone are typical strata that is permeable and contain water, while clay is an impermeable strata layer and thus contains less water. Having a combination of strong-weak-strong strata layers, particularly in a longwall mine, could possibly become a major influence on longwall induced stresses and deformation. Therefore, it can be expected that the 
vertical gas well analysis for the case study could possibly experience higher possibility to fail in the horizon where the dominance of laminated strong and weak strata take place.

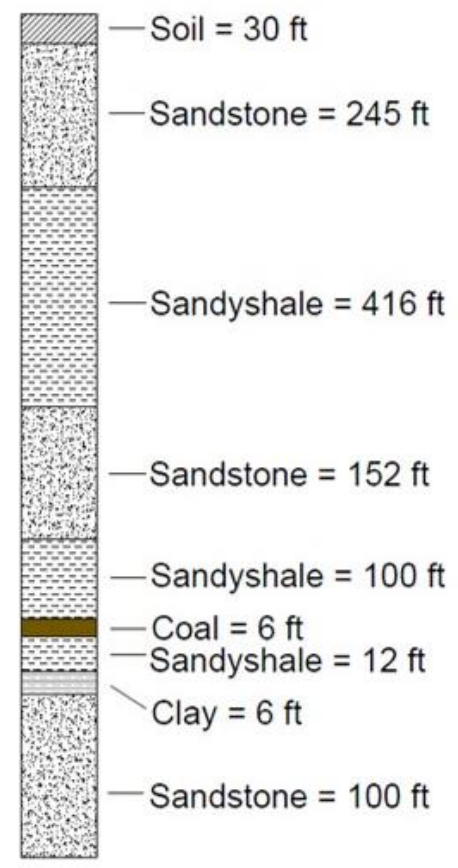

Figure 3.2 Column of lithology of the case study (Peng et al. 2003)

As expected, field observations indicated that the failure occurred in the clay (soft) layer which was at a depth of $16.5 \mathrm{ft}(5 \mathrm{~m})$ below the coal seam, after second panel (Figure 3.3). Peng et al. (2003) used the Finite Element Method through ABAQUS software to assess the gas well stability affected by longwall mining operation. The magnitude of strain developed in the gas well casing caused by longwall mining operation was used as a criterion to assess the stability of the gas well. The result of their ABAQUS analysis showed that the maximum magnitude of vertical strain located in the clay had a magnitude of 0.0056 in/in followed by 0.0046 in/in in the coal seam layer. Therefore, the gas well failed at the clay layer due to the vertical strain which exceeded a critical magnitude of $0.005 \mathrm{in} / \mathrm{in}$. Peng et al. (2003) reported that the gas well failed in the clay layer due to high compressive strain as a result of second panel mining. No other gas well failure 
was observed at the site. Peng et al. (2003) concluded that the presence of the clay layer between two strong strata could induce high stresses on the gas well casing and causing the high compressive strain occurred at the gas failure horizon.

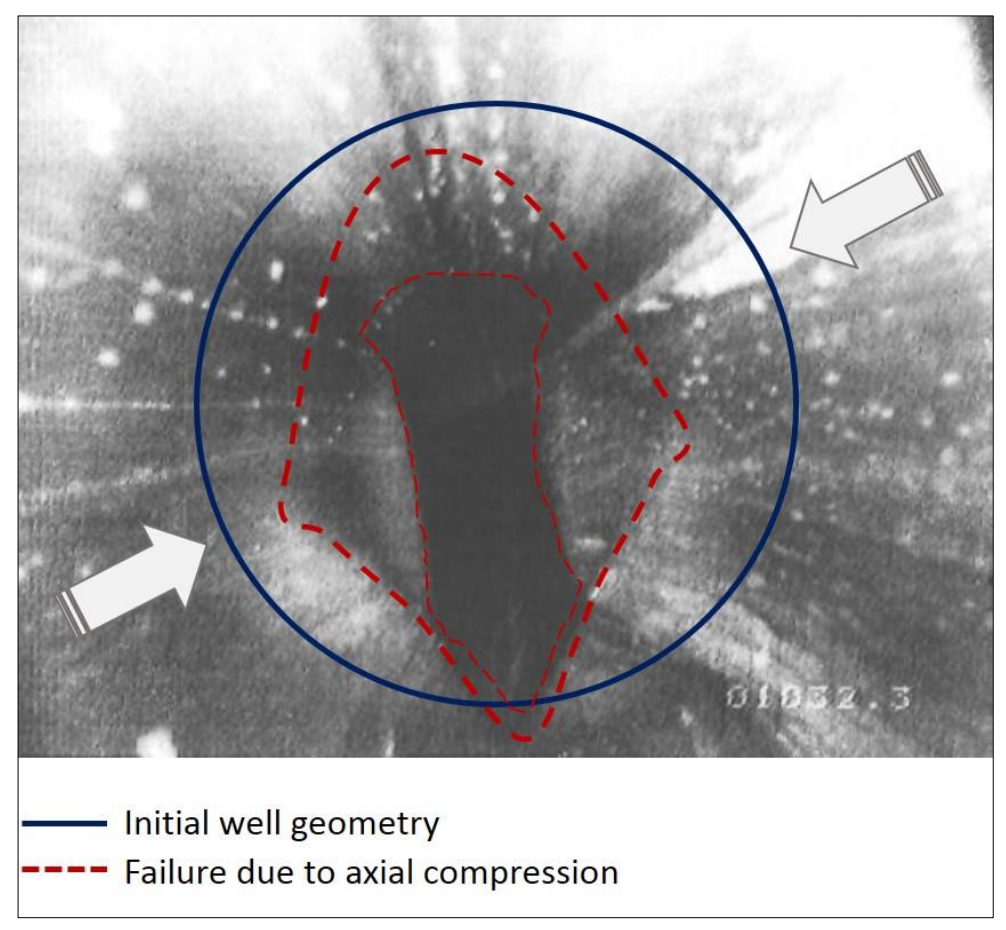

Figure 3.3 Gas well failure recorded in the field (Modified from Luo et al. 1999)

For this thesis, this case study will be used as an extension of the previous study conducted by Peng et al. (2003) to assess the influence of overburden depth and the presence of the soft strata under the given geological condition and mining geometry of the case study. In addition, the optimal pillar size determination for protecting gas well from failure due to longwall mining operation will also be investigated.

\subsection{Numerical Model Development}

Various three dimensional models using finite difference method in FLAC ${ }^{3 D}$ software (Itasca, 2017) were developed to assess the progressively induced stress and strain distribution 
along the gas well trajectory, as a result of longwall mining. FLAC ${ }^{3 \mathrm{D}}$ is a three dimensional numerical modeling program using for analysis, testing, and design by geotechnical, civil, petroleum, and mining engineers. FLAC ${ }^{3 \mathrm{D}}$ utilizes an explicit finite difference formulation that can model complex behaviors, such as problems that consist of several stages, large displacement and strain as well as non-linear material behavior. The simulated model using in this study has been calibrated against the observed gas well failure of an actual case study as presented in Peng et al. (2003).

\subsubsection{Model Geometry and Boundary Condition}

Two model scenarios, having their own geometry, were built in this thesis. The first and second model scenarios were built, respectively, for assessing the influence of overburden depth and the presence of soft strata on the stability of vertical gas well of the case study.

The previous study showed that any added resistance of the vertical gas well has a negligible influence compared to the strata deformation occurring in a gas well during longwall mining development (Liang et al. 2014; Liang et al. 2015; Liang et al. 2017; and Peng et al. 2003). Hence, in predicting the gas well failure, various zones and nodes representing the gas well trajectory were analyzed. For this study, the gas well was embedded in the simulated model using the solid element in $\mathrm{FLAC}^{3 \mathrm{D}}$ in order to obtain an accurate prediction results. The casing of the gas well had an outer diameter and thickness of 8-5/8 and 0.875 inches, respectively, running from the top to the bottom side of the model. The wellbore cement of the gas well was not considered due to at the depth of interest there is no cement surrounding the gas well casing.

\section{Scenario I - Simulated model for assessing the influence of the overburden depth}

In the first scenario, six FLAC ${ }^{3 \mathrm{D}}$ models were developed to assess the influence of overburden depth and to determine the critical overburden depth that the gas well can survive 
under the given geological and mining condition. The six FLAC ${ }^{3 \mathrm{D}}$ models correspond to the model with overburden depth of $500 \mathrm{ft}(152 \mathrm{~m}), 600 \mathrm{ft}(183 \mathrm{~m}), 650 \mathrm{ft}(198 \mathrm{~m}), 750 \mathrm{ft}(229 \mathrm{~m}), 850 \mathrm{ft}$ (259 m), and $943 \mathrm{ft}(287.4 \mathrm{~m})$ (actual field condition).

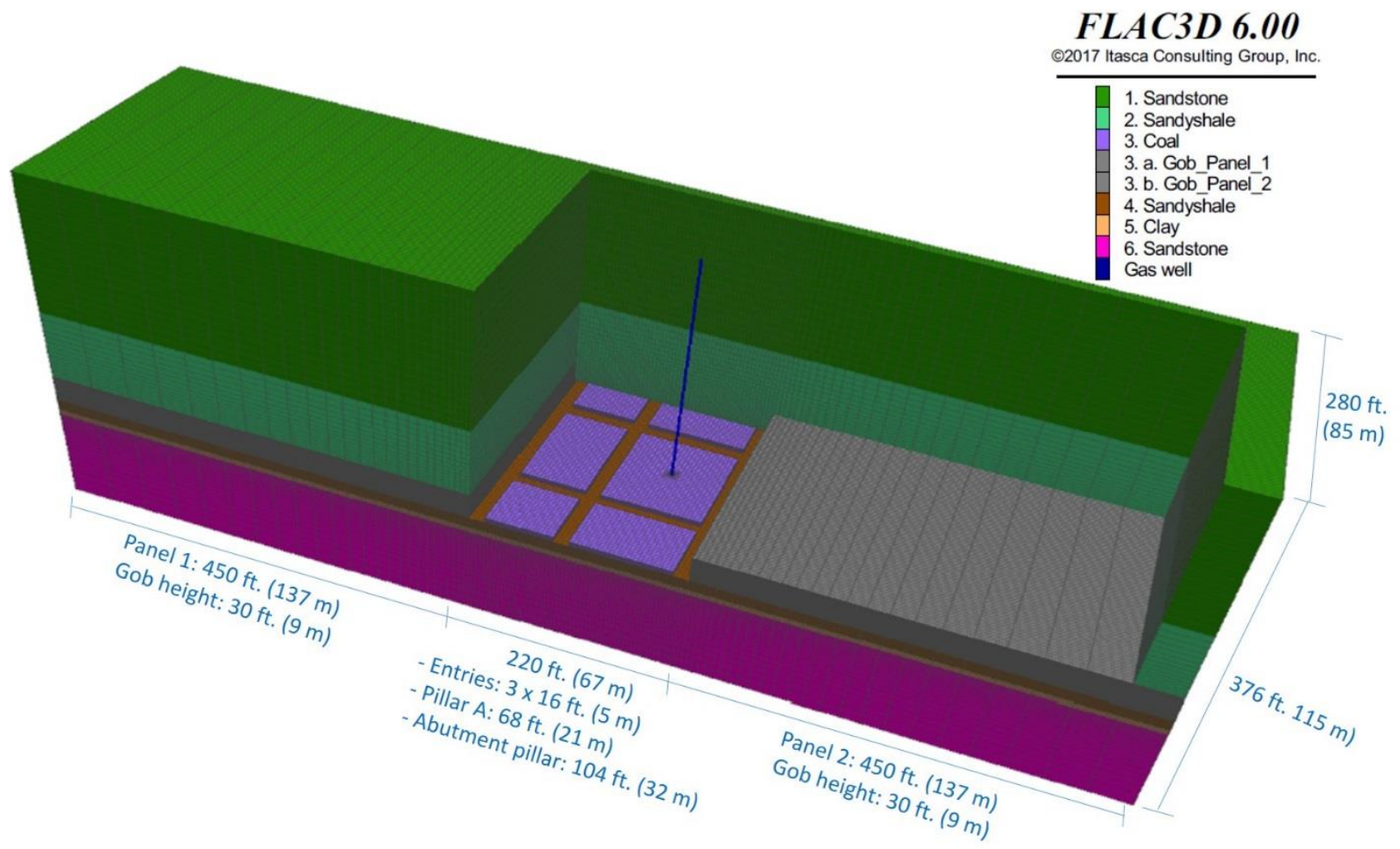

Figure 3.4 FLAC ${ }^{3 \mathrm{D}}$ Model Geometry for the scenario I. The gas well showing on blue colour is penetrated through longwall mining abutment pillar from surface to the bottom of the simulated model.

The simulated model typifies a longwall mining geometry and geological condition of the mine is shown on Figure 3.4. The case study had longwall panels with width and length of $900 \mathrm{ft}$ $(274.3 \mathrm{~m})$ and 5,000 ft $(1524 \mathrm{~m})$, respectively, and overburden depth of $943 \mathrm{ft}(287.4 \mathrm{~m})$. Due to the large extent of the mining geometry, the model was built using symmetric condition, considering half width of the longwall mine panel, which is $450 \mathrm{ft}(137 \mathrm{~m})$. The panel length was modeled to be $280 \mathrm{ft}(85 \mathrm{~m})$ and the overburden depth was built to be $252 \mathrm{ft}(77 \mathrm{~m})$. The load acting from the rest of overburden depth, which is $691 \mathrm{ft}(211 \mathrm{~m})$, was embedded on the model by 
applying a 5.41 MPa of normal stress on the top face of the model. In assessing the overburden depth influence, the applied normal load for the overburden depth varying from $500 \mathrm{ft}$ (152 m) to $850 \mathrm{ft}(259 \mathrm{~m})$ ranged from 2.0 $\mathrm{MPa}$ to $4.725 \mathrm{MPa}$. The zone sizes varying from the smallest in the focused analysis area, which is in the pillar and gas well area, to the largest size, which is at the far end of the longwall gateroad entries system. This significantly reduced the computational time for running the simulated model. In terms of boundary conditions, the bottom side of the simulated models were fixed in both horizontal and vertical direction, while in the north, south, east and west side direction of the model was fixed in the horizontal direction.

\section{Scenario II - Assessing the influence of the presence of soft strata}

In the second scenario, two FLAC ${ }^{3 \mathrm{D}}$ models were developed to assess the influence of the presence of soft strata on the stability of gas well subjected to longwall mining operation. The first FLAC $^{3 \mathrm{D}}$ model corresponds to the actual condition of the case study, which has the soft strata presence at the depth of 12 to $18 \mathrm{ft}(3.7$ to $5.5 \mathrm{~m})$ below the coal seam. Next, for investigating the influence of soft strata, we eliminated the presence of soft strata (clay layer) on the model simulated, in contrast to the actual condition in the field. This approach was performed to verify whether or not the presence of soft strata has influence on the stability of vertical gas well subjected to a longwall mining operation.

Figure 3.5 shows the model geometry of the 2 simulated models. Both two models have the same mining geometry. The only difference is one model has the presence of soft strata (clay layer), while the other model excludes the clay layer. In terms of boundary condition of the simulated model, the bottom side of the model was fixed in both horizontal and vertical direction, while in the north, south, east and west side direction of the model was fixed in the horizontal direction. The zone sizes varying from the smallest in the focused analysis area, which is in the 
pillar and gas well area, to the largest size, which is at the far end of the longwall gateroad entries system.

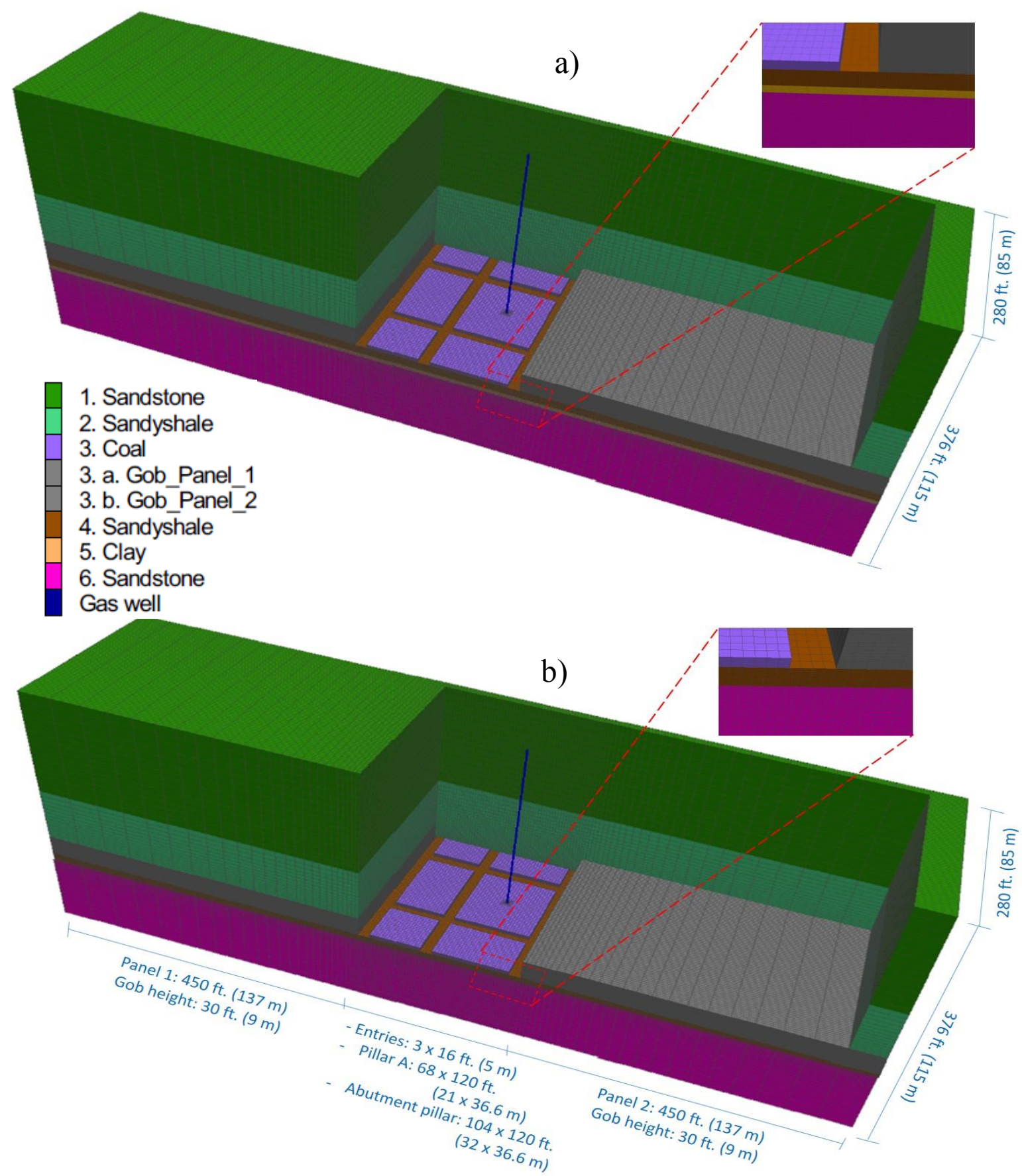

Figure 3.5 FLAC ${ }^{3 \mathrm{D}}$ Model Geometry for the scenario II: $a$. Model with the presence of soft strata, $b$. Model without soft strata presence. The gas well showing on blue colour is penetrated through longwall mining abutment pillar from surface to the bottom of the simulated model. 
The longwall mining panel has a geometry of $900 \mathrm{ft}(274.3 \mathrm{~m})$ in width and 5,000 $\mathrm{ft}(1,524$ $\mathrm{m})$ in length, under the overburden depth of $943 \mathrm{ft}(274.3 \mathrm{~m})$. The model was built in symmetric condition, considering the half width of the longwall panel and extents to a length of $280 \mathrm{ft}(85 \mathrm{~m})$ in the direction perpendicular to panel width. The overburden depth was built to be $252 \mathrm{ft}(77 \mathrm{~m})$. Thus, the load acting on the rest of overburden depth (691 ft or $211 \mathrm{~m}$ ) was embedded on the model by applying a 5.41 MPa of normal stress on the top of the simulated model.

\subsubsection{Selected Constitutive Model}

In this study, the entire rock layers of the simulated model was built using the Elasto-plastic model under Mohr-Coulomb failure criterion, while the gob element was built under the doubleyield constitutive model considering the strain hardening material behavior. The detail explanation of these two constitutive model were described on Chapter 2, sub-section 2.7.

\subsubsection{Insitu Stress Initialization}

The geo-materials of each strata layers were considered to be homogenous and isotropic. This assumption was made due to the fact that $\mathrm{FLAC}^{3 \mathrm{D}}$ is a continuum model. The insitu stress was calculated through a theoretical approach, as given in the following equations,

$$
\begin{array}{ll}
\sigma_{\mathrm{v}}=\rho g h & \text { Equation } 3.1 \\
\sigma_{\mathrm{h}}=k \sigma_{\mathrm{v}} & \text { Equation } 3.2
\end{array}
$$

Where, $\sigma_{\mathrm{v}}$ and $\sigma_{\mathrm{h}}$ is the vertical stress and horizontal stress, respectively, $\rho$ is the density of the rock strata, $g$ is the acceleration due to gravity, $h$ is the thickness of rock layer, and $k$ is the ration of horizontal stress over vertical stress. 


\subsubsection{Physical and Mechanical Properties of the Rock Strata}

The adopted rock properties, including the physical and mechanical properties, are presented in Table 3.1. These values are typically consistent with the rock mass properties as indicated by Peng et al. (2003).

Table 3.1 Physical and Mechanical properties of rock strata and casing used in the model

\begin{tabular}{|c|c|c|c|c|c|c|}
\hline \multirow[b]{2}{*}{ Lithology } & \multirow[b]{2}{*}{$\begin{array}{c}\text { Density } \\
(\gamma) \\
\mathrm{Kg} / \mathrm{m}^{3}\end{array}$} & \multicolumn{2}{|c|}{ Elastic Properties } & \multicolumn{3}{|c|}{ Plastic Properties } \\
\hline & & $\begin{array}{c}\text { Modulus of } \\
\text { elasticity }(E) \\
\qquad \mathrm{MPa}\end{array}$ & $\begin{array}{c}\text { Poisson's } \\
\text { ratio }(\mu)\end{array}$ & $\begin{array}{c}\text { Cohesion } \\
\text { (c) } \\
\mathrm{MPa}\end{array}$ & $\begin{array}{l}\text { Tensile } \\
\text { strength } \\
(T) \mathrm{MPa}\end{array}$ & $\begin{array}{l}\text { Friction } \\
\text { angle }(\phi) \\
\text { (degree) }\end{array}$ \\
\hline Soil & 1,901 & 1,523 & 0.35 & 0.83 & 0.28 & 28 \\
\hline Coal & 1,314 & 4,137 & 0.36 & 1.86 & 0.62 & 28 \\
\hline Clay & 2,242 & 5,506 & 0.2 & 1.34 & 0.45 & 28 \\
\hline Sandstone & 2,402 & 20,684 & 0.18 & 5.84 & 2.24 & 35 \\
\hline Sandyshale & 2,402 & 12,401 & 0.19 & 2.19 & 0.86 & 30 \\
\hline Gas Well Casing & 7,849 & 193,743 & 0.26 & - & - & - \\
\hline
\end{tabular}

\subsubsection{Steps of Excavation}

After the model is built, it was solved in four steps. The first step involved the solution of the model in virgin condition, without any excavation. The second, third, and fourth steps involved creation of entries, excavation of the first panel and excavation of the second panel, respectively. Longwall entries and panels were created by deleting the zones in the model representing the longwall entries and panels. Each longwall panel for all the simulated models were excavated in 5 steps. The first excavation was to excavate a rectangular block having a size of $450 \mathrm{ft}(137 \mathrm{~m})$ wide and $100 \mathrm{ft}(30.5 \mathrm{~m})$ long. The subsequent steps from second to fifth steps were to excavate the remaining $180 \mathrm{ft}(55 \mathrm{~m})$ length of the longwall panel. Thus, $45 \mathrm{ft}(13.7 \mathrm{~m})$ long by $450 \mathrm{ft}$ (137 m) wide excavation was performed for the second to fifth excavation steps. The gob element was 
modelled during the first and second panel mining after completion of each stages of excavation. Finally, the magnitudes of stresses and displacements distribution in the lateral and axial direction acting along the vertical gas well trajectory were stored and analyzed.

\subsection{GOB Model Simulation}

GOB refers to the broken material formed due to the longwall panel extraction. When FLAC $^{3 \mathrm{D}}$ is used to simulate the gob compaction process, the double yield model can be used. In this study, Salamons's model (Salamon, 1990) is used to model the behavior of gob material, following equation 2.9. The three constant parameters needed to be defined for Salamon's model analysis are initial tangential modulus $\left(E_{o}\right)$, maximum strain $\left(\varepsilon_{\mathrm{m}}\right)$ and bulking factor $(b)$. These three parameters can be determined using Equation 2.16, 2.17, 2.18, respectively.

Bulking factor and caving height parameters ranges from 1.2 to 1.25 and 2 to 8 of coal seam height, respectively (Peng, 2006). For this study, the coal seam height is 6 feet $(1.8 \mathrm{~m})$ and the caving height was assumed to be 5 times of the coal seam height, which is 30 feet $(9.1 \mathrm{~m})$. Hence, the predicted bulking factor (b), maximum strain $\left(\varepsilon_{\mathrm{m}}\right)$, and initial modulus $\left(E_{o}\right)$ of gob is 1.2, 0.16, and 20.55 $\mathrm{MPa}$, respectively. Using salamon's approach, the stress and strain relationship for the gob material is shown on Table 3.2.

Table 3.2 Predicted cap pressure for double-yield of gob model

\begin{tabular}{lllllllll}
\hline Strain (in/in) & 0.01 & 0.02 & 0.03 & 0.04 & 0.05 & 0.06 & 0.07 & 0.08 \\
\hline Stress (MPa) & 0.22 & 0.47 & 0.75 & 1.08 & 1.46 & 1.91 & 2.46 & 3.12 \\
\hline Strain (in/in) & 0.09 & 0.10 & 0.11 & 0.12 & 0.13 & 0.14 & 0.15 & 0.16 \\
\hline Stress (MPa) & 3.96 & 5.04 & 6.48 & 8.52 & 11.60 & 16.81 & 27.55 & 62.40 \\
\hline
\end{tabular}


Since the double yielding model in FLAC $^{3 \mathrm{D}}$ is controlled by two group parameters, including material properties and cap pressure as discussed in Chapter 2 under sub-section 2.8, the Salamon's model needs to be converted to double yielding model. However, there is no defined approach to convert the salamon's model into FLAC $^{3 \mathrm{D}}$ model. Therefore, in this study, a trial and error scheme is used in order to match the stress-strain relation curve of the double-yield model that is given by Salamon's model.

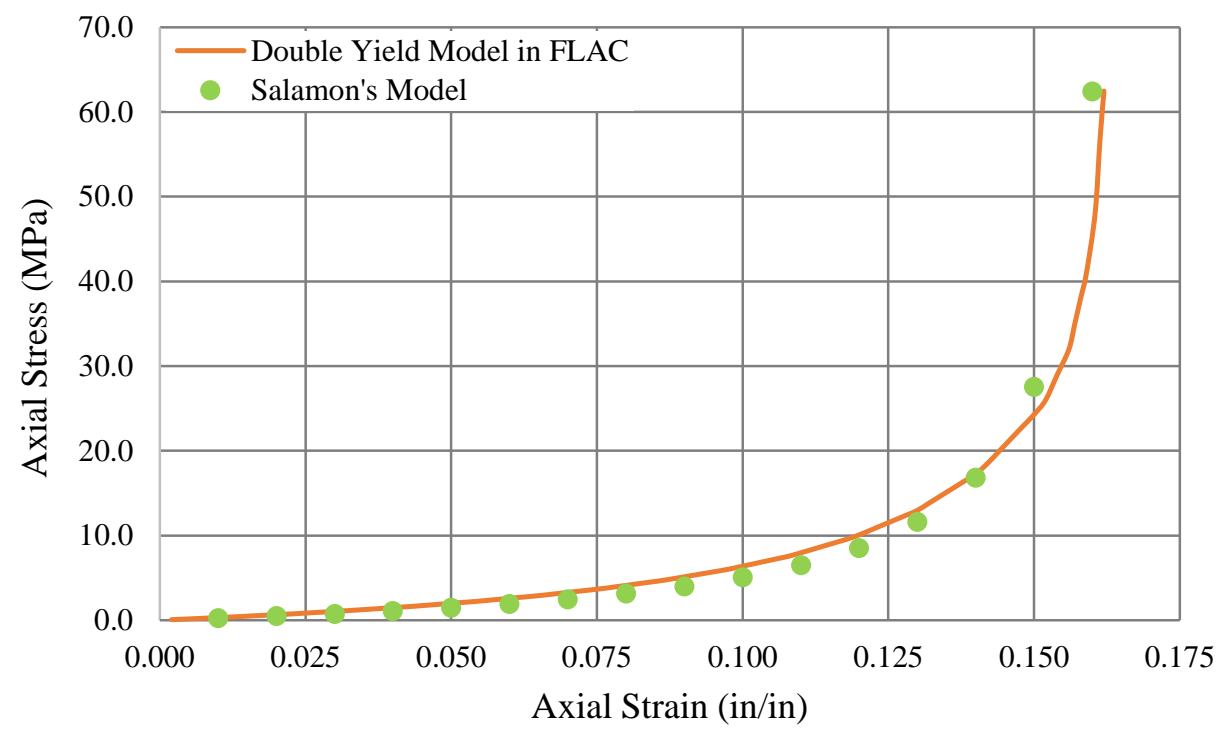

Figure 3.6 Comparison of strain-hardening curve for GOB material obtained by Salamon's equation and Double-yield model in $\mathrm{FLAC}^{3 \mathrm{D}}$ program.

Table 3.3 Obtained mechanical properties for the gob material

\begin{tabular}{ccccc}
\hline $\begin{array}{c}\text { Density }(\gamma) \\
\mathrm{Kg} / \mathrm{m}^{3}\end{array}$ & $\begin{array}{c}\text { Bulk } \\
\text { modulus }(K) \\
\mathrm{MPa}\end{array}$ & $\begin{array}{c}\text { Shear modulus } \\
(G)\end{array}$ & $\begin{array}{c}\text { Friction } \\
\text { angle }(\phi)\end{array}$ & $\begin{array}{c}\text { Dilation } \\
\text { angle }(\varphi) \\
\text { degree }\end{array}$ \\
\hline 1250 & 8700 & 6400 & 20 & 5 \\
\hline
\end{tabular}

The converted stress-strain behavior of the double yielding model for the gob material is tested by a simulated $1 \mathrm{ft}^{3}$ model in FLAC ${ }^{3 \mathrm{D}}$. The model is loaded by a gradual compression from 
the top surface of the model in vertical direction. The rate of compression was controlled by a velocity. As the stress in the model increased, failure and deformation of the tested model will be monitored and recorded. The model behavior is monitored by FISH functions; the average of vertical stress at the middle of the simulated were calculated which represent the stress of the model. The pillar strain is obtained by averaging the displacement magnitudes between the top and bottom side into the original length of the model. Figure 3.6 presents the comparison result of matching stress-strain relationship curve of the Double-Yield model in FLAC ${ }^{3 \mathrm{D}}$ program with the Salamon's model. Obviously, they matched very well. Table III.3 shows the obtained mechanical properties of the gob model.

\subsection{Gas Well Stability Analysis Approach}

Earlier studies report that majority of the gas well failure occurred within a distance of 34 $\mathrm{ft}$ vertically from the extracted coal seam, with only about $10 \%$ of gas failure cases occurred within a distance of $34 \mathrm{ft}(10.4 \mathrm{~m})$ from the roof and $100 \mathrm{ft}(30.5 \mathrm{~m})$ from the floor of extracted coal seam (Commonwealth of Pennsylvania, 1957). Therefore, in this study, our focus will be to analyze and assess the stress, displacement and strain distribution occurring along the vertical gas well within the distance of $100 \mathrm{ft}(30.5 \mathrm{~m})$ vertically from the roof and floor of the extracted coal seam. The results from the simulations will then be used to assess the influence of overburden depth under the presence of soft strata on the vertical gas well stability in a longwall mining operation.

The induced stress and strain distribution along the gas well caused by the movement of overlying and underlying strata are the fundamental parameters needed in assessing the stability of gas well subjected to longwall mining operation (Liang et al. 2015). Gas well failure in longwall mining area due to shear, distortion, tension and or compression is mainly caused due to the strata 
deformation after longwall panel is excavated (Liang et al. 2014). The failure modes of a vertical gas well can be assessed in FLAC $^{3 \mathrm{D}}$ model by assessing the numerical model results of displacements and strain magnitudes and their distribution along the gas well trajectory.

The American Petroleum Institute (API) provides standard guideline for casing that is used in the oil and gas industry. API requires the yield strength of a casing (except for steel grades of P-105 and P-110, which has a higher yield strength) to be the strength required to produce a strain of $0.5 \%$ which will be the critical strain of the gas well (Lyons, 1996). The critical strain proposed by the API corresponds to the maximum strain a gas well can handle in compressive and tensile failure mode and for both axial and lateral direction. Gas wells would typically fail when the magnitude of strain acting on the gas well is greater than its critical value. Therefore, in order to protect a gas well from the effect of longwall mining, it is typical to limit the strain to its allowable strain magnitude.

Strain along the gas well trajectory can be calculated from the predicted displacement at each zones obtained from the FLAC ${ }^{3 \mathrm{D}}$ model analysis, using the following formula,

$$
\varepsilon_{x x / z z}=\frac{\Delta U_{x x / z z}}{L}
$$

Where, $\varepsilon_{x x}$ and $\varepsilon_{z z}$ is the lateral and axial strain, $U_{x x}$ and $U_{z z}$ is the displacement in lateral and axial direction, $L$ is the initial zone size.

In assessing the gas well failure under shear failure mode, we quantify the shear offset of the vertical gas well. The following equations are used to predict the shear offset of a gas well subjected to longwall mining operation (Liang et al. 2015).

$$
\begin{aligned}
& U_{\text {off-H }}=\sqrt{U^{2}{ }_{\text {off-x }}+U^{2}{ }_{\text {off-y }}} \quad \text { Equation 3.13 } \\
& U_{\text {off- } x / y}=U_{(i, j+1)-x / y}-U_{(i, j)-x / y} \quad \text { Equation } 3.14
\end{aligned}
$$


Where, $U_{\text {off- } H}, U_{\text {off- }-x}, U_{\text {off-y } y}$ are the total horizontal shear offset on the horizontal plane (X-Y plane), and its two components - the lateral shear offsets in the $\mathrm{X}$ and $\mathrm{Y}$ directions, respectively. $U_{(i, j+1)-x / y}-U_{(i, j)-x / y}$ are the predicted horizontal displacement from the FLAC $^{3 \mathrm{D}}$ simulation in the $\mathrm{X}$ and $\mathrm{Y}$ directions.

The critical shear offset of a vertical gas well is $10 \mathrm{~cm}$ (Liang et al. 2014; Liang et al. 2015). This critical shear offset corresponds to the annular space between the production casing and the coal protection casing. Gas well would typically fail under shear mode when the predicted shear offset is greater than $10 \mathrm{~cm}$.

\subsection{Model Validation}

It is imperative to validate the simulated numerical model in order to agree with the actual field condition when using a numerical model for a study. In validating the current study, two approaches were used. The first approach is to compare with the previous study conducted by Peng et al. (2003) and the second approach is to validate the stress distribution in the gob area.

\subsubsection{Validation of the Simulated Model with the Previous Study}

Peng et al. (2003) conducted a gas well stability analysis study for the same case study, which this thesis refers to, using Finite Element Method in ABAQUS program. Field observations showed that the failure occurred in the clay (soft) layer which was at a depth of $16.5 \mathrm{ft}$ below the coal seam, after second panel mining. The magnitude of plastic strain developed in gas well as a result of longwall mining operation was used as a criterion to assess the stability of the gas well. The result of their ABAQUS analysis showed that the maximum magnitude of vertical strain located in the clay had a magnitude of $0.0056 \mathrm{in} / \mathrm{in}$ followed by $0.0046 \mathrm{in} / \mathrm{in}$ in the coal seam layer. Therefore, the gas well failed at the clay layer due to vertical strain exceeding a critical magnitude 
of $0.005 \mathrm{in} / \mathrm{in}$. The gas well failed in the clay layer due to high compressive strain as a result of second panel mining. Figure 3.9 presents the results of the analysis from the current study compare to the previous study conducted by Peng et al. (2003). It can be noted that the magnitude and distribution of axial strain from the current study and the previous study is in good agreement.

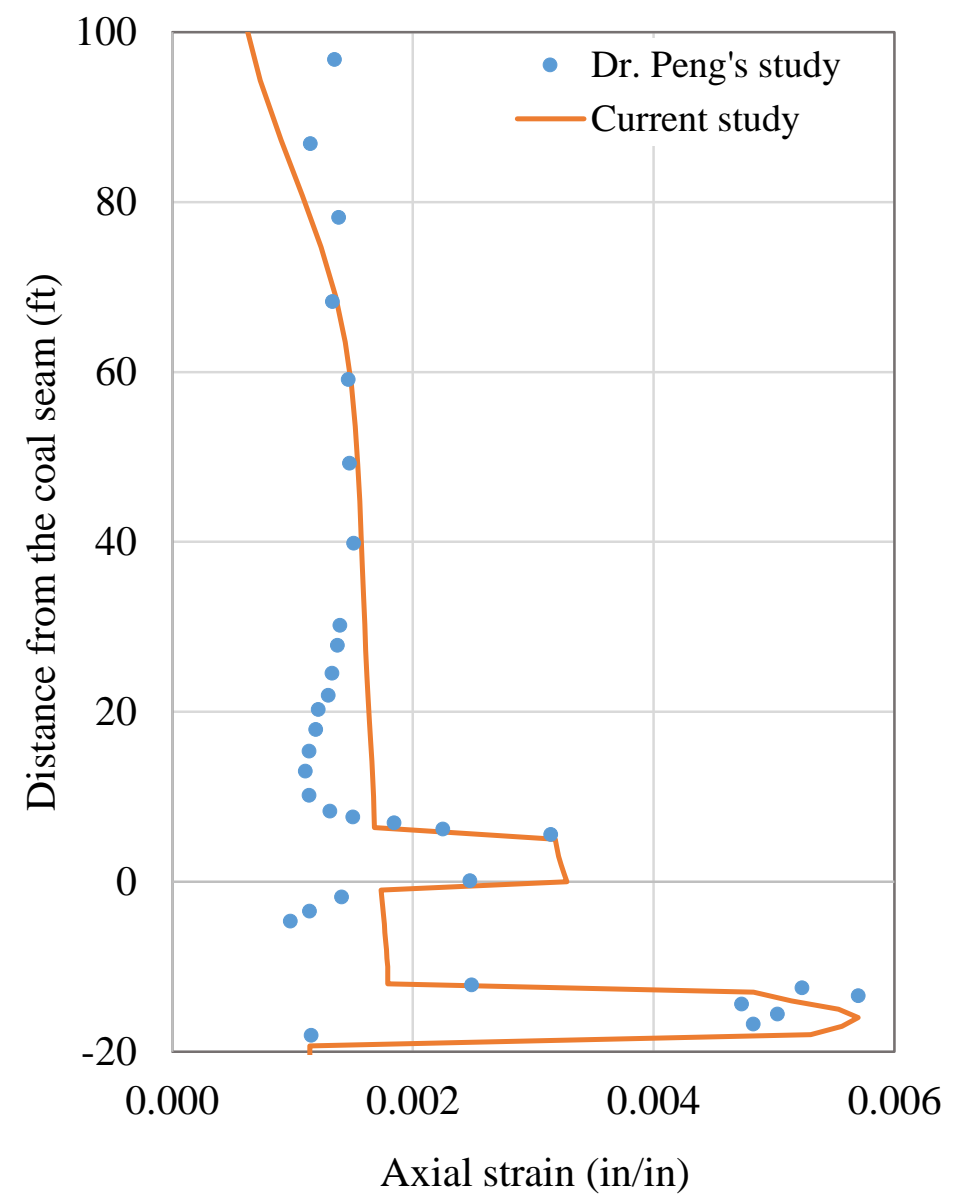

Figure 3.9 Analysis results for model calibration. The model is calibrated against the previous study (Peng et al. 2003).

\subsubsection{Validation of the Stress Distribution on the GOB area and Pillar System}

In order to validate the reliability of the gob model, the distribution of vertical stress after longwall retreat was assessed. Previous study by Wilson and Carr (1982) and Campoli et al. (1993) suggest that the vertical stress at edge of the longwall panel should be zero and would increase to 
almost the virgin stress value at a distance of 0.3 times the overburden depth, towards the center of the gob.

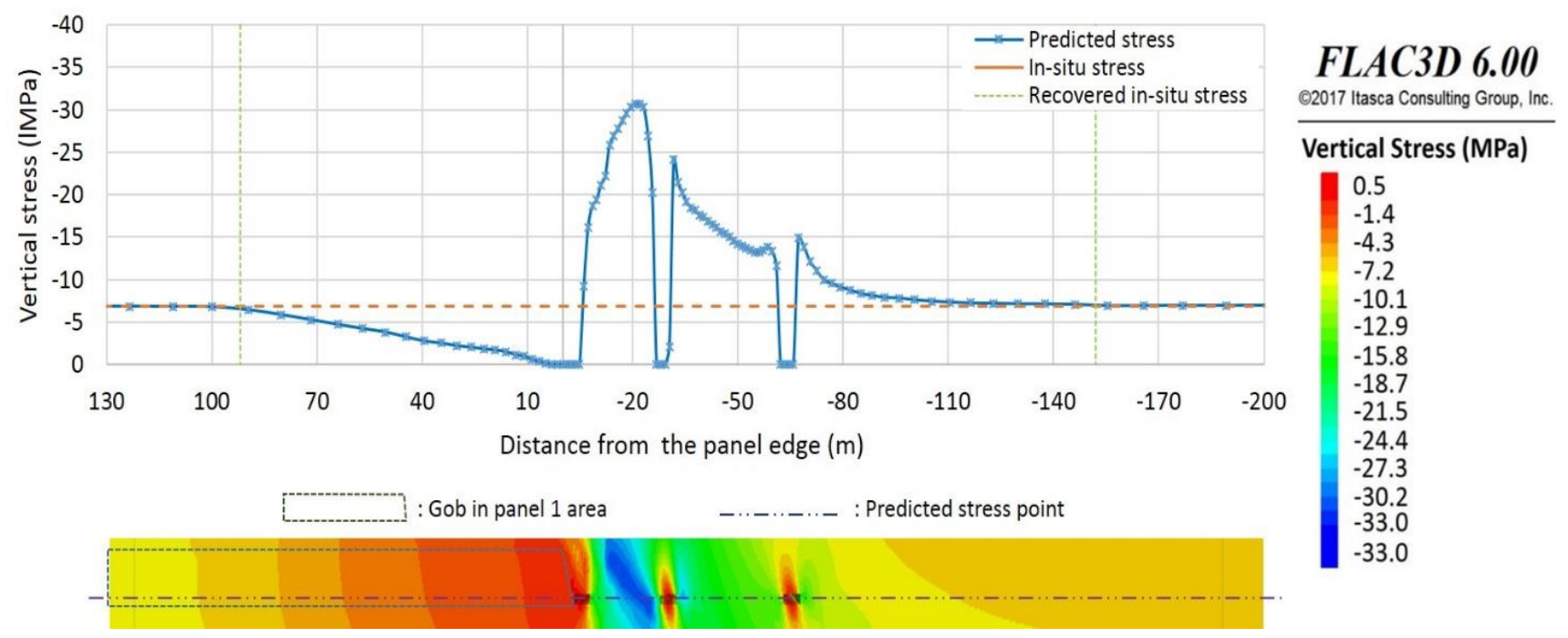

Figure 3.10 Vertical stress distribution recorded on the gob area and pillar system after first panel mining

Figure 3.10 shows the predicted vertical stress magnitudes and its distribution on the gob area and pillar system. It can be seen that the vertical stress magnitude at the panel edge is 0 and increases towards the gob center, reaching a magnitude of $6.85 \mathrm{MPa}$ at the distance of $87 \mathrm{~m}$ away from the panel edge. In other words, the gob model results show that the insitu vertical stress has been recovered at a distance of $30 \%$ of the overburden depth $(87 \mathrm{~m}$ of $287.4 \mathrm{~m})$ from the panel edge. Therefore, it can be concluded that the results of the gob simulation matches very well with the longwall mining stress theory given by Wilson and Carr (1982) and Campoli et al. (1993).

In order to validate the stress distribution in the pillar system, the prediction result of this current simulated model was compared with the analysis results given by ALPS analysis, using the Equation 3.12 (Mark, 1987).

$$
\sigma_{a}=\frac{3 L s}{D^{3}}(D-x)^{2}
$$


Where, $L s$ is side abutment load (calculating using the equation 2.7), $D$ is the extent of side abutment load (calculating using the equation 2.9), $x$ is the distance from the edge of the panel.

For this study, the overburden depth is $943 \mathrm{ft}$ (287.43 m), therefore, the extended side of abutment load $(D)$ is $285.6 \mathrm{ft}(87 \mathrm{~m})$ and the side abutment load $(L s)$ is $121752.6 \mathrm{kN}$. The analysis results of abutment stress acting on the pillar is shown on the Figure 3.11.
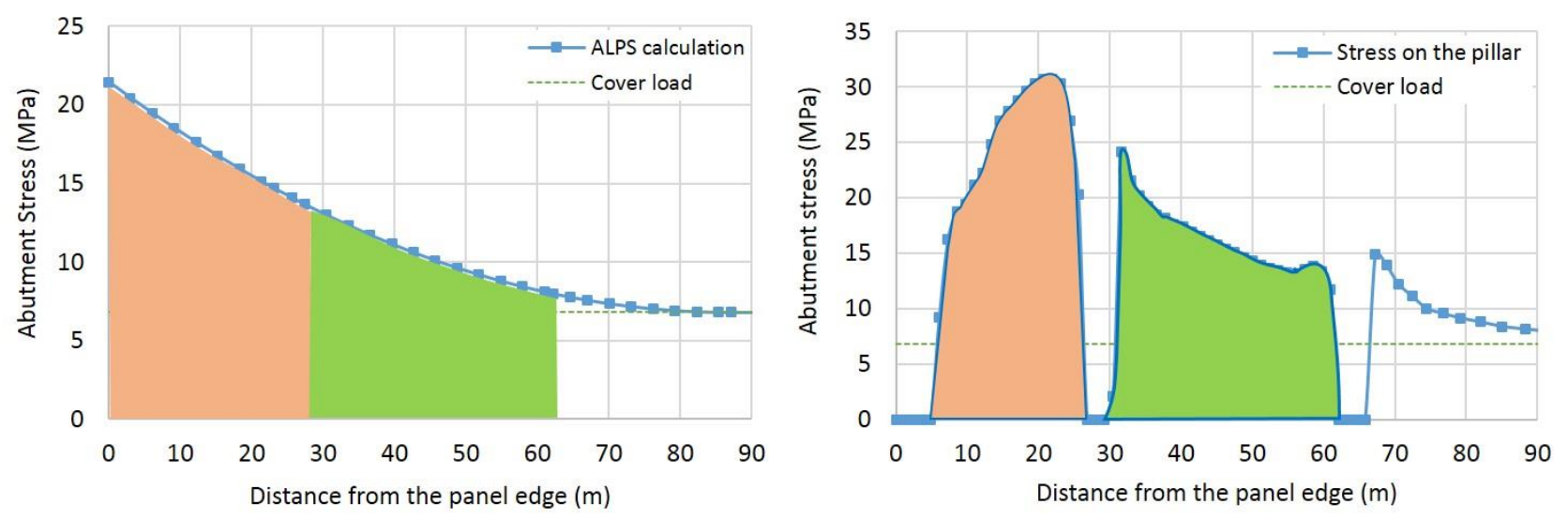

Figure 3.11 Predicted stress on the pillar system obtained by ALPS and FLAC ${ }^{3 \mathrm{D}}$ analysis

The predicted stress magnitudes on Figure 3.11 was then used to calculate the abutment load acting on the pillar. The total load on the pillar is calculated based on the total area marked on Figure 3.11 corresponds to the pillar A and abutment pillar, using the integration rules. The predicted total load is presented on Table 3.4.

Table 3.4 Predicted total load acting on the pillar system

\begin{tabular}{|l|c|c|}
\hline \multicolumn{1}{|c|}{ Description } & ALPS analysis & FLAC $^{3 \mathrm{D}}$ analysis \\
\hline Total load on Pillar A $(\mathrm{kN})$ & 449238.9 & 486894.2 \\
\hline Total Load on Abutment pillar $(\mathrm{kN})$ & 407325.2 & 452045.5 \\
\hline
\end{tabular}

It can be seen from Table 3-4 that the predicted total load given by ALPS and FLAC analysis is consistent. Therefore, it can be concluded that the prediction result of this study gives a good agreement with ALPS analysis. 


\section{CHAPTER 4 ANALYSIS RESULTS AND DISCUSSION}

"It is better to be approximately right than precisely wrong" - Warren Buffett

As a result of longwall mining, the insitu stresses are disturbed and strata movement takes place in both vertical and horizontal directions. In the following section, the analysis of the influence of the overburden depth and the presence of soft strata on the stability of vertical gas well is analyzed and discussed. This is accomplished by analyzing the distribution of total horizontal shear offset $\left(U_{\text {off- } H}\right)$, and axial and lateral strain $\left(\varepsilon_{z z}\right.$ and $\left.\varepsilon_{x x}\right)$ occurring along the vertical gas well. The predicted magnitudes of lateral stress and strain in the Y direction $\left(\sigma_{y y}\right.$ and $\left.\varepsilon_{y y}\right)$ are not discussed due to their magnitudes are relatively smaller compared to the magnitude of lateral stress and strain in $\mathrm{X}$ direction $\left(\sigma_{x x}\right.$ and $\left.\varepsilon_{x x}\right)$. The total shear offset $\left(U_{o f f-H}\right)$ and strain analysis in axial and lateral direction ( $\varepsilon_{z z}$ and $\varepsilon_{x x}$ ) are analyzed using the Equation 3.13 and 3.12, respectively.

\subsection{Assessing the Effect of Overburden Depth}

\subsubsection{Induced Stresses $\left(\sigma_{z z / x x}\right)$ Analysis}

The predicted induced stresses magnitudes and its distribution along the vertical gas well are restored from the numerical model analysis results. The predicted induced axial stress $\left(\sigma_{z z}\right)$ and lateral stress $\left(\sigma_{x x}\right)$ as a result of longwall mining for various overburden depth input parameter is shown on figure 4.1. The magnitudes of $\sigma_{z z}$ and $\sigma_{x x}$ varies with varying overburden depth of a mine. The predicted peak magnitude of induced $\sigma_{z z}$ for all overburden depth input parameters are concentrated at the depth of 15 to $17 \mathrm{ft}(4.6$ to $5.2 \mathrm{~m}$ ) below the coal seam. In contrast, the peak magnitude of induced $\sigma_{x x}$ are concentrated at the coal seam layer. 

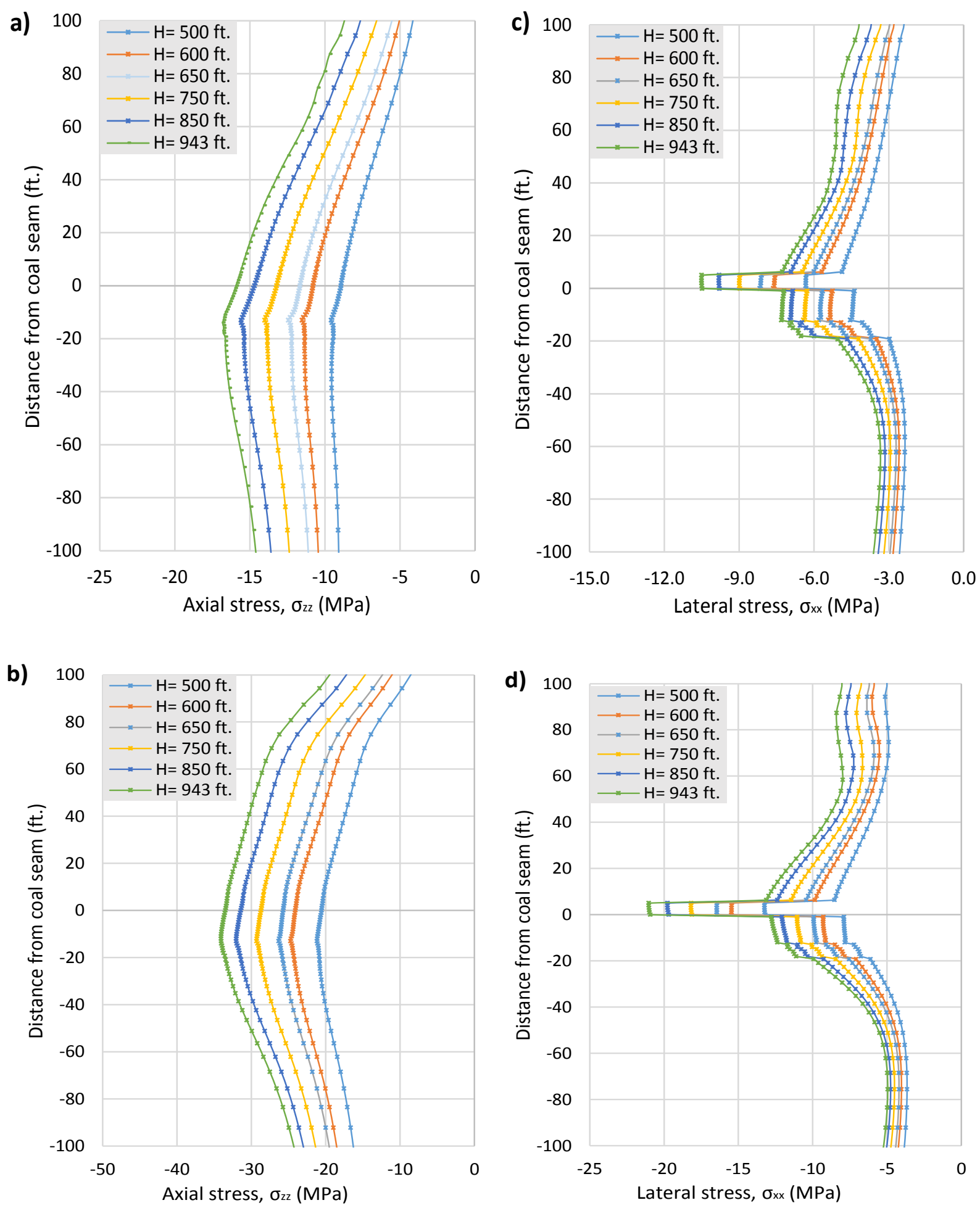

Figure 4.1 Predicted induced stresses distribution in axial and lateral direction with varying overburden depth, after: a and c. first panel mining, $b$ and $d$. second panel mining. 
Figure 4.2 presents the analysis of the predicted maximum induced $\sigma_{z z}$ and $\sigma_{x x}$ for all overburden depth input parameter, ranging from the depth of 500 to $943 \mathrm{ft}$ (152 to $287.4 \mathrm{~m}$ ). The induced stresses in axial and lateral direction increase linearly as overburden depth raises. After first panel mining, the peak magnitudes of induced $\sigma_{z z}$ for overburden depth of $500 \mathrm{ft}$ to $943 \mathrm{ft}$ ranges from a minimum of 9.6 $\mathrm{MPa}$ to a maximum of $16.8 \mathrm{MPa}$, while the magnitudes of induced $\sigma_{x x}$ varies from 6.3 to $10.5 \mathrm{MPa}$. Next, after second panel mining, the peak magnitudes of induced $\sigma_{z z}$ and induced $\sigma_{x x}$ are both increased by double compare to their magnitudes after first panel mining.
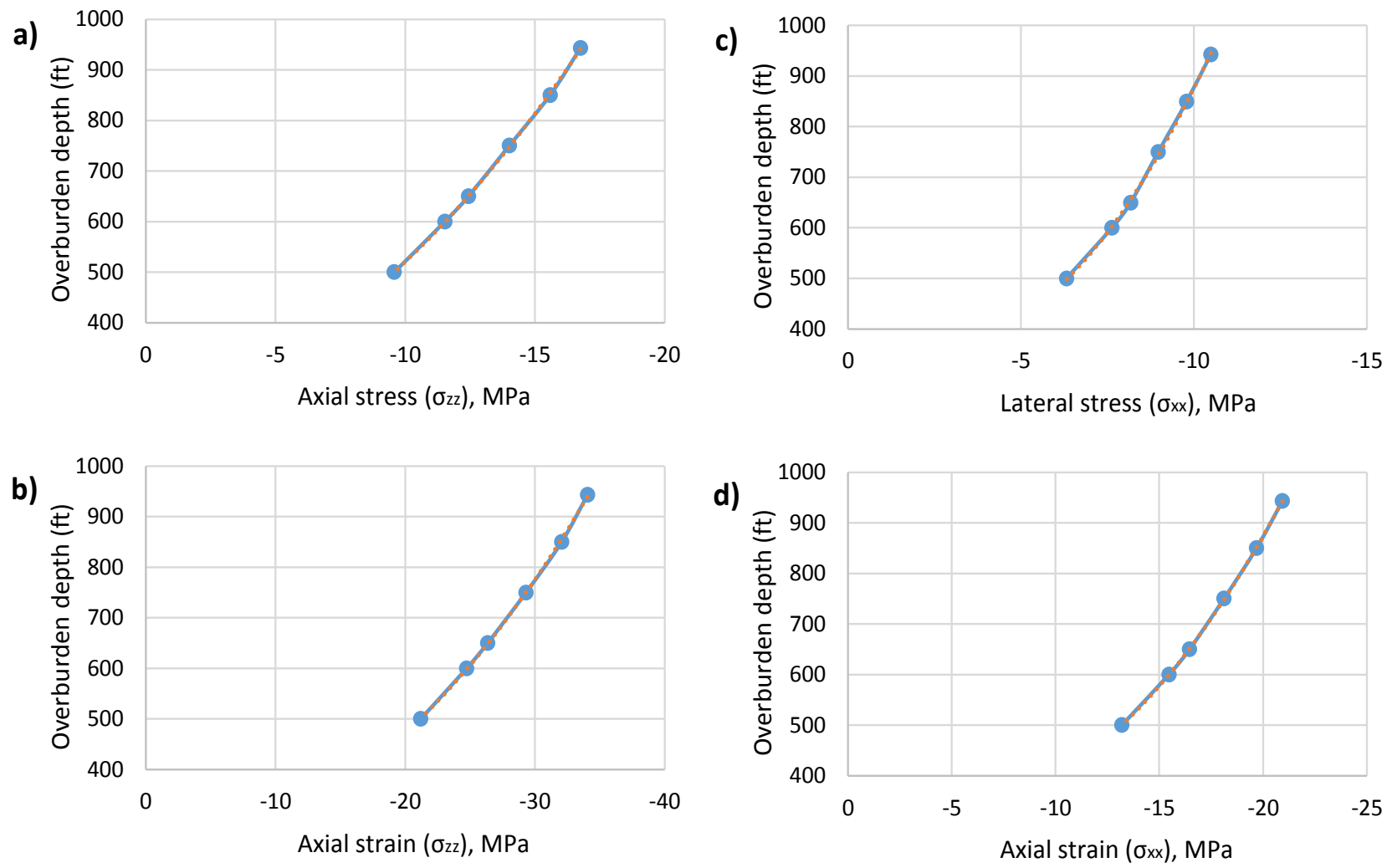

Figure 4.2 Analysis of predicted maximum induced stresses distribution with varying overburden depth, after: a and c. first panel mining, b and d. second panel mining. 


\subsubsection{Total Shear Offset $\left(U_{\text {off-H}}\right)$ Analysis}

The total shear offset is analyzed using equation 3.13. The predicted total lateral shear offset $\left(U_{\text {off- } H}\right)$ magnitudes and its distribution along gas well trajectory for various overburden depth input parameters are presented in figure 4.3. It can be seen that after first panel and second panel mining, the peak magnitudes of $U_{\text {off- } H}$ occurs at the depth of 15 to $17 \mathrm{ft}$ (4.6 to $5.2 \mathrm{~m}$ ) below the coal seam floor, followed by the $U_{\text {off- } H}$ magnitudes at the coal seam layer.

Figure 4.4 shows the analysis results of maximum predicted $U_{\text {off- } H}$ for each overburden depth parameter, ranging from $(152 \mathrm{~m})$ to $943 \mathrm{ft}$. $(287.4 \mathrm{~m})$. The predicted $U_{\text {off-H}}$ increases linearly with increase in the overburden depth. After mining the first panel, the maximum magnitudes of $U_{\text {off-H }}$ for overburden depth varying from $500 \mathrm{ft}(152 \mathrm{~m})$ to $943 \mathrm{ft}(287.4 \mathrm{~m})$ ranges from a minimum of $0.33 \mathrm{~cm}$ to a maximum of $0.5 \mathrm{~cm}$. The magnitude of total $U_{\text {off }-H}$ is decreased slightly after second panel mining. This condition occurs because when the first panel excavation takes place, the gas well horizontally deforms more towards the first panel side, and then after the second panel is completely mined, the gas well slightly rebounds to the second panel side. The larger magnitude of predicted $U_{\text {off- } H}$ occurred with the increase in overburden depth. Therefore, it can be concluded that the deeper the depth of cover, the higher total shear offset occur along the gas well trajectory.

In assessing the influence of overburden depth on the gas well stability, total shear offset $\left(U_{\text {off-H}}\right)$ and its magnitude is used to assess whether or not the gas well will experience shear failure with the given geological condition and mining parameters, as a result of longwall mining. The critical shear offset for gas wells to fail under shear is when the shear offset reaches or higher than the magnitude of $10 \mathrm{~cm}$ (Liang et al. 2014). 

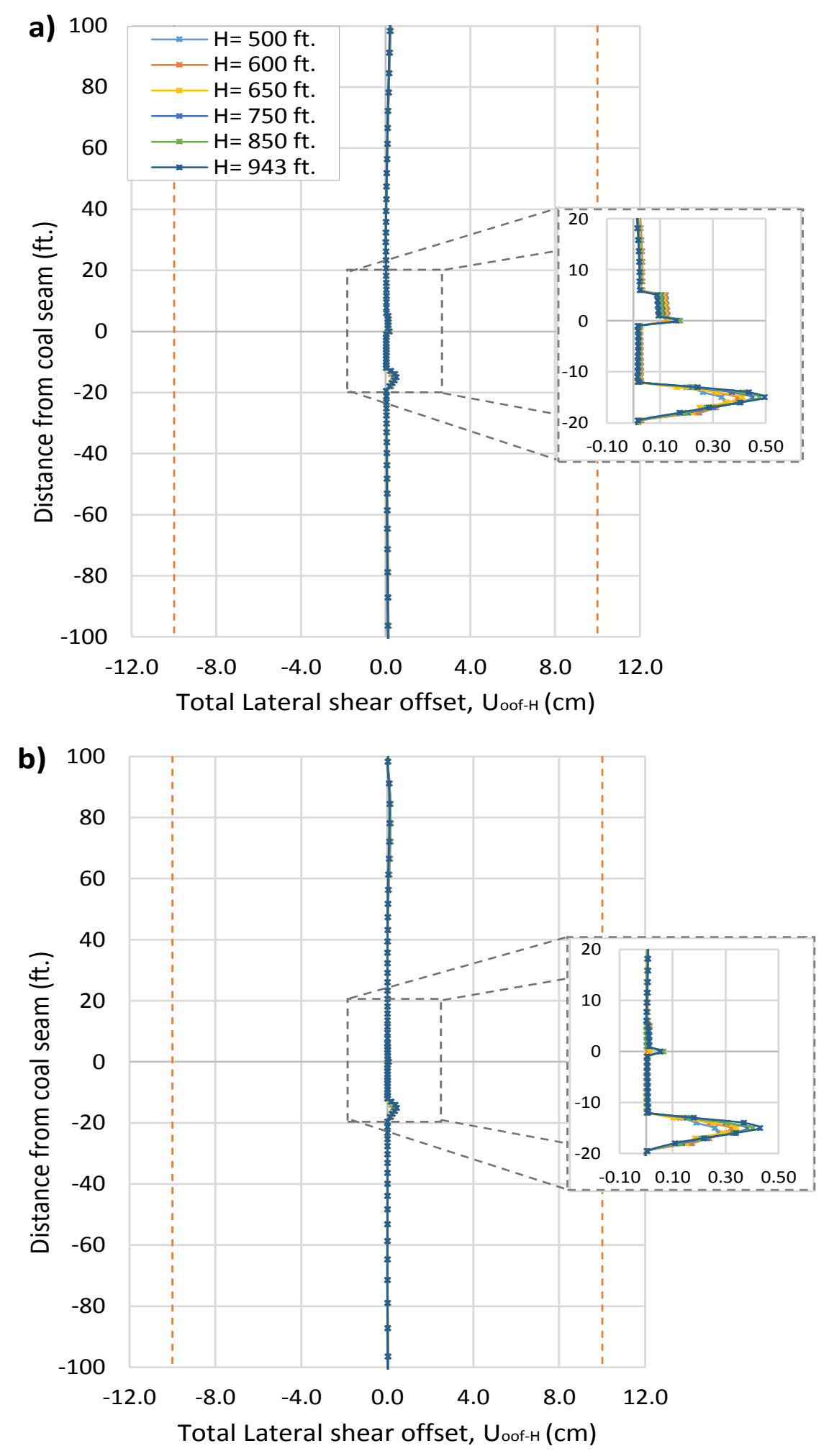

Figure 4.3 Predicted total lateral shear offset $\left(U_{\text {off- } H}\right)$, after: a. first panel mining, $\mathrm{b}$. second panel mining. Orange dashed line refers to the critical lateral shear offset. 
From the analysis results presented on Figure 4.3 and Figure 4.4, the maximum predicted of $U_{\text {off-H }}$ for all overburden input parameter ranges from $0.26 \mathrm{~cm}$ to $0.50 \mathrm{~cm}$, which means that all the predicted $U_{\text {off- } H}$ are far below the critical value of shear offset. Therefore, it can be said that under the given geological condition and longwall mining geometry, the gas well will typically not experience a shear failure mode. The results of this analysis are in agreement with the field measurements, where no failure occurred under shear after first and second panel mining.
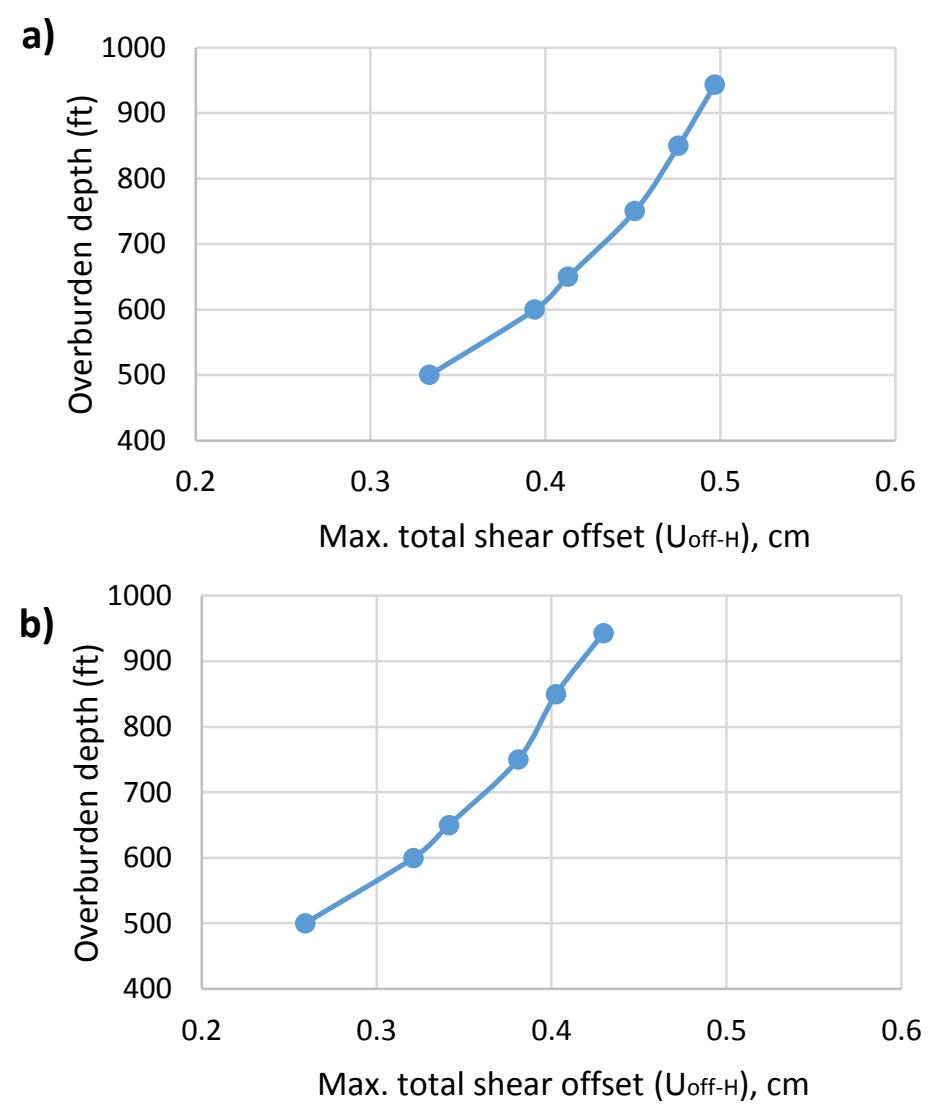

Figure 4.4 Analysis of predicted maximum total shear offset $\left(U_{\text {off- } H}\right)$ as a function of overburden depth, after: a. first panel mining, b. second panel mining.

\subsubsection{Induced Strain $\left(\varepsilon_{z z-x x}\right)$ Analysis}

The predicted induced strain magnitudes and their distributions are calculated using Equation 3.12. Figure 4.5 and 4.6 present the results of predicted axial strain $\left(\varepsilon_{z z}\right)$ and lateral strain 
$\left(\varepsilon_{x x}\right)$ distribution magnitudes along vertical gas well trajectory after first and second panel mining. The magnitudes of $\varepsilon_{z z}$ and $\varepsilon_{x x}$ along the gas well trajectory differs with varying in overburden depth. From figure 4.5 and 4.6, it can be noted that after first and second panel mining, the peak magnitude of $\varepsilon_{z z}$ occurred in compression at the depth of $16.5 \mathrm{ft}(5 \mathrm{~m})$ below the coal seam for all overburden depth input parameters. Whereas, the peak magnitude of $\varepsilon_{x x}$ occurred in tension at the depth of $16.5 \mathrm{ft}(5 \mathrm{~m})$ below the coal seam and in compression in the coal seam layer and then propagates vertically from roof of the coal seam towards the surface. The magnitude of $\varepsilon_{z z}$ and $\varepsilon_{x x}$ tends to increase with increased overburden depth. This happens because the deeper the overburden, the higher induced stress distribution in both axial and lateral direction will be acting along the gas well trajectory, resulting from longwall mining.

The data for analysis of maximum predicted $\varepsilon_{z z}$ and $\varepsilon_{x x}$ is presented on Figure 4.7 and 4.8, respectively. The induced strain in axial and lateral direction increases with increased in overburden depth. After first panel mining, the maximum magnitude of $\varepsilon_{z z}$ for overburden depth of $500 \mathrm{ft}(152 \mathrm{~m})$ to $943 \mathrm{ft}(287.4 \mathrm{~m})$ ranges from 0.00175 to $0.00274 \mathrm{in} / \mathrm{in}$, while the peak magnitudes of $\varepsilon_{x x}$ range from 0.00046 to 0.00118 in/in. Following second panel mining, the peak magnitude of $\varepsilon_{z z}$ has a range of 0.00413 to $0.00570 \mathrm{in} / \mathrm{in}$., while the magnitude of $\varepsilon_{x x}$ has a range of $0.00025 \mathrm{in} /$ in to $0.00114 \mathrm{in} / \mathrm{in}$. It can be noted that the magnitude of $\varepsilon_{z z}$ increases after second panel mining. In contrast, the magnitude of $\varepsilon_{x x}$ decreases. This condition is in agreement with the horizontal shear offset prediction results showed in the previous section, which explains that after second panel mining, the gas well horizontally deformed towards the second panel direction, and therefore leads to the reduction of the deformation and strain magnitudes in lateral direction. 

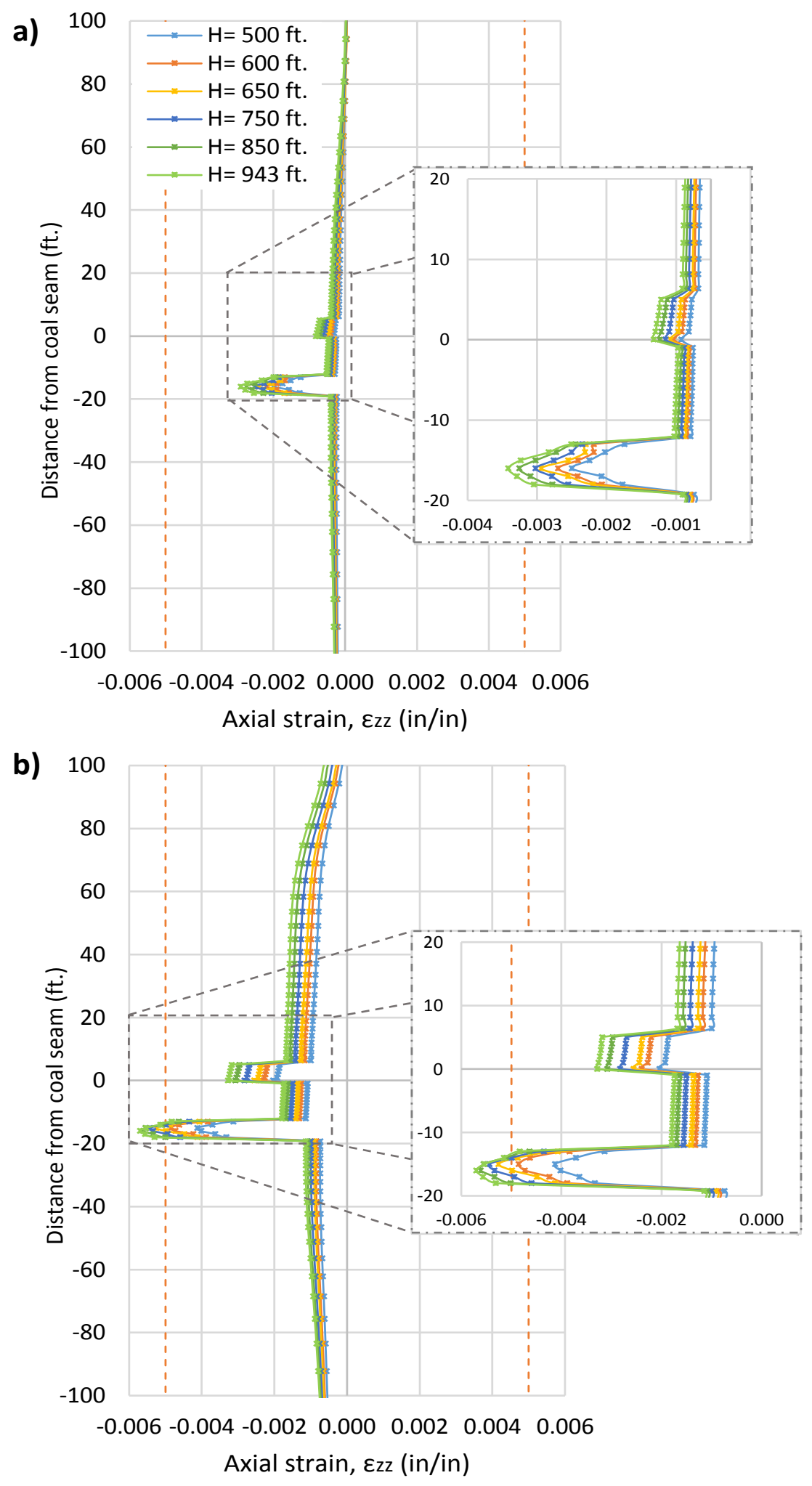

Figure 4.5 Predicted axial strain $\left(\varepsilon_{z z}\right)$, after: a. first panel mining, b. second panel mining, with varying overburden depth. Orange dashed line refers to the critical axial strain (0.005). 

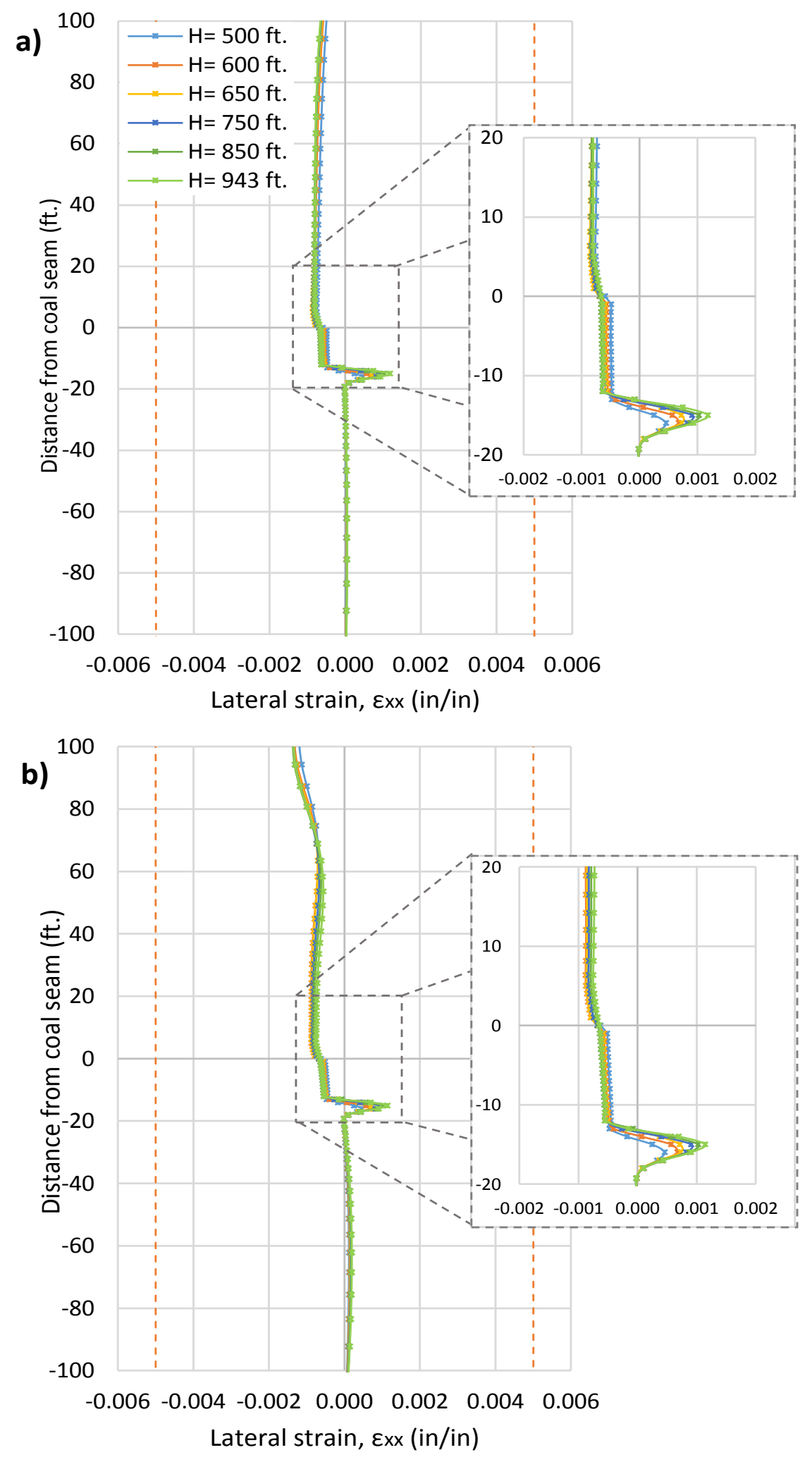

Figure 4.6 Predicted lateral strain $\left(\varepsilon_{x x}\right)$ after: a. first panel mining, b. second panel mining, with varying overburden depth. Orange dashed line refers to the critical lateral strain (0.005). 
For predicting the gas well failure under compressive and the tension failure mode, the critical strain magnitude proposed by American Petroleum Institute (API) is used to assess whether or not the gas well failed under compression and or tension. The API standard suggest that gas well would typically fail if the predicted $\varepsilon_{z z}$ and $\varepsilon_{x x}$ is higher than $0.5 \%$ (Lyons, 1996). From the results discussed, showing on Figure 4.5 to 4.8 , the maximum $\varepsilon_{x x}$ for all overburden depth parameter after longwall mining development ranges from 0.00025 to $0.00118 \mathrm{in} / \mathrm{in}$. Therefore, it can be said that under the given geological and mining condition of the case study, the gas well does not experience any failure mode in lateral direction. However, after second panel mining, the peak predicted magnitude of $\varepsilon_{z z}$ ranges from 0.00413 to $0.00570 \mathrm{in} / \mathrm{in}$. In other words, the predicted critical strain after first panel mining for the overburden depth higher than $600 \mathrm{ft}(183 \mathrm{~m})$ is higher than critical strain proposed by API. The failure is located at the depth of $16.5 \mathrm{ft}(5 \mathrm{~m})$ below the coal seam layer.
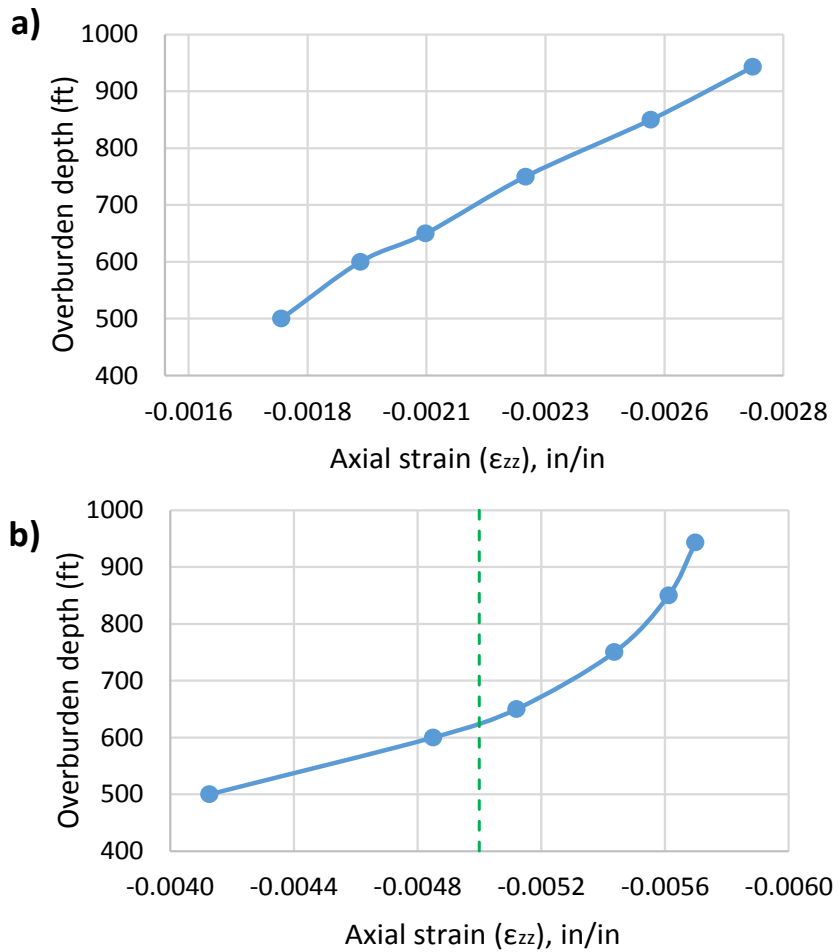

Figure 4.7 Analysis of predicted maximum axial strain $\left(\varepsilon_{z z}\right)$, after: a. first panel mining, b. second panel mining. Green dashed line refers to the critical strain magnitude. 

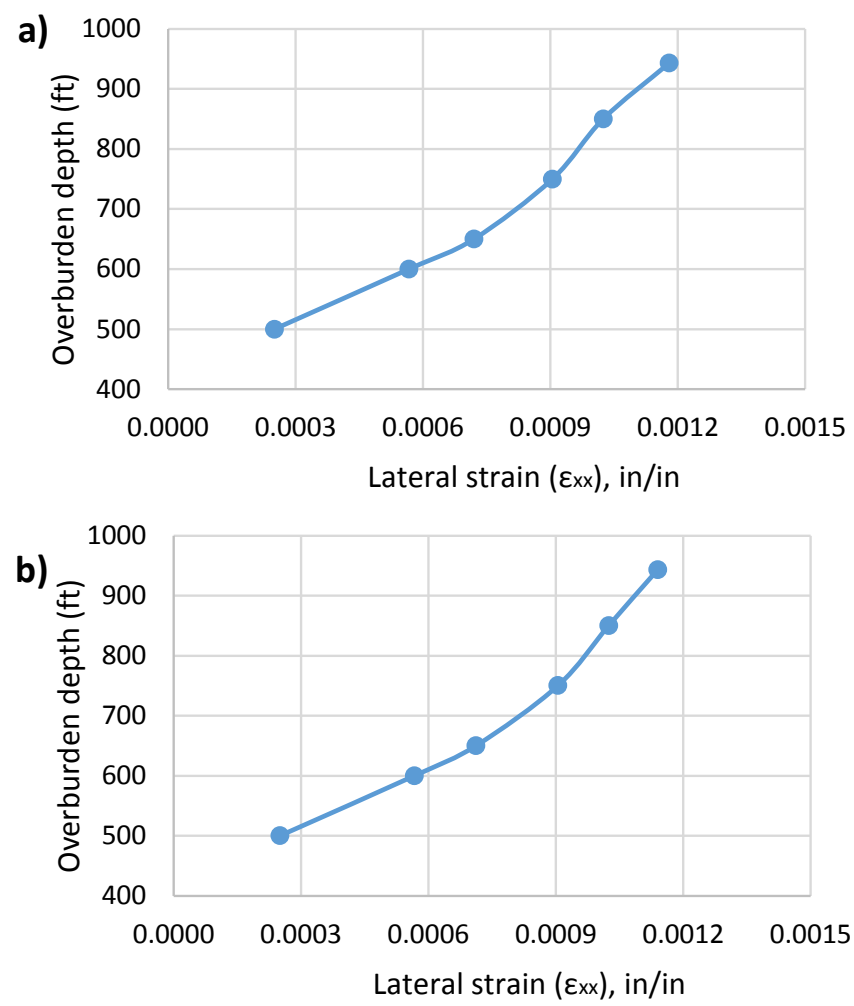

Figure 4.8 Analysis of Predicted maximum lateral strain $\left(\varepsilon_{x x}\right)$ as a function of overburden depth, after: a. first panel mining, b. second panel mining.

The analysis results of this study is in agreement with the previous study conducted by Peng et al. (2003), which concluded that the presence of soft strata (clay layer) located below the coal seam could induce high induced strain on the gas well casing and leads to gas well failure at the depth of $16.5 \mathrm{ft}(5 \mathrm{~m})$ below the coal seam. Through the numerical modelling analysis performed in this study, it is determined that the critical overburden depth where the gas well can survive under the given geology and mining condition of the case study is $600 \mathrm{ft}(183 \mathrm{~m})$. However, it should be noted that the critical overburden depth obtained in this study is specific to the given case study only. 


\subsection{Assessing the Effect of the Presence of Soft Strata}

The previous study conducted by Peng et al. (2003) concludes that the presence of soft strata (clay layer) in between sandstone and sandyshale is the main reason the gas well failed under axial compression. However, there was no further study for assessing the influence of soft strata on the vertical gas well stability for this case study. Therefore, in the following section, the effect of clay layer presence on the gas well stability will be investigated. The magnitudes of total horizontal shear offset $\left(U_{o f f-H}\right)$, and axial and lateral strain $\left(\varepsilon_{z z}\right.$ and $\left.\varepsilon_{x x}\right)$ occurring along the vertical gas well will be used as a criterion to assess the stability of the gas well as a result of longwall mining operation. The total shear offset $\left(U_{\text {off-H}}\right)$ and strain analysis in axial and lateral direction $\left(\varepsilon_{z z}\right.$ and $\varepsilon_{x x}$ ) are analyzed using the Equation 3.13 and 3.12, respectively.

\subsubsection{Induced Stresses Magnitudes $\left(\sigma_{z z / x x}\right)$}

The predicted induced axial stress $\left(\sigma_{z z}\right)$ and lateral stress $\left(\sigma_{x x}\right)$ as a result of longwall mining for the model with and without the presence of soft strata is presented on figure 4.9. It can be seen from Figure 4.9. that the predicted peak magnitude of $\sigma_{z z}$ for model with the presence of strata are concentrated at the depth of 15 to $17 \mathrm{ft}(4.6$ to $5.2 \mathrm{~m})$ below the coal seam. In contrast, for model without the presence of clay layer, the peak magnitude of $\sigma_{z z}$ is located at the depth of 10 to $12 \mathrm{ft}$ ( 3 to $3.6 \mathrm{~m}$ ) below the coal seam, which is at the depth where the interface between sandyshale and sandstone takes place. For the lateral stress analysis, the peak magnitudes of $\sigma_{x x}$ is consistent for both model, which is located at the coal seam layer.

It can be noted that the magnitude and distribution of $\sigma_{z z}$ and $\sigma_{x x}$ are almost similar for both model scenarios. The only difference is the distribution at the immediate floor, where the model with the presence of soft strata has higher induced stresses at the depth of 12-18 $\mathrm{ft}(3.7-5.5 \mathrm{~m})$ below the coal seam layer. 

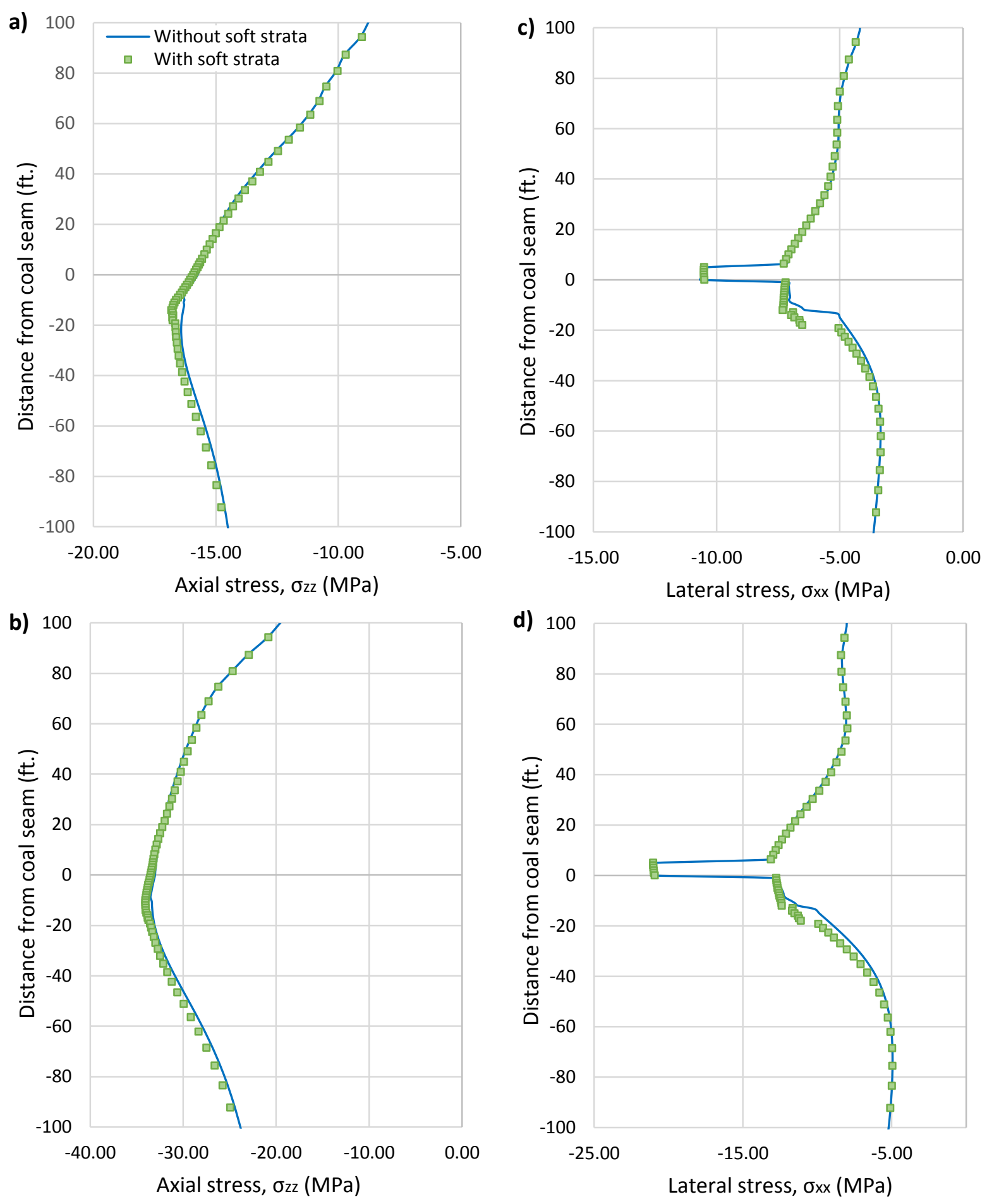

Figure 4.9 Predicted induced stresses distribution in axial and lateral direction, after: a and c. first panel mining, $b$ and $d$. second panel mining. 
Table 4.1 Summary of predicted maximum induced stresses acting on the gas well for model with and without the presence of soft strata.

\begin{tabular}{lcccc}
\hline \multirow{2}{*}{ Model Description } & \multicolumn{2}{c}{ First panel mining } & \multicolumn{2}{c}{ Second panel mining } \\
& $\sigma_{\mathrm{zz}}(\mathrm{MPa})$ & $\sigma_{\mathrm{xx}}(\mathrm{MPa})$ & $\sigma_{\mathrm{zz}}(\mathrm{MPa})$ & $\sigma_{\mathrm{xx}}(\mathrm{MPa})$ \\
\hline With soft strata & -16.8 & -10.5 & -34.1 & -20.9 \\
Without soft strata & -16.3 & -10.5 & -33.4 & -20.9 \\
\hline
\end{tabular}

Table 4.1 shows the recapitulation data of predicted maximum $\sigma_{z z}$ and $\sigma_{x x}$ acting on the gas well for model with and without the presence of soft strata (clay layer). After first panel mining, for model with the presence of soft strata, the peak magnitude of $\sigma_{z z}$ and $\sigma_{x x}$ is 16.8 and $10.5 \mathrm{MPa}$, respectively, while for the model without the presence of soft strata, the predicted peak magnitudes of $\sigma_{z z}$ and $\sigma_{x x}$ is 16.3 and $10.5 \mathrm{MPa}$, respectively. Following the second panel mining, the peak magnitudes of $\sigma_{z z}$ and $\sigma_{x x}$ are both increased by double of their magnitudes in first panel mining for the two simulated model scenarios.

It can be noted from Table 4.1 that the magnitudes of induced stresses for both simulated model scenarios does not change much. However, this little stress change may lead to a higher displacement for the model having the presence of soft strata. This happens due to the clay layer has a lower strength compare to the strong strata, such as sandstone. Therefore, even the stresses are almost significant, but the magnitudes of displacement may be different when compare the model with the presence of soft strata and the other one that does not consider the soft strata presence.

\subsubsection{Total Shear Offset $\left(U_{o f f-H}\right)$ Analysis}

The predicted total total lateral shear offset $\left(U_{o f f-H}\right)$ magnitude for the simulated models, with and without the presence of soft strata, are presented on figure 4.10. The total shear offset is 
analyzed using equation 3.13. It can be noted from Figure 4.10 that there is no shear offset that occurs when the model is built without the presence of soft strata. However, when soft strata is considered, the magnitudes are raised, even though it does not reach the critical value of $U_{\text {off- } H}$ that the gas well can possibly fail in shear. As stated on chapter 3, section 3.4 that the critical shear offset for gas well to fail under shear is $10 \mathrm{~cm}$.

Table 4.2 shows the recapitulation data of predicted maximum $U_{\text {off- } H}$ of the gas well for model with and without the presence of soft strata (clay layer). The peak magnitudes of $U_{\text {off- } H}$ after first and second panel mining is 0.5 and $0.43 \mathrm{~cm}$, respectively, for model built considering the presence of soft strata. For model that does not consider the presence of soft strata, the peak magnitudes of $U_{\text {off- } H}$ after first and second panel mining is 0.01 and $0.004 \mathrm{~cm}$, respectively. It can be noted from figure 4.10 that the concentrated peak magnitudes of $U_{\text {off- } H}$ is located at the depth of 16 to $17 \mathrm{ft}$ below the coal seam floor, followed by the $U_{\text {off- } H}$ magnitudes at the coal seam layer. In conclusion, the magnitudes of $U_{\text {off- } H}$ on the gas well is higher when the gas well is drilled through a soft strata.

Table 4.2 Summary of predicted maximum total shear offset al.ong the gas well trajectory for model with and without the presence of soft strata.

\begin{tabular}{|l|c|c|}
\hline \multirow{2}{*}{ Input parameter } & \multicolumn{2}{|c|}{ Max Uoff-H (cm) } \\
\cline { 2 - 3 } & First panel mining & Second panel mining \\
\hline With soft strata & 0.50 & 0.430 \\
\hline Without soft strata & 0.01 & 0.004 \\
\hline
\end{tabular}



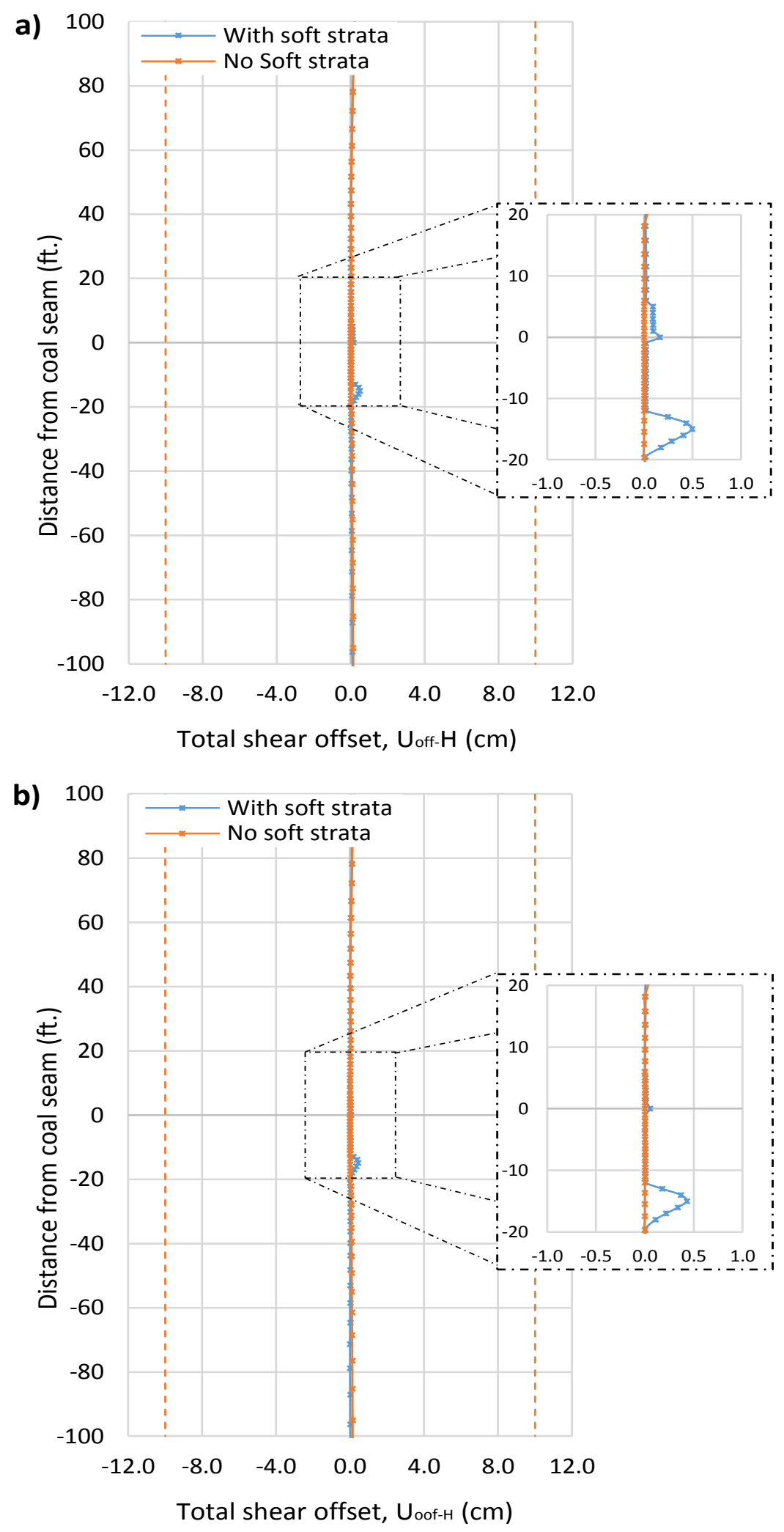

Figure 4.10 Predicted total lateral shear offset $\left(\mathrm{U}_{\text {off-H}}\right)$, after: a. first panel mining, b. second panel mining. Orange dashed line refers to the critical lateral shear offset. 


\subsubsection{Induced Strain $\left(\varepsilon_{z z-x x}\right)$ Analysis}

The predicted induced strain in both axial and lateral direction for the model with and without the presence of soft strata is shown in Figure 4.11.
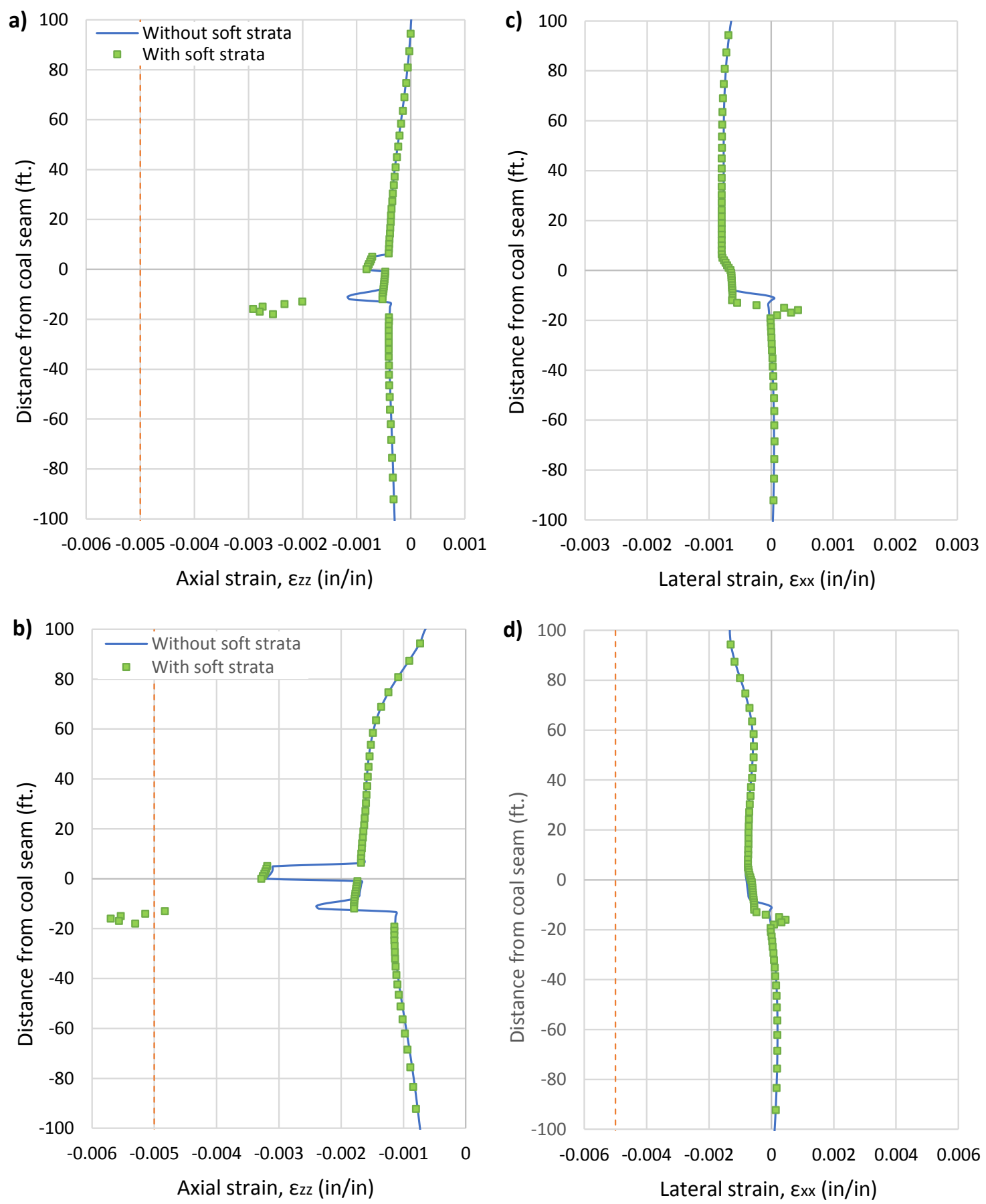

Figure 4.11 Predicted induced strain in axial and lateral direction, after: a and c. first panel mining, $b$ and $d$. second panel mining. Orange dashed line refers to the critical strain (0.005). 
The magnitude and distribution of $\varepsilon_{\mathrm{zz}}$ and $\varepsilon_{x x}$ are consistent for both model scenarios from the depth of $100 \mathrm{ft}$ above the coal seam layer towards the depth of 12 feet below the coal seam. The difference in magnitudes of $\varepsilon_{\mathrm{zz}}$ and $\varepsilon_{x x}$ can be seen from the depth below 12 feet, where the model with soft strata has higher induced strain. Figure 4.11 shows that for the model with the presence of soft strata, the peak magnitudes of $\varepsilon_{\mathrm{zz}}$ is concentrated at the depth of 16 to $17 \mathrm{ft}$ below the coal seam, which is at the clay layer. Conversely, for the model without the presence of a soft strata, the peak magnitudes of $\varepsilon_{\mathrm{zz}}$ is concentrated at the depth of $12 \mathrm{ft}$ below the coal seam, which is at the depth where the interface between sandyshale and sandstone takes place. For the $\varepsilon_{\mathrm{xx}}$ results analysis, the peak magnitudes of $\varepsilon_{x x}$ is consistent for both model, which is concentrated at the coal seam layer.

Table 4.3 Summary of maximum predicted induced strain magnitudes of the gas well for model with and without the presence of soft strata.

\begin{tabular}{ccccc}
\hline \multicolumn{1}{c}{ Model } & \multicolumn{2}{c}{ First panel mining } & \multicolumn{2}{c}{ Second panel mining } \\
Description & $\varepsilon_{\mathrm{zz}}(\mathrm{in} / \mathrm{in})$. & $\varepsilon_{\mathrm{xx}}(\mathrm{in} / \mathrm{in})$. & $\varepsilon_{\mathrm{zz}}(\mathrm{in} / \mathrm{in})$. & $\varepsilon x x$ (in/in.) \\
\hline With soft strata & -0.00291 & -0.00080 & -0.00570 & 0.00075 \\
Without soft strata & -0.00112 & -0.00077 & -0.00235 & 0.00075 \\
\hline
\end{tabular}

Table 4.3 summarizes the maximum predicted induced strain after first and second panel mining. The maximum magnitudes of $\varepsilon_{z z}$ after first panel mining for model with and without the presence of soft strata is 0.0029 and $0.0011 \mathrm{in} / \mathrm{in}$, respectively. When second panel is excavated, the magnitudes of $\varepsilon_{\mathrm{zz}}$ raised to 0.0057 and $0.0024 \mathrm{in} / \mathrm{in}$ for model with and without the presence of soft strata, respectively. For lateral strain magnitudes, the results are almost consistent for both cases, with peak magnitudes of 0.0012 and 0.0003 in/in after first and second panel mining, respectively. 
It can be noted that from Table 4.3 that after first panel mining, the gas well did not fail in both modelling scenarios. For the model without the presence of strata, the gas well remains stable after second panel mining. However, for the model scenario that includes the presence of soft strata, after second panel mining, the gas well failed under axial compression due to the predicted axial strain is higher than the critical strain of 0.005 . The gas well failure occurs in the horizon where the soft strata (clay layer) takes place. Such failure mechanism occurs due to the clay layer has a lower strength compare to the strong strata, such as sandstone. It is observed that when the gas well drilled through a soft layer such as clay, the displacements occur in such horizon after longwall mining tend to be higher compare to when the gas well penetrated through the strong layer such as sandstone layer. Therefore, such behavior leads to a high strain magnitudes.

This study concludes that the presence of soft strata plays an important role on the stability of a gas well. The gas well would typically face more instability issue when it is drilled through a horizon, where there is a presence of soft strata in between two layers of strong strata. The results of this analysis are in agreement with the previous study's conclusion given by Peng et al. (2003). 


\title{
CHAPTER 5 - DETERMINATION OF SUITABLE PILLAR SIZE FOR PROTECTING THE GAS WELL FROM FAILURE
}

\author{
"Software is a great combination between \\ artistry and engineering" \\ -Bill Gates
}

\subsection{Introduction}

An earlier study by Kicker and Park (1986) suggested that the longwall mining method requires an accurate decision in determining the entry size and pillar system. In addition, Peng et al. (2003) proposed that the pillar size of a longwall mining operation, where a gas well is penetrated, should be designed adequately in order to maintain the stability of the gas well. Therefore, it is critical to determine an optimal pillar size for protecting the gas well from failure as a result of longwall mining operation.

Field observation of the case study, which this study refers to, showed that the gas well failed after second panel mining (Peng et al. 2003). The location of the gas well failure is at a depth of $16.5 \mathrm{ft}(5 \mathrm{~m})$ below the coal seam. This horizon is represented by a soft strata (clay layer). However, to the author of this thesis knowledge, there was no study conducted earlier to adequately select a pillar size for protecting the gas well from failure for the case study. Therefore, this study will be focused on determining a suitable pillar size for protecting the gas well subjected to longwall mining operation, under the given geological condition and mining geometry of the case study. In order to achieve the goal mentioned, two pillar design scenarios were developed using Finite Difference Method in FLAC ${ }^{3 \mathrm{D}}$ program. The first and second pillar design scenarios correspond to the pillar design for three and four entry-system, respectively. 


\subsection{Model Development and Analysis Approach}

Various three dimensional numerical models using FLAC $^{3 \mathrm{D}}$ program were built for two pillar design scenarios for the three-entry and four-entry system of a longwall mining. Both model scenarios were built considering the overburden depth, mining height, and entry width of $943 \mathrm{ft}$ $(287.4 \mathrm{~m}), 6 \mathrm{ft}(2 \mathrm{~m})$, and $16 \mathrm{ft}(5 \mathrm{~m})$, respectively, with the panel width and length of $900 \mathrm{ft}$ (274 $\mathrm{m})$ and 5,000 ft (1,524 m), accordingly.

In order to reduce the computational running time of the simulated model and due to the large extent of the actual mining geometry, both model scenarios were built in symmetric condition, considering half width of the longwall mine panel with the extension of $280 \mathrm{ft}$ ( $85 \mathrm{~m}$ ) to the direction perpendicular to the panel width. The overburden depth was built at $252 \mathrm{ft}(77 \mathrm{~m})$. In order to account for the overburden depth of the case study, which is $943 \mathrm{ft}(287.4 \mathrm{~m})$, a normal stress of 5.41 MPa was applied on the top face of the simulated model.

Figure 5.1 and 5.2 present the geometry of the simulated model for the two model scenarios, representing a typical three-entry system and four-entry system of an underground longwall mining method. For the three-entry system, the first model (figure 5.1.a) has a pillar size of $56 \mathrm{ft}(17 \mathrm{~m}$ ), while the second and third model (figure 5.1.b and 5.1.c) have the pillar size of 68 and $80 \mathrm{ft}$ ( 21 and $24.3 \mathrm{~m}$ ), respectively. For the four-entry system, the first, second and third model (figure 5.2.a, 5.2.b, and 5.2.c) have the pillar size of 36, 48, and $60 \mathrm{ft}(11,14.6$ and $18.3 \mathrm{~m}$ ), respectively. The abutment pillar, where the gas well is penetrated through, has a larger pillar size, and for all the simulated models the abutment pillar size was kept at a size of $104 \mathrm{ft}(31.7 \mathrm{~m})$. This abutment pillar size corresponds to the pillar size of the field condition and was selected for this study according to the standard pillar size guideline proposed by the Pennsylvania oil and Gas Division (Commonwealth of Pennsylvania, 1957). 
a) FLAC3D 6.00

(C)2017 Itasca Consulting Group, Inc.

LEGEND
$\begin{aligned} & \text { 1. Sandstone_a } \\ & \text { 2. Sandyshale_a } \\ & \text { 3. Gob } \\ & \text { 4. Coal } \\ & \text { 5. Sandyshale_b } \\ & \text { 6. Clay } \\ & \text { 7. Sandstone_b } \\ & \text { Gas Well }\end{aligned}$

b) FLAC3D 6.00 (C)2017 Itasca Consulting Group, Inc.

\section{LEGEND}

1. Sandstone_a

2. Sandyshale_a

3. Gob

4. Coal

5. Sandyshale_b

6. Clay

7. Sandstone_b

Gas Well

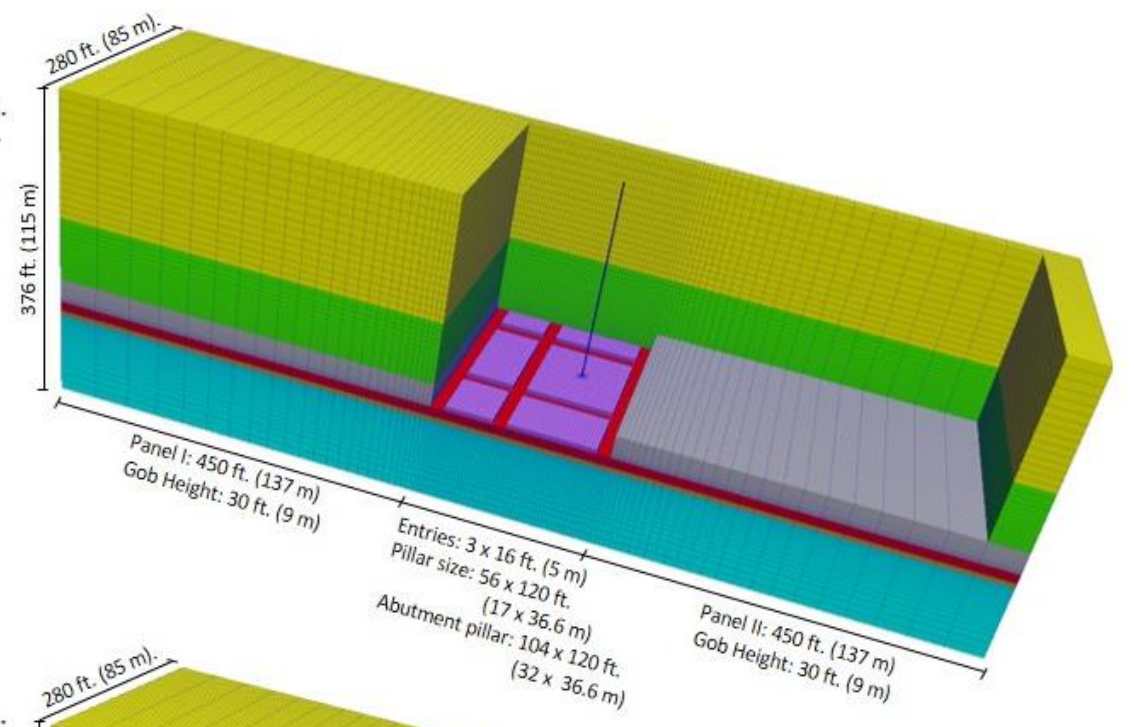

c) FLAC3D 6.00 (C)2017 Itasca Consulting Group, Inc.

LEGEND
1. Sandstone_a
2. Sandyshale_a
3. Gob
4. Coal
5. Sandyshale_b
6. Clay
7. Sandstone_b
Gas Well

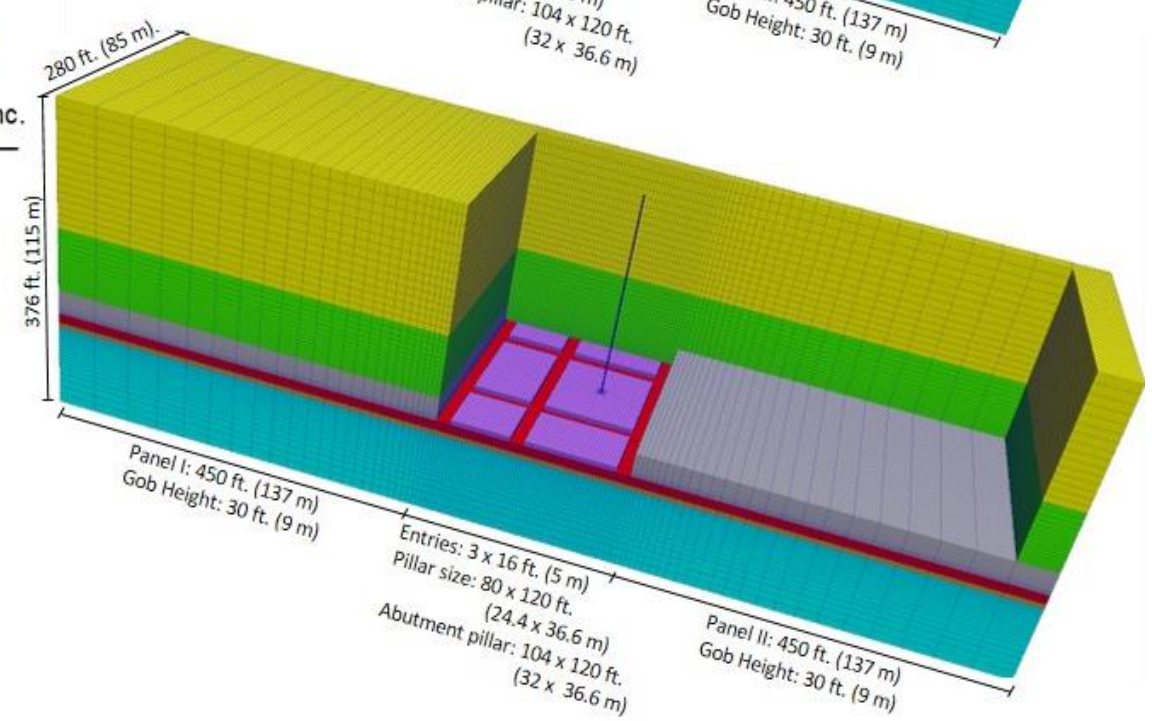

Figure 5.1 FLAC $^{3 \mathrm{D}}$ Model Geometry for the first scenario (Three-entry system). The gas well showing on blue colour is penetrated through longwall mining abutment pillar from surface to the bottom of the simulated model. 
a) FLAC3D 6.00 C2017 Itasca Consulting Group, Inc.

\section{LEGEND}

1. Sandstone_a

2. Sandyshale_a

3. Gob

4. Coal

5. Sandyshale_b

6. Clay

7. Sandstone_b

Gas Well b) FLAC3D 6.00 C2017 Itasca Consulting Group, Inc.

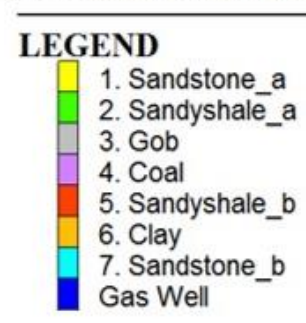

c) FLAC3D 6.00

(C)2017 Itasca Consulting Group, Inc.

\section{LEGEND}

1. Sandstone a

2. Sandyshalēa

3. Gob

4. Coal

5. Sandyshale_b

6. Clay

7. Sandstone_b

Gas Well
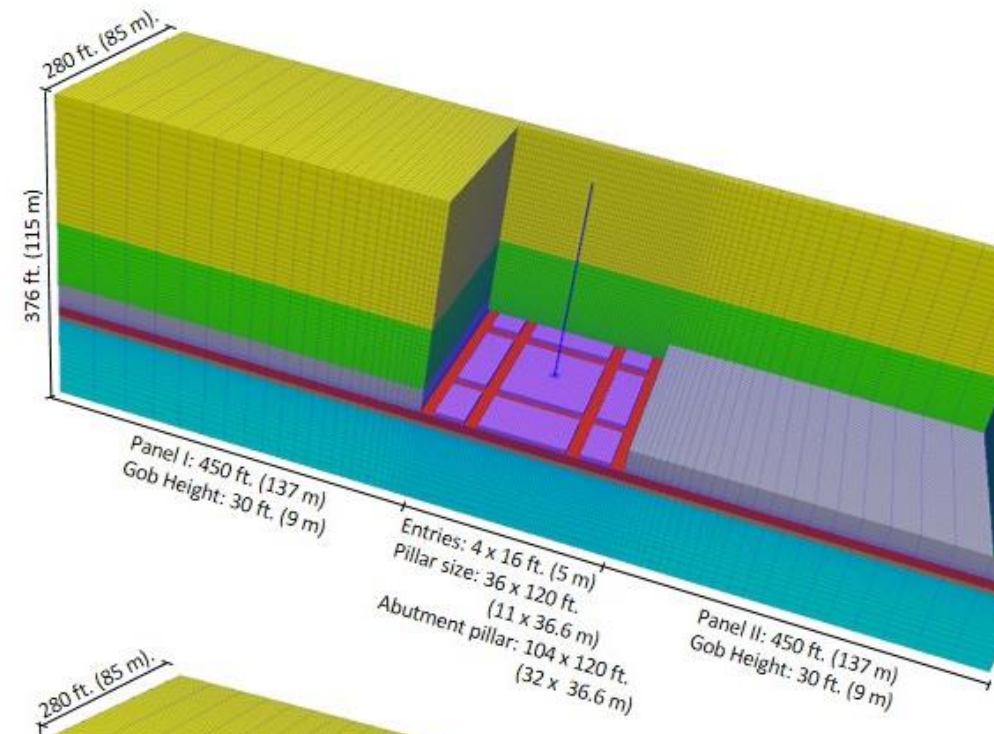

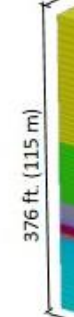
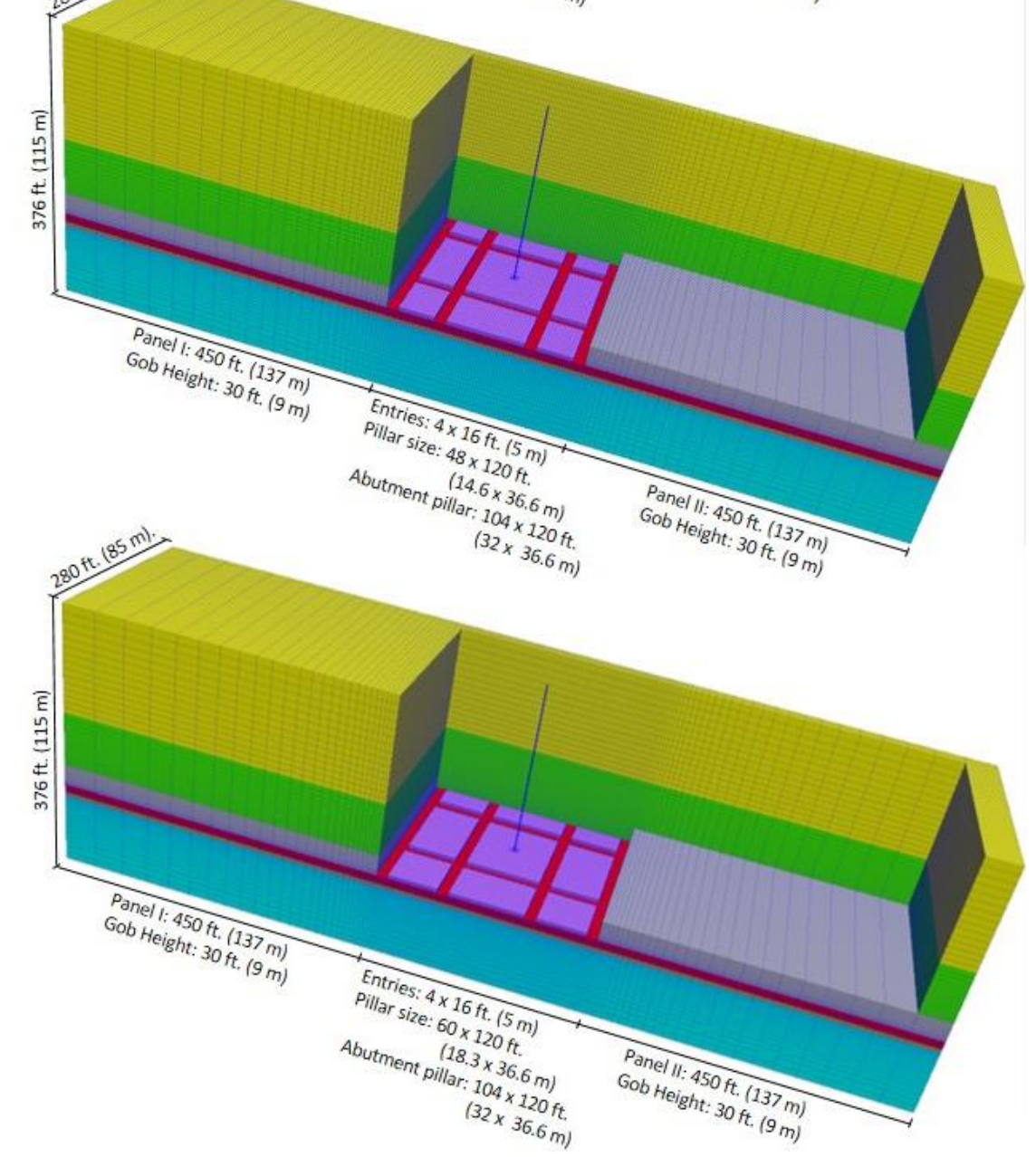

Figure 5.2 FLAC $^{3 \mathrm{D}}$ Model Geometry for the second scenario (Four-entry system). The gas well showing on blue colour is penetrated through longwall mining abutment pillar from surface to the bottom of the simulated model. 
The adopted rock properties are identical with the rock properties being introduced in the Chapter 3, under sub-section 3.2.4 and are listed in Table 3.1. The gas well was embedded in the simulated model using the solid element, having an outer diameter and thickness of 8-5/8 and 0.875 inches, respectively. The bottom side of the model was fixed in both horizontal and vertical direction, while in the north, south, east and west side direction of the model was fixed in the horizontal direction.

All the simulated model for two model scenarios in this study were solved in four steps. The first step involved the solution of the model in virgin condition, without any excavation. The second, third, and fourth steps involved creation of entries, excavation of the first panel and excavation of the second panel, respectively. Longwall entries and panels were created by deleting the zones in the model representing the longwall entries and panels. Each longwall panel was excavated in 5 steps. The first excavation was to excavate a rectangular block which was $450 \mathrm{ft}$ $(137 \mathrm{~m})$ wide and $100 \mathrm{ft}(30.5 \mathrm{~m})$ long. The subsequent steps from second to fifth steps was to excavate the remaining $180 \mathrm{ft}(55 \mathrm{~m})$ length of the longwall panel. Thus, $45 \mathrm{ft}(13.7 \mathrm{~m})$ long by $450 \mathrm{ft}(137 \mathrm{~m})$ wide excavation was performed for the second to fifth excavation steps. The gob element was modeled during the first and second panel mining after completion of each stages of excavation. Finally, the magnitudes of displacements and induced strain distribution along the vertical gas well trajectory were stored and analyzed.

The stability of the gas well was assessed by analyzing the distribution of total shear offset $\left(U_{o f f-H}\right)$, and axial and lateral strain $\left(\varepsilon_{z z}\right.$ and $\left.\varepsilon_{x x}\right)$ occurring along the vertical gas well. The total shear offset $\left(U_{o f f-H}\right)$ and strain analysis in axial and lateral direction $\left(\varepsilon_{z z}\right.$ and $\left.\varepsilon_{x x}\right)$ were analyzed using the Equation 3.13 and 3.12, respectively. As described on the analysis approach, listed on chapter 3 - 
Sub-section 3.4, the critical magnitudes of total shear offset $\left(U_{\text {off- } H}\right)$ and strain magnitudes were set to be $10 \mathrm{~cm}$, and $0.5 \%$, respectively.

\subsection{Analysis Results}

\subsubsection{Analysis of Total Shear Offset $\left(U_{o f f-H}\right)$}

Equation 3.13 is used to quantify the total shear offset $\left(U_{\text {off- } H}\right)$ magnitudes and their distribution along the gas well. Figure 5.3 shows the analysis results of total lateral $U_{\text {off-H }}$ magnitudes for the two simulated model scenarios. It can be noted from Figure 5.3 that as a result of longwall mining, the peak magnitude of $U_{\text {off- } H}$ concentrates at the depth of $16.5 \mathrm{ft}(5 \mathrm{~m})$ below the floor of the coal seam being extracted, with a small magnitude of shear offset occurring at the coal seam layer.

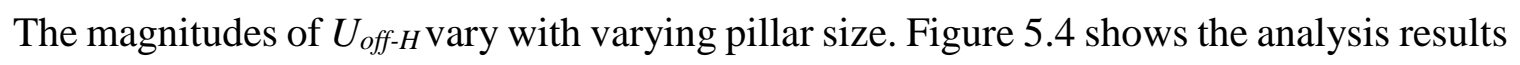
of maximum predicted $U_{o f f-H}$ after first and second panel mining, for the two simulated model scenarios. It can be noted that the magnitudes of $U_{\text {off-H }}$ decreases linearly with increase of the pillar size. After first panel mining for the three entry system simulated model scenario, the maximum magnitudes of $U_{\text {off-H }}$ for the pillar size of 56,68 and $80 \mathrm{ft}(17,21$, and $24.4 \mathrm{~m})$ is $0.43 \mathrm{~cm}, 0.35$ $\mathrm{cm}$, and $0.29 \mathrm{~cm}$, respectively. While for the four entry system the peak magnitudes of $U_{\text {off- } H}$ for the pillar size of 36,48 and $60 \mathrm{ft}(11,14.6$ and $18.3 \mathrm{~m})$ is $0.49 \mathrm{~cm}, 0.42 \mathrm{~cm}$, and $0.36 \mathrm{~cm}$, respectively. Following second panel mining, the magnitudes of $U_{\text {off- } H}$ decreased slightly, for both simulated model scenarios. The gas well deformed more towards the first longwall panel side after the first panel is completely excavated, and then when the second panel is subsequently mined, the gas well bounces back slightly to the second panel mining side. This in turn leads to the increasing of $U_{\text {off- } H}$ magnitudes after second panel mining. 

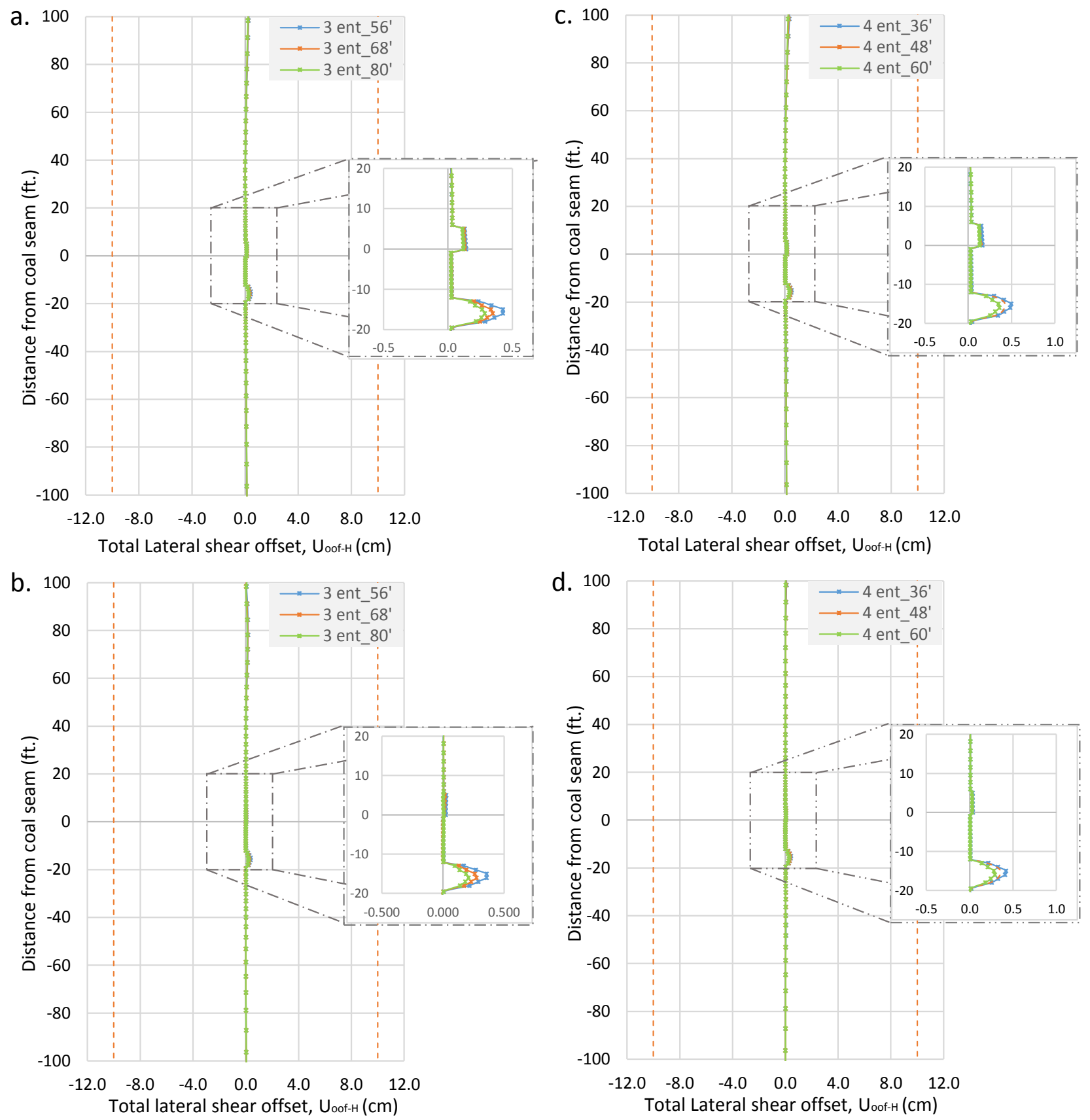

Figure 5.3 Predicted total lateral shear offset $\left(U_{\text {off- } H}\right)$, after: first panel mining (a and c), b. second panel mining ( $b$ and $d$ ). Orange dashed line refers to the critical lateral shear offset. Figures 5.3.a and $\mathrm{b}$ corresponds to the simulated model scenario for the three-entry system, while Figures 5.3.c and $\mathrm{d}$ corresponds to the four-entry system. $1 \mathrm{ft}=0.3048 \mathrm{~m}$. 

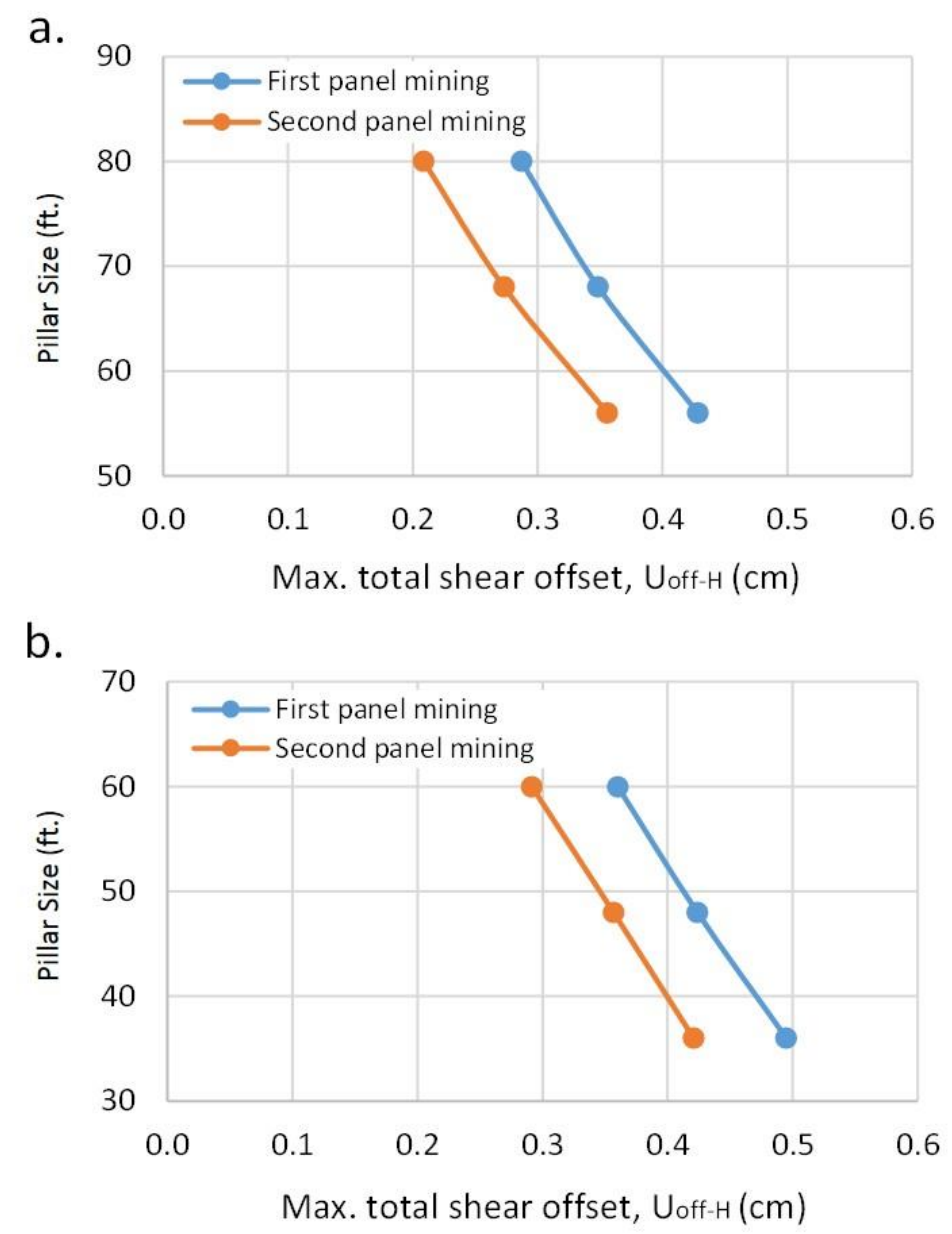

Figure 5.4 Analysis results of maximum predicted total lateral shear offset $\left(U_{\text {off-H}}\right)$. Figure 10.a and $\mathrm{b}$ corresponds to the three-entry and four-entry system model scenario, respectively.

\subsubsection{Analysis of Lateral and Axial Strain $\left(\varepsilon_{x x / z z}\right)$ Distribution}

The lateral strain $\left(\varepsilon_{x x}\right)$ and axial strain $\left(\varepsilon_{z z}\right)$ is analyzed using equation 3.12. The lateral strain in the $\mathrm{Y}$ direction $\left(\varepsilon_{y y}\right)$, which is parallel to the mining direction, is not presented and analyzed due to its magnitude being small compared to the $\varepsilon_{x x}$ magnitude. Figure 5.5. and 5.6 present the predicted $\varepsilon_{z z}$ and $\varepsilon_{x x}$ after first panel and second panel mining, for the three and four entry system model scenarios, respectively. The magnitude of $\varepsilon_{x x}$ is comparatively small to the magnitude of $\varepsilon_{z z}$. The strain magnitudes in lateral and axial direction along the gas well trajectory differs with varying size of the yield pillar. For the two simulated model scenarios, the peak 
magnitudes of $\varepsilon_{z z}$ concentrated at the depth of $16.5 \mathrm{ft}(5 \mathrm{~m})$ below the coal seam under compression, while the peak magnitudes of $\varepsilon_{x x}$ occurred in tension at the depth of $16.5 \mathrm{ft}(5 \mathrm{~m})$ below the coal seam and occurred in compression at the coal seam layer and propagates away from the coal seam roof towards the surface direction.

The analysis results of maximum predicted $\varepsilon_{z z}$ and $\varepsilon_{x x}$ with varying the pillar size for the two model scenario is shown on figure 5.7. The magnitude of $\varepsilon_{z z}$ and $\varepsilon_{x x}$ decreased linearly with increase in the pillar size. In three-entry system, after first panel mining, the peak magnitude of $\varepsilon_{x x}$ ranges from 0.00075 to $0.00087 \mathrm{in} / \mathrm{in}$, while the peak magnitude of $\varepsilon_{z z}$ ranges from 0.0021 to $0.0036 \mathrm{in} / \mathrm{in}$. Following second panel mining, the magnitudes of $\varepsilon_{x x}$ decreased with a variation ranging from 0.00070 to $0.00079 \mathrm{in} / \mathrm{in}$. In contrast, the magnitudes of $\varepsilon_{z z}$ increased after second panel mining, with the magnitude of $0.048,0.0057$, and $0.0064 \mathrm{in} /$ in for the yield pillar size of 80 , 68 , and $56 \mathrm{ft}(24.4,21$, and $17 \mathrm{~m})$ respectively.

For the model scenario considering the four-entry system, the peak magnitude of $\varepsilon_{x x}$ after first and second panel mining ranges from 0.00075 to $0.00087 \mathrm{in} / \mathrm{in}$ and 0.0070 to $0.00079 \mathrm{in} / \mathrm{in}$, respectively. In this model scenario, after first panel mining, the predicted peak magnitudes of $\varepsilon_{z z}$ ranges from 0.00299 to $0.00459 \mathrm{in} /$ in. Following second panel mining, the peak magnitudes of $\varepsilon_{z z}$ increases to the magnitude of $0.004,0.005$, and $0.0064 \mathrm{in} /$ in for the yield pillar size of 36,48 , and $60 \mathrm{ft}(11,48$, and $18.3 \mathrm{~m})$, respectively. 

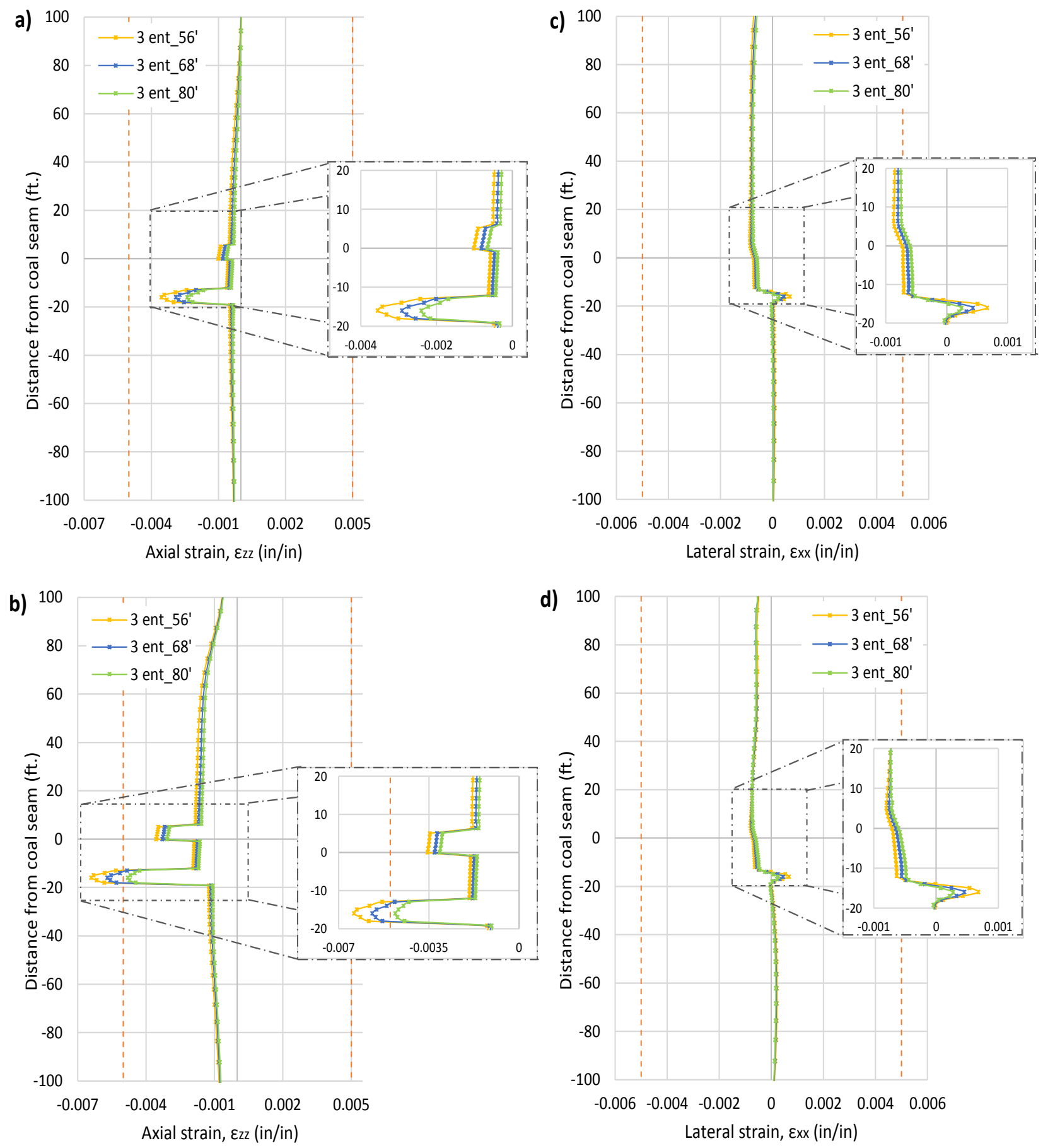

Figure 5.5 Predicted axial strain $\left(\varepsilon_{z z}\right)$ and lateral strain $\left(\varepsilon_{x x}\right)$, after: first panel mining (a and c), and second panel mining ( $b$ \& d), for the three-entry system model scenario. $1 \mathrm{ft}=0.3048 \mathrm{~m}$. 

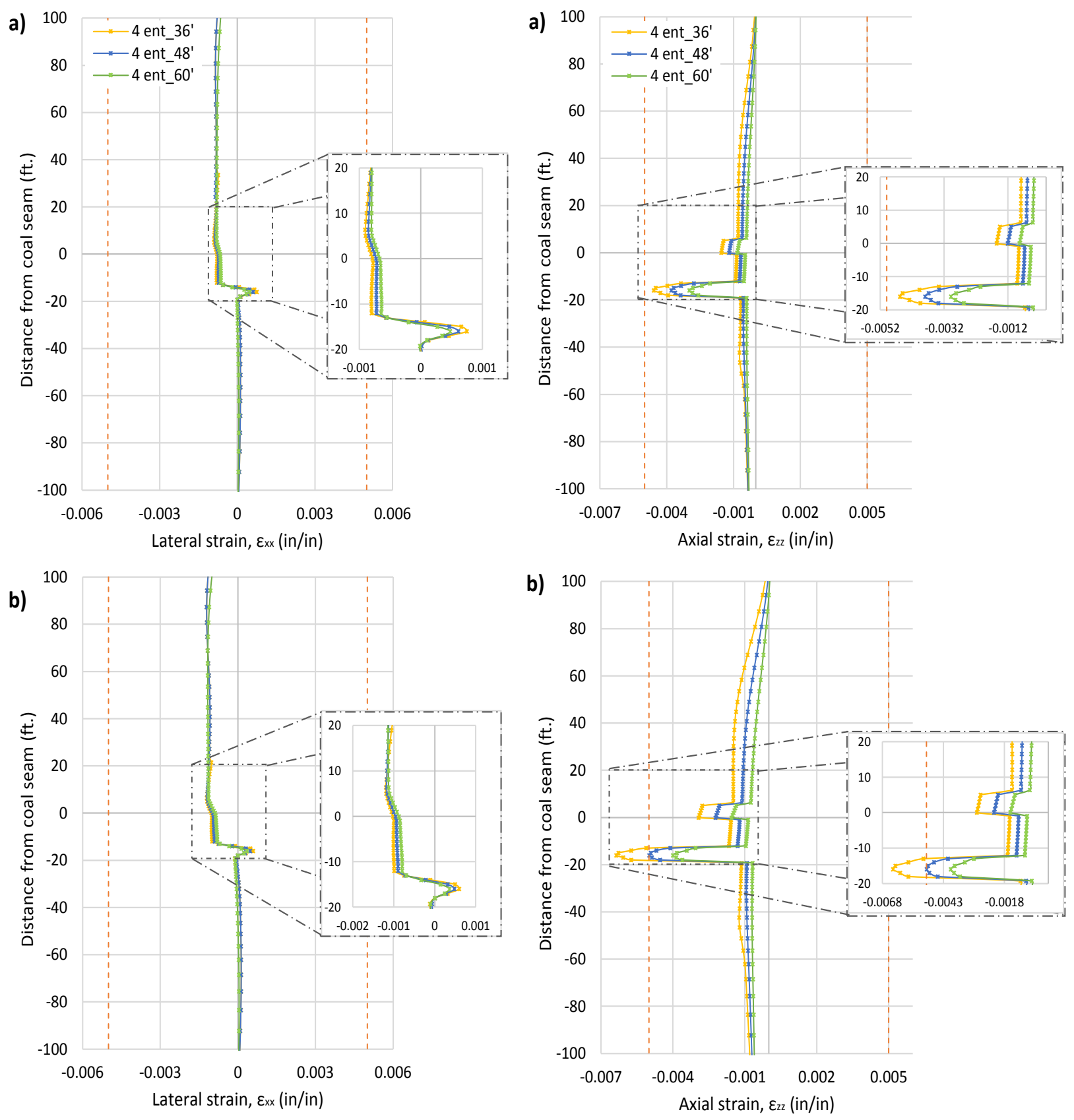

Figure 5.6 Predicted axial strain $\left(\varepsilon_{z z}\right)$ and lateral strain $\left(\varepsilon_{x x}\right)$, after: first panel mining (a and c), and second panel mining (b \& d), for the four-entry system model scenario. $1 \mathrm{ft}=0.3048 \mathrm{~m}$. 

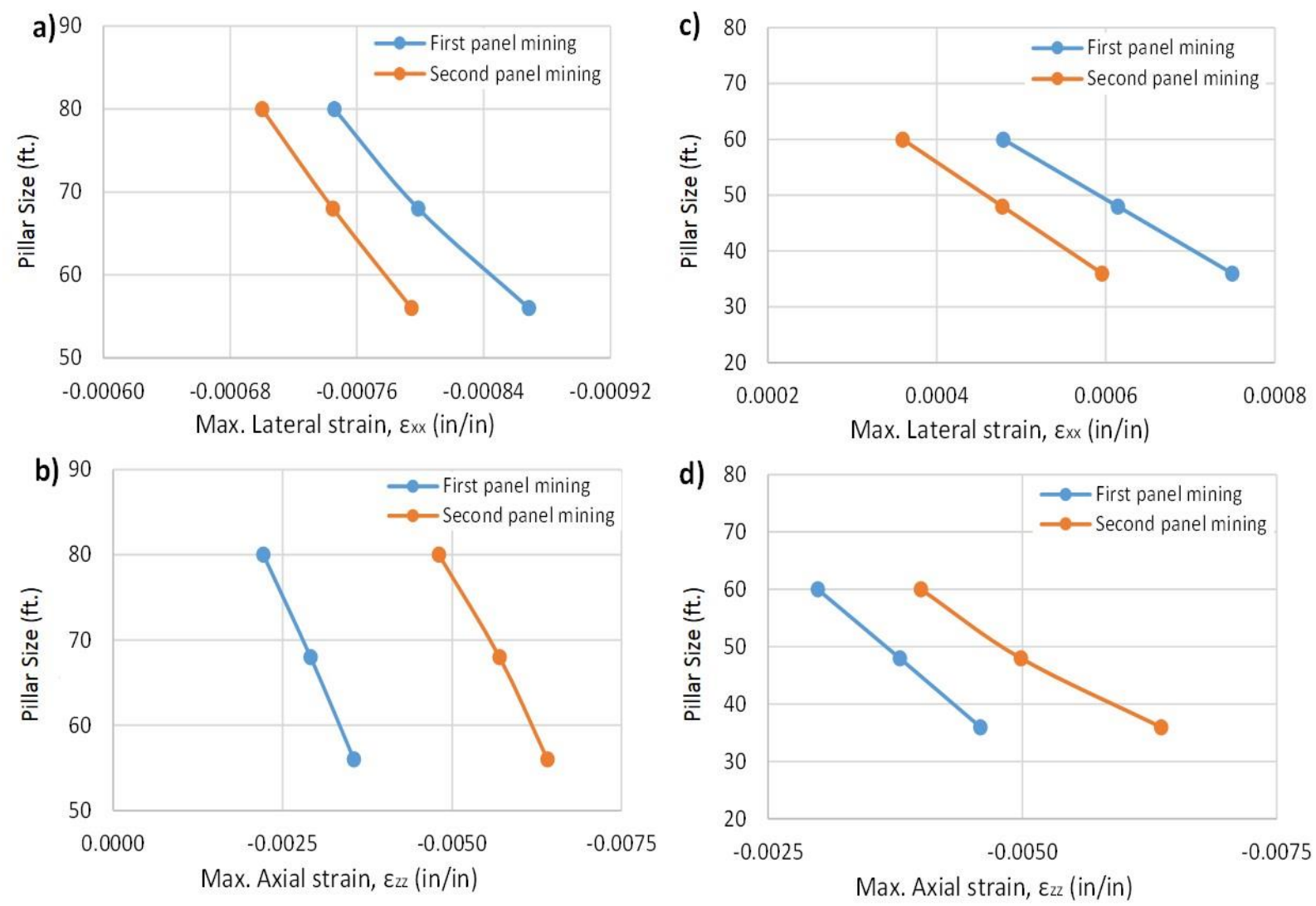

Figure 5.7 Analysis results of the maximum predicted axial strain $\left(\varepsilon_{z z}\right)$ and lateral strain $\left(\varepsilon_{x x}\right)$, after: first panel and second panel mining. Figures 5.7.a and b corresponds to the three-entry system, while Figures 5.7. $\mathrm{c}$ and d corresponds to the four-entry system of the simulated model scenario. $1 \mathrm{ft}=0.3048 \mathrm{~m}$.

\subsection{Discussion}

The required pillar size guideline for protecting gas well in longwall mining area was enacted in 1957 by the Pennsylvania oil and Gas Division (Commonwealth of Pennsylvania, 1957). It is proposed that for overburden depth more than $250 \mathrm{ft}$. (76 m), the gas well should be protected with a minimum abutment pillar size of $100 \mathrm{ft} .(30.5 \mathrm{~m})$. However, this guideline was not developed considering the modern longwall mining method, rather it was developed based on 66 gas well failure cases caused by room and pillar mining. Therefore, it is imperative to address 
the need for required protective pillar size that can be applied to a modern longwall mining method under the given geological condition and mining geometry.

The vertical gas well in longwall mining area can potentially fail under shear, compression, and tension due to the strata deformation as a result of longwall mining. In addressing the gas well failure under shear, the predicted magnitudes of total shear offset $\left(U_{\text {off-H}}\right)$ along the gas well trajectory is assessed, considering a critical total shear offset of $10 \mathrm{~cm}$. From the analysis performed, the predicted peak magnitudes of $U_{\text {off- } H}$ for all models ranging from 0.29 to $0.49 \mathrm{~cm}$. In other words, those predicted magnitudes did not reach the magnitude of critical shear offset, which is $10 \mathrm{~cm}$. Therefore, it is concluded in this study that shear failure will typically not occur as a result of longwall mining for the given geological condition and mining geometry of the case study.

In assessing the gas well stability considering compression and tension failure mode, the predicted strain magnitudes and their distribution along the gas well trajectory was assessed. The critical strain is limited to $0.5 \%$ as proposed by American Petroleum Institute (Lyons, 1996). From the predicted axial strain $\left(\varepsilon_{z z}\right)$ and lateral strain $\left(\varepsilon_{x x}\right)$ of this study, the gas well did not fail after first panel mining for all simulated model scenarios. However, for the three-entry model scenario having a pillar size of 56 and $68 \mathrm{ft} .(17$ and $21 \mathrm{~m})$ and for the four-entry system model scenario having pillar size of $36 \mathrm{ft} .(11 \mathrm{~m})$, the gas well yielded in axial direction under compression, after second panel mining due to the predicted magnitudes of $\varepsilon_{z z}$ reached the critical strain proposed by API. Based on the work of this study, it is determined that in order to maintain the stability of the gas well for the case study, considering three entry system, the pillar size should be $80 \mathrm{ft}(24.4 \mathrm{~m})$ wide rib to rib. Whereas if the four-entry system is used, the size of the pillar should be kept at $48 \mathrm{ft}$. (14.6 m) wide rib to rib. 
It should be noted that induced stress and strain distribution in a longwall mining that leads to the instability issue for a gas well is site-specific. In addition, this study was mainly focus on a specific case study. Further studies is required to completely determine the pillar size guideline that can be applied in entire longwall mining operations in the U.S. However, the numerical modelling approach proposed in this study is applicable to effectively determine the appropriate pillar size for protecting gas well from failure, as a result of longwall mining operation. 


\section{CHAPTER 6 CONCLUSION AND RECOMMENDATION}

"Continuous improvement is better than delayed perfection" -Mark Twain

In the subsequent sections, the conclusion and recommendation for future research of the current research topic are presented.

\subsection{Conclusion}

Vertical gas wells penetrating longwall mining abutment pillars could possibly fail due to the strata deformation that leads to high induced strain resulting from the coal extraction. This in turn may lead to the failure of the gas well and potentially affect the safety of the underground longwall mining operation. Therefore, maintaining the stability of a vertical gas well drilled though a longwall mining abutment pillar is always become a challenging task. This gas well safety issue raises the awareness of the current research to study the instability issue of the vertical gas well subjected to longwall mining operation. In order to achieve the objective mentioned, various three

dimensional numerical models were built using FLAC $^{3 \mathrm{D}}$ program in order to assess the effect of overburden depth, presence of soft strata, and pillar size geometry on the stability of a vertical gas well penetrating longwall mining abutment pillar. An elasto-plastic model under Mohr-Coulomb failure criterion was used to simulate the rock behavior, while the Double-Yield constitutive model was employed for simulating the gob behavior in during longwall mining development stages.

Through extensive analysis from the various numerical analysis performed in this study, the following conclusions are summarized: 
[1] It is observed in this study that the critical location where the gas well could possibly fail as a result of longwall mining is located at the horizon where soft strata presents. For this study, such horizon (clay layer) was observed at the depth of 12 to 18 feet (3.7 $\mathrm{m}$ to 5.5 $\mathrm{m})$ below the coal seam floor. The horizon from the depth of 12 to $18 \mathrm{ft}$ ( 3.7 to $5.5 \mathrm{~m}$ ) contains of weak bedding plane of soft strata (clay layer) lying in between sandyshale and sandstone strata. Such failure mechanism occurs due to the clay layer has a lower strength compare to the strong strata, such as sandstone. It is observed that when the gas well drilled through a soft layer such as clay, the displacements occur in such horizon after longwall mining tend to be higher compare to when the gas well penetrated through the strong layer such as sandstone layer. Therefore, such behavior leads to a high strain magnitudes. This analysis results are in agreement with the field condition and previous study conducted by Peng et al. (2003) that the gas well failed due to the presence of soft strata. Therefore, it is concluded that the gas well would typically face more instability issue when it is drilled through a horizon, where there is a presence of soft strata takes place in between two layers of strong strata layers.

[2] It was observed that under the given geological and mining condition of the case study, the gas well will not fail under shear. The predicted results of total shear offset for this study is less than its critical magnitude that may cause the gas well to fail under shear. This result is in agreement with the field condition reported by Peng et al. (2003) that there was no shear failure occurred in the field.

[3] The result of parametric study for overburden depth influence indicates that the overburden depth of a mine plays an important role on the stability of the gas well when it is drilled through a longwall mining abutment pillar. The deeper the overburden depth 
of a mine, the higher possibility for gas well to fail under axial compression. It is determined that the critical overburden depth for the gas well to survive is $600 \mathrm{ft}$. (183 m). However, it should be noted that the critical overburden depth obtained in this study is specific to the given case study only.

[4] In addressing the need of suitable pillar size of the case study, it is determined in this study that in order to maintain the stability of the gas well for the case study, considering three entry system, the pillar size should be $80 \mathrm{ft}(24.4 \mathrm{~m})$ wide rib to rib. Whereas if the four-entry system is used, the size of the pillar should be kept at $48 \mathrm{ft}$. (14.6 m) wide rib to rib.

The main significance of this study is that it not only proposes a three dimensional numerical modelling procedure for assessing the stability of gas well subjected to longwall mining operation for the given case study, but it can also be used for other similar projects. This study concludes that with the accurate data input of rock and casing properties, as well as the gob model simulation, the numerical modelling analysis approach presented in this article will be able to accurately predict the stability of the vertical gas well penetrating longwall mining abutment pillar.

\subsection{Recommendation for Future Research}

The future study needed for the current field of research is described as following:

[1] This study investigates majority of the critical factors that affect the stability of a vertical gas well in longwall mining operation, i.e. the effect of overburden depth, presence of soft strata and the size of a pillar. However, it is also imperative to study the influence of the gas well casing properties and insitu stress magnitudes on the stability of a vertical gas well subjected to longwall mining operation. 
[2] The simulated numerical model built in this study does not consider any interface between the embedded rock stratum, and between the casing and the rock stratum. Future study can use interface properties in order to obtain more realistic prediction results.

[3] Induced stress and strain distribution in a longwall mining that leads to instability issue for a gas well is site-specific. In addition, this study only focus on the given case study. Therefore, more study with field calibration is needed to completely determine the pillar size guideline that can be applied for the longwall mining operation in the U.S. 


\section{REFERENCES}

Abbasi, B. (2016). “An Improved Rock Mass Behaviour Numerical Model and its Application to Longwall Coal Mining." Ph.D. Dissertation, Southern Illinois University, Carbondale, Illinois. ProQuest Number: 10138115, 164 pp.

Board, M. (2006). “Geotechnical Basis, Conceptual Engineering - Chuquicamata Underground Project". Prepared for Codelco Norte, Division. Minneapolis: Itasca Consulting Group Inc. (Internal Report Codelco Chile).

Bureau of Mines (1913). "Oil and Gas Wells through Workable Coal Beds - Paper and Discussions.” Department of the Interior.

Campoli, A. A., Barton, T. M., Dyke. F. and Gauna, M. (1993). "Gob and gate road reaction to longwall mining in bump-prone strata.” Bureau of Mines, Report of Investigation 9445, 148.

Carter, J. P., Desai, C. S., Potts, D. M., F., S. H., and Sloan, S. W. (2000). "Computing and Computer Modelling in Geotechnical Engineering." ISRM International Symposium, Melbourne. 1: 1157-1252. Retrieved from https://www.onepetro.org/conference-paper/ ISRM-IS-2000-029

Chen, J., Wang, T., Zhou, Y., Zhu, Y. and Wang, X. (2012) "Failure modes of the surface venthole casing during longwall coal extraction: a case study." International Journal of Coal Geology. 90-91, 135-148. doi:10.1016/j.coal.2011.11.007

Chun, L., Fubao, Z., Kangkang, Y., Xiang, X. and Yingke, L. (2014) "Failure Analysis of Borehole Liners in Soft Coal Seam for Gas Drainage.” Engineering Failure Analysis. 42, 274-283.

Commonwealth of Pennsylvania. (1957). "Gas Well Pillar Study." Department of Mines and Mineral Industries, Oil and Gas Division. 1-16. 
Department of Environmental Protection (2002) "Criteria for Approving Coal Pillar Configurations in longwall Mines". 11, 1-4.

Esterhuizen, E., Mark, C. and Murphy, M. (2010) "Numerical model calibration for simulation coal pillars, gob and overburden response.” Paper presented at the 29th international conference on ground control in mining, Morgantown, 46-57.

Itasca. (2017) FLAC3D: Fast Lagrangian Analysis of Continua, user's guide, Itasca Consulting Group, Minneapolis, Minnesota.

Iwanek, S., Carter, J. P. and Hambleton, J. P. (2016). “Geomechanics of Subsidence above Single and Multi-Seam coal Mining." International Journal of Rock Mechanics and Geotechnical Engineering. 8, 304-313.

Jing, L. (2003). "A review of techniques, advances and outstanding issues in numerical modelling for rock mechanics and rock engineering." International Journal of Rock Mechanics and Mining Sciences. 40(3), 283-353.

Jing, L., \& Hudson, J. A. (2002). "Numerical methods in rock mechanics." International Journal of Rock Mechanics and Mining Sciences. 39(4), 409-427.

Kolebaevna, J.M. (1968). "Theory of Ground Movement in Rock Mass," Nedra, Moscow, Russian, pp. 101. Retrieved at https://www.fhwa.dot.gov/engineering/geotech/ hazards/ mine/workshops/iawkshp/ betourna2.cfm.

Kicker, D. C. and Park, D.-W. (1986). "Yield Pillar Simulation Using Physical Modelling." American Rock Mechanics Association." Paper presented at the $27^{\text {th }}$ U.S. Symposium on Rock Mechanics, Tuscaloosa-Alabama, 23-25. 
Li, Y., Peng. S. and Zhang, J. (2015). "Impact of Longwall Mining on Groundwater above the Longwall Panel in Shallow Coal Seams.” Journal of Rock Mechanics and Geotechnical Engineering. 7: 298-305.

Li, W., Bai, J., Peng. S., Wang, X., and Xu, Y. (2015). "Numerical modelling for yield pillar design: a case study." Rock Mechanics and Rock Engineering. 48:305-318. doi: 10.1007/s00603-013-0539-8.

Liang, S., Elsworth, D., Li, X., Fu, X., Sun, B, Yao, Q. (2017). "Key strata characteristics controlling the integrity of deep wells in longwall mining areas." International Journal of Coal Geology. 172: 31-42.

Liang, S., Elsworth, D., Li, X.; X., Fu., Yang, D., Yao, Q. and Wang, Y. (2015). “Dynamic impacts of the survivability of shale gas wells piercing longwall panels." Journal of Natural Gas Science and Engineering. 26: 1130-1147.

Liang, S., Elsworth, D., Li, X. and Yang, D. (2014). “Topographic Influence on Stability for Gas Wells Penetrating longwall Mining Areas." International Journal of Coal Geology. 132: 23-36.

Lyons, C.W. (1996). Standard Handbook of Petroleum and Natural Gas Engineering (Vol.1). Gulf Publishing Company. Houston, TX.

Liu, C., Zhou, F., Yang, K., Xiao, X. and Liu, Y. (2014). "Failure Analysis of Borehole Liners in Soft Coal Seam for Gas Drainage." Engineering Failure Analysis. 42: 274-283.

Liu, S.H., Zheng, H.L., Zhu, X.H. and Tong, H. (2014). "Equations to Calculate Collapse Strength of Sefective Casing for Steam Injection Wells.” Engineering Failure Analysis. 42: 240251. 
Luo, Y., Kimutis, R., Yang, K., Cheng, J. (2010). "Mitigation of Longwall Subsidence Effects on Operating Railroad." Paper presented at the $2^{\text {nd }}$ international conference on ground control in mining, Morgantown, 89-96.

Luo, Y., Peng, S.S. and Zhang, Y.Q. (1999). "Analysis of the Observed Failure on the Inner Tubing of Gas Well W-510 below the Coal Seam. A report submitted to Cyprus Cumberland Resources Corp. College of Engineering and Mineral Resources, West Virginia University pp 11.

Luo, Y., (1989). "Integrated Computer Model for Predicting Surface Subsidence Due to Underground Coal Mining - CISPM.” Ph.D. Dissertation, West Virginia University, Morgantown, WV, UMI order No. 9020385, 168 pp.

Mark, C., (1987). “Analysis of Longwall Pillar Stability.” Ph.D. Dissertation, The Pennsylvania State University, PA, 288 pp.

Newman, C., Agioutantis, Z. and Leon, G. B. J. (2017). "Assessment of Potential Impacts to Surface and Subsurface Water Bodies due to Longwall Mining." International Journal of Mining Science and Technology. 27: 57-64.

Peng, S. S. (2008). Coal Mine Ground Control, 3rd edition. ISBN: 978-0-0789383-4-5. 743 pp.

Peng, S. S. (2006). Longwall mining, 2nd edition. ISBN: 0-9789383. 613 pp.

Peng, S., Morsey, K., Zhang, Y., Luo, Y., Heasley, K. (2003). “Technique for assessing the effects of longwall mining on gas wells-Two case studies." Paper presented at the annual meeting for the Society for Mining, Metallurgy, and Exploration, Cincinnati-Ohio, September, 314:107-115. 
Salamon, M. (1990). "Mechanism of caving in longwall coal mining." In: Rock mechanics contribution and challenges." proceedings of the 31st US symposium of rock mechanics, Golden, Colorado, 161-168.

Salmi, E. F., Nazem, M. and Karakus, M. (2017). "Numerical Analysis of a Large Landslide Induced by Coal Mining Subsidence.” Engineering Geology. 217: 141-152.

Starfield, A. M., \& Cundall, P. A. (1988). "Towards a methodology for rock mechanics modelling." In International Journal of Rock Mechanics and Mining Sciences \& Geomechanics Abstracts (Vol. 25, No. 3, pp. 99-106). Pergamon.

Su, W.H. (2017). "Effects of Longwall-Induced Stress and Deformation on the Stability and Mechanical Integrity of Shale Gas Wells Drilled Through a Longwall Abutment Pillar.” International Journal of Mining Science and Technology. 27:115-120.

U.S. Energy Information Administration. December. (2017). "Energy Overview." Monthly Energy Review. 27 pp.

U.S. Energy Information Administration (2017). "Marcellus and Utica Production Wells (Jan 2004-November 2017).” Appalachian oil and natural gas research consortium, and U.S. geological survey." Retrieved from https://www.eia.gov/todayinenergy/detail.php?id= 33972\#tab2

Wang, Y., Watson, R., Rostami, J., Wang, J., Limbruner, M., He, Z. (2014). “Study of Borehole Stability of Marcellus shale wells in longwall mining areas." Journal of Petroleum Exploration and Production Technology. 4: 59-71. doi: 10.1007/s13202-013-0083-9

Wang, R.H., Zang, Y.B., Zhang, R., Bu, Y.H. and Li, H.Z. (2011). “Drillstring Failure Analysis and its Prevention in Northeast Sichuan, China." Engineering Failure Analysis. 18:12331241. doi:10.1016/j.engfailanal.2011.03.005 
Wanger, H. and Eng D. (1980). "Pillar Design in Coal Mines." Journal of the South African Institute of Mining and Technology. pp 37-45.

Whittles, D.N., Lowndes, I.S., Kingman, S.W., Yates, C. and Jobling, S. (2007). "The Stability of Methane Capture Boreholes around a Longwall Coal Panel.” International Journal of Coal Geology. 71:313-328.

Wilson, A. H. and Carr, F. (1982). "A new Approach to the Design of Multientry Developments of Retreat Longwall Mining." Paper presented at the $2^{\text {nd }}$ international conference on ground control in mining, Morgantown, 1-21.

Yavuz, H. (2004). “An Estimation Method for Cover Pressure Reestablishment Distance and Pressure Distribution in the Goaf of Longwall Coal Mines.” International Journal of Rock Mechanic and Mining Sciences. 41: 193-205.

Zhang, Z., Bai, J., Chen, Y. and Yan, S. (2015). “An Innovative Approach for Gob-side Entry Retaining in Highly Gassy Fully-mechanized Longwall Top-coal Caving.” International Journal of Rock Mechanics and Mining Sciences. 80:1-11.

Zeynali, M.E. (2012). "Mechanical and Physico-chemical Aspects of Wellbore Stability during Drilling Operations." Journal of Petroleum Science and Engineering. 82-83: 120-124. doi:10.1016/j.petrol.2012.01.006. 